Emprego de técnicas de análise exploratória de dados utilizados em Química Medicinal

Use of different techniques for exploratory data analysis in Medicinal Chemistry 
Jadson Castro Gertrudes

\title{
Emprego de técnicas de análise exploratória de dados utilizados em Química Medicinal
}

\section{Use of different techniques for exploratory data analysis in Medicinal Chemistry}

\begin{abstract}
Dissertação apresentada ao Programa de Pós-graduação em Sistemas de Informação da Escola de Artes, Ciências e Humanidades da Universidade de São Paulo como requisito parcial para obtenção do título de Mestre em Ciências.
\end{abstract}

Versão corrigida contendo as alterações e correções sugeridas pela banca examinadora. A versão original encontra-se na Biblioteca da Escola de Artes, Ciências e Humanidades da Universidade de São Paulo.

Orientadora: Profa. Dr. ${ }^{a}$ Káthia Maria Honório

São Paulo

Setembro 2013 
Autorizo a reprodução e divulgação total ou parcial deste trabalho, por qualquer meio convencional ou eletrônico, para fins de estudo e pesquisa, desde que citada à fonte.

\section{CATALOGAÇÃO-NA-PUBLICAÇÃO \\ Biblioteca}

Escola de Artes, Ciências e Humanidades da Universidade de São Paulo

\section{Gertrudes, Jadson Castro}

Emprego de técnicas de análise exploratória de dados utilizados em química medicinal / Jadson Castro Gertrudes ; orientadora Kathia Maria Honório. - São Paulo, 2013.

$$
97 \text { f. : il. }
$$

Dissertação (Mestrado em Ciências) - Programa de PósGraduação em Sistemas de Informação, Escola de Artes, Ciências e Humanidades, Universidade de São Paulo, em 2013.

Versão corrigida.

1. Química médica. 2. Química farmacêutica. 3. Relações estrutura-atividade. 4. Análise de componentes principais. I. Honório, Káthia Maria, orient. II. Título.

CDD 22.ed. -615.19 
Dissertação de mestrado sob o título "Emprego de técnicas de análise exploratória de dados utilizados em Química Medicinal", defendida por Jadson Castro Gertrudes e aprovada em 10 de setembro de 2013, em São Paulo, Estado de São Paulo, pela banca examinadora constituída pelos doutores:

Prof. ${ }^{a}$ Dr. ${ }^{a}$ Káthia Maria Honório
Orientadora

Prof. ${ }^{\text {a }}$ Dr. ${ }^{\text {a }}$ Ana Carolina Lorena

Universidade Federal de São Paulo

Prof. ${ }^{a}$ Dr. ${ }^{a}$ Ariane Machado Lima

Universidade de São Paulo

Escola de Artes, Ciências e Humanidades 


\section{Agradecimentos}

A Deus por tudo conquistado até hoje.

As professoras Káthia Maria Honório (orientadora) e Patrícia Rufino Oliveira por todas as discussões, revisões e contribuições dadas ao longo do mestrado, e que foram fundamentais na concepção desse trabalho.

Aos meus pais Josenilza e Gonçalo e aos meus irmãos Jardel e Josiney pelos ensinamentos e valores que carrego comigo até hoje e pela compreensão da minha ausência.

Aos meus tios e primos, em especial meus tios Isabel e Wanderley por todo o suporte e pelos momentos marcantes.

A Vinícius, Danielle e Sheila, que auxiliaram no entendimento de diversos aspectos da área de Química, além das contribuições nesse trabalho.

A todos meus amigos, em especial os amigos da Ordem da Nutella (Roberto, Leila, Renata, Rosiane, Éric, Fernando e Jônatas), por todo apoio e pelo momentos de descontração.

A minha namorada Jessica, pelo seu companherismo, incentivo e principalmente pela sua paciência, para que eu atingisse meus objetivos no mestrado.

A todos os professores do Programa de Pós-Graduação em Sistemas de Informação por toda a orientação dada durante o período de mestrado.

Ao CNPq pelo auxílio financeiro. 


\section{Resumo}

GERTRUDES, Jadson Castro. Emprego de técnicas de análise exploratória de dados utilizados em Química Medicinal. 2013. 97 f. Dissertação (Mestrado em Sistemas de Informação) - Escola de Artes, Ciências e Humanidades, Universidade de São Paulo, São Paulo, 2013.

Pesquisas na área de Química Medicinal têm direcionado esforços na busca por métodos que acelerem o processo de descoberta de novos medicamentos. Dentre as diversas etapas relacionadas ao longo do processo de descoberta de substâncias bioativas está a análise das relações entre a estrutura química e a atividade biológica de compostos. Neste processo, os pesquisadores da área de Química Medicinal analisam conjuntos de dados que são caracterizados pela alta dimensionalidade e baixo número de observações. Dentro desse contexto, o presente trabalho apresenta uma abordagem computacional que visa contribuir para a análise de dados químicos e, consequentemente, a descoberta de novos medicamentos para o tratamento de doenças crônicas. As abordagens de análise exploratória de dados, utilizadas neste trabalho, combinam técnicas de redução de dimensionalidade e de agrupamento para detecção de estruturas naturais que reflitam a atividade biológica dos compostos analisados. Dentre as diversas técnicas existentes para a redução de dimensionalidade, são discutidas o escore de Fisher, a análise de componentes principais e a análise de componentes principais esparsas. Quanto aos algoritmos de aprendizado, são avaliados o $k$-médias, fuzzy $c$-médias e modelo de misturas ICA aperfeiçoado. No desenvolvimento deste trabalho foram utilizados quatro conjuntos de dados, contendo informações de substâncias bioativas, sendo que dois conjuntos foram relacionados ao tratamento da diabetes mellitus e da síndrome metabólica, o terceiro conjunto relacionado a doenças cardiovasculares e o último conjunto apresenta substâncias que podem ser utilizadas no tratamento do câncer. Nos experimentos realizados, os resultados alcançados sugerem a utilização das técnicas de redução de dimensionalidade juntamente com os algoritmos não supervisionados para a tarefa de agrupamento dos dados químicos, uma vez que nesses experimentos foi possível descrever níveis de atividade biológica dos compostos estudados. Portanto, é possível concluir que as técnicas de redução de dimensionalidade e de agrupamento podem possivelmente ser utilizadas como guias no processo de descoberta e desenvolvimento de novos compostos na área de Química Medicinal.

Palavras-chave: Redução de dimensionalidade, seleção de variáveis, análise de componentes principais, análise de componentes principais esparsas, agrupamento de dados, análise entre estrutura química e atividade biológica. 


\section{Abstract}

GERTRUDES, Jadson Castro. Use of different techniques for exploratory data analysis in Medicinal Chemistry. 2013. 97 p. Dissertation (Master in Information Systems) - School of Arts, Sciences and Humanities, University of São Paulo, São Paulo, 2013.

Researches in Medicinal Chemistry's area have focused on the search of methods that accelerate the process of drug discovery. Among several steps related to the process of discovery of bioactive substances there is the analysis of the relationships between chemical structure and biological activity of compounds. In this process, researchers of medicinal chemistry analyze data sets that are characterized by high dimensionality and small number of observations. Within this context, this work presents a computational approach that aims to contribute to the analysis of chemical data and, consequently, the discovery of new drugs for the treatment of chronic diseases. Approaches used in exploratory data analysis, employed in this work, combine techniques of dimensionality reduction and clustering for detecting natural structures that reflect the biological activity of the analyzed compounds. Among several existing techniques for dimensionality reduction, we have focused the Fisher's score, principal component analysis and sparse principal component analysis. For the clustering procedure, this study evaluated $k$-means, fuzzy $c$-means and enhanced ICA mixture model. In order to perform experiments, we used four data sets, containing information of bioactive substances. Two sets are related to the treatment of diabetes mellitus and metabolic syndrome, the third set is related to cardiovascular disease and the latter set has substances that can be used in cancer treatment. In the experiments, the obtained results suggest the use of dimensionality reduction techniques along with clustering algorithms for the task of clustering chemical data, since from these experiments, it was possible to describe different levels of biological activity of the studied compounds. Therefore, we conclude that the techniques of dimensionality reduction and clustering can be used as guides in the process of discovery and development of new compounds in the field of Medicinal Chemistry.

Keywords: Dimensionality reduction, variable selection, principal component analysis, sparse principal component analysis, clustering, structure activity relationship. 


\section{Sumário}

Lista de Figuras $\quad$ viii

Lista de Tabelas $\quad$ x

1 Introdução 1

1.1 Contextualização e motivação . . . . . . . . . . . . . . . . . . . 1

1.2 Definição do problema . . . . . . . . . . . . . . . . . . 3

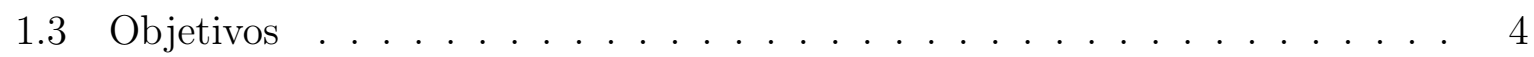

1.4 Estrutura da dissertação . . . . . . . . . . . . . . . . . . . 4

2 Química Medicinal: Planejamento de Substâncias Bioativas 6

2.1 Alvo biológico . . . . . . . . . . . . . . . . 7

2.2 Processo de descoberta de medicamentos . . . . . . . . . . . . . . 8

2.3 Conjuntos de dados estudados . . . . . . . . . . . . . . . . . . . . . . . 10

2.4 Considerações finais . . . . . . . . . . . . . . . . . 22

3 Redução de Dimensionalidade $\quad 23$

3.1 Conceitos iniciais . . . . . . . . . . . . . . . 24

3.1.1 Propriedades de vetores e matrizes . . . . . . . . . . . . 24

3.1.1.1 Normas e ortogonalidade. . . . . . . . . . . . . 24

3.1.2 Transformações lineares . . . . . . . . . . . . . . . . 25

3.1.3 Autovalores e autovetores . . . . . . . . . . . . . 25

3.1.4 Decomposição em valores singulares . . . . . . . . . . . . . . 26 
3.2 Escore de Fisher para seleção de variáveis . . . . . . . . . . . . . . . . . . 26

3.3 Análise de componentes principais $(\mathrm{PCA}) \ldots \ldots \ldots$. . . . . . . . . 28

3.4 Análise de componentes principais esparsas (SPCA) . . . . . . . . . . . . . 30

3.4.1 Análise de componentes principais esparsas por meio de regressão $(\mathrm{SPCA}-\mathrm{ZOU}) \ldots \ldots \ldots \ldots \ldots$

3.4.2 Análise de componentes principais esparsas por meio do método da potência, via penalização pela norma $\ell_{1}(\mathrm{GP})$. . . . . . . . . . . . 35

3.4.3 Análise de componentes principais esparsas por meio do método da

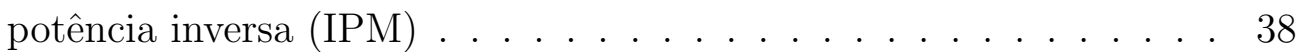

3.5 Considerações finais . . . . . . . . . . . . . . . . . . . . . 40

4 Métodos de Agrupamento de Dados 41

4.1 Algoritmo $k$-médias . . . . . . . . . . . . . . . . . . . . . 43

4.2 Algoritmo fuzzy $c$-médias $(\mathrm{FCM}) \ldots \ldots \ldots \ldots 4 \ldots$

4.3 Modelo de misturas ICA aperfeiçoado . . . . . . . . . . . . . . . . . . . 46

4.4 Validação de agrupamentos . . . . . . . . . . . . . . . . . . . . . . 48

4.5 Considerações finais . . . . . . . . . . . . . . . . . . . 50

5 Resultados Experimentais $\quad 51$

5.1 Detalhes de implementação . . . . . . . . . . . . . . . . . . 51

5.2 Experimentos com o conjunto de dados $\operatorname{PPAR} \delta-1 \ldots \ldots \ldots$. . . . . . . 52

5.2.1 Primeiro esquema de análise exploratória: aplicação das técnicas de escore de Fisher e PCA e do conhecimento de especialista no domínio 52

5.2.2 Segundo esquema de análise exploratória: aplicação das técnicas $\mathrm{PCA}$ e SPCA . . . . . . . . . . . . . . . . . . 55

5.2.3 Terceiro esquema de análise exploratória: aplicação de todas as técnicas de redução de dimensionalidade . . . . . . . . . . . . . . . 57

5.2.3.1 Análise gráfica dos resultados . . . . . . . . . . . . . . 59

5.3 Experimentos com o conjunto de dados $\operatorname{PPAR} \delta-2 \ldots \ldots$. . . . . . . . 62 
5.3.1 Análise gráfica dos resultados . . . . . . . . . . . . . . . 63

5.4 Experimentos com o conjunto de dados AT1 . . . . . . . . . . . . 66

5.4 .1 Análise gráfica dos resultados . . . . . . . . . . . . . . . . . 68

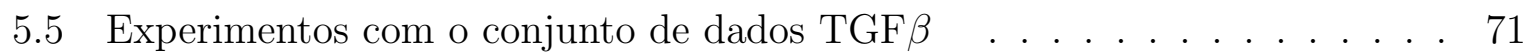

5.5.1 Análise gráfica dos resultados . . . . . . . . . . . . . . . . 73

5.6 Considerações finais . . . . . . . . . . . . . . . . . . 75

6 Conclusões, Contribuições e Trabalhos Futuros $\quad 77$

6.1 Contribuições . . . . . . . . . . . . . . . . . . . 78

6.2 Trabalhos futuros . . . . . . . . . . . . . . . . 78

$\begin{array}{ll}\text { Referências } & 80\end{array}$ 


\section{Lista de Figuras}

1 Possíveis interações entre uma substância bioativa e o seu alvo biológico (VERLI; BARREIRO, 2005). . . . . . . . . . . . . . . . 7

2 Processo de descoberta e desenvolvimento de novos medicamentos (Imagem adaptada de: http://www.noesisinformatics.com). . . . . . . . . . . 8

3 Etapas envolvidas nas análises SAR (SCIOR et al., 2009). . . . . . . . . . 9

4 Primeiro esquema proposto para redução de dimensionalidade, derivando cinco conjuntos de dimensão reduzida. . . . . . . . . . . . . . . . . . . . 52

5 Resultados de validação de agrupamentos obtidos pelas técnicas $k$-médias, FCM e EICAMM, para o conjunto $\operatorname{PPAR} \delta-1$ no primeiro esquema de análise exploratória. . . . . . . . . . . . . . . . . . . 54

6 Segundo esquema proposto para redução de dimensionalidade, derivando quatro conjuntos de dimensão reduzida. . . . . . . . . . . . . . . . . . . 55

7 Resultados de validação de agrupamentos obtidos pelas técnicas $k$-médias, FCM e EICAMM, para o conjunto $\operatorname{PPAR} \delta$-1, no segundo esquema de análise exploratória. . . . . . . . . . . . . . . . . 56

8 Terceiro esquema proposto para redução de dimensionalidade, derivando diversos conjuntos de dimensão reduzida . . . . . . . . . . . . . . . . . 57

9 Resultados de validação de agrupamentos obtidos pelas técnicas $k$-médias, FCM e EICAMM, para o conjunto $\operatorname{PPAR} \delta$-1, no terceiro esquema de análise exploratória. . . . . . . . . . . . . . . . . . . 5 58

10 Resultados de agrupamento obtidos pelo método $k$-médias em combinação com as técnicas escore de Fisher e GP, escore de Fisher e IPM e escore de Fisher e SPCA-ZOU: (a) Visualização dos resultados de agrupamento obtidos com o algoritmo $k$-médias; (b) Visualização dos dados de acordo com o nível de atividade biológica definido pelo especialista no domínio. . . 60 
11 Resultados de validação de agrupamentos obtidos pelas técnicas $k$-médias, FCM e EICAMM, para o conjunto $\operatorname{PPAR} \delta$-2, após aplicação do terceiro esquema de análise exploratória (descrito na Seção 5.2.3) . . . . . . . . . . 63

12 Resultados de agrupamento obtidos pelo método EICAMM em combinação com as técnicas de escore de Fisher e GP, para o conjunto PPAR $\delta$-2: (a) Visualização dos resultados de agrupamento; (b) Visualização dos dados de acordo com o nível de atividade biológica definido pelo especialista no domínio. . . . . . . . . . . . . . . . . . . . . 64

13 Resultados de validação de agrupamentos obtidos pelas técnicas $k$-médias, FCM e EICAMM, para o conjunto AT1, após aplicação do terceiro esquema de análise exploratória (descrito na Seção 5.2.3) . . . . . . . . . . . . . . 67

14 Resultados de agrupamento obtidos pelo método EICAMM, para o conjunto AT1, em combinação com as técnicas GP, IPM e escore de Fisher e GP: (a) Visualização dos resultados de agrupamento; (b) Visualização dos dados de acordo com o nível de atividade biológica definido pelo especialista no domínio. . . . . . . . . . . . . . . . . . . 69

15 Resultados de validação de agrupamentos obtidos pelas técnicas $k$-médias, FCM e EICAMM, para o conjunto TGF $\beta$, após aplicação do esquema de análise exploratória (descrito na Seção 5.2.3) . . . . . . . . . . . . . . 7

16 Resultados de agrupamento obtidos pelo método $k$-médias em combinação com as técnicas escore de Fisher e PCA, escore de Fisher e GP, escore de Fisher e IPM e escore de Fisher e SPCA-ZOU, para o conjunto TGF $\beta$ : (a) Visualização dos resultados de agrupamento; (b) Visualização dos dados de acordo com o nível de atividadde biológica definido pelo especialista no domínio. . . . . . . . . . . . . . . . . . 74 


\section{Lista de Tabelas}

1 Conjunto de dados $\operatorname{PPAR} \delta$-1. Compostos relacionados com o tratamento da DM e SM. Estrutura geral e valor de atividade biológica $\left(\mathrm{pEC}_{50}\right)$. . . . 11

2 Conjunto de dados PPAR $\delta$-2. Compostos relacionados com o tratamento da DM e SM. Estrutura geral e o valor de atividade biológica $\left(\mathrm{pEC}_{50}\right)$. . . 13

3 Conjunto de dados AT1. Compostos relacionados com o tratamento de doenças cardiovasculares. Estrutura e o valor de atividade biológica $\left(\mathrm{pIC}_{50}\right)$. 17

4 Conjunto de dados TGF $\beta$. Compostos relacionados com o tratamento do câncer. Estrutura geral e o valor de atividade biológica $\left(\mathrm{pIC}_{50}\right)$. . . . . . . 20

5 Parâmetros estatísticos de atividade biológica dos grupos rotulados pelo algoritmo $k$-médias, para o conjunto de dados $\operatorname{PPAR} \delta-1 . \quad \ldots . . . . .61$

6 Parâmetros estatísticos de atividade biológica dos grupos rotulados pelo algoritmo EICAMM e observados pelo especialista de domínio, para o conjunto de dados $\operatorname{PPAR} \delta-2 \ldots \ldots \ldots$. . . . . . . . . . . . . . . . 65

7 Parâmetros estatísticos de atividade biológica dos grupos rotulados pelo algoritmo EICAMM e observados pelo especialista de domínio, para o conjunto de dados AT1. . . . . . . . . . . . . . . . . . . . . . 70

8 Parâmetros estatísticos de atividade biológica dos grupos rotulados pelo algoritmo $k$-médias e observados pelo especialista de domínio, para o con-

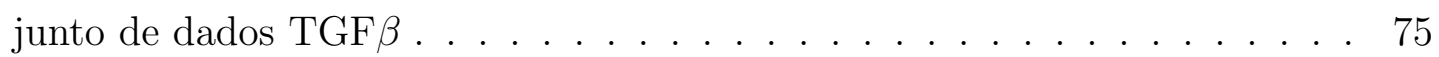




\section{Introdução}

\subsection{Contextualização e motivação}

As pesquisas realizadas na área de Química Medicinal (QM) têm por objetivo compreender os principais mecanismos relacionados com o desenvolvimento de uma doença, de forma a propor novas substâncias químicas candidatas a medicamentos (YOUNG, 2009). Para isso, os pesquisadores são responsáveis por validar os alvos biológicos, descobrir e desenvolver um candidato a fármaco com melhor atividade biológica, assim como realizar testes biológicos em laboratório, entre outras tarefas.

Dentre as diversas atividades existentes no processo de descoberta de novos medicamentos, há uma estratégia de análise de dados que realiza o estabelecimento das relações entre a estrutura química e a atividade biológica $(\mathrm{SAR})^{1}$ de uma série de moléculas, método fundamental para determinar grupos de substâncias químicas com diferenciado nível de atividade biológica, responsáveis por uma determinada ação no organismo (SILVA et al., 2008). Nessa etapa, são avaliados conjuntos de dados com observações (moléculas) e atributos (descritores químicos) contendo informações sobre as propriedades das substâncias bioativas, as quais são analisadas com o auxílio de métodos computacionais.

Uma das principais características encontradas na maioria dos dados analisados pelos pesquisadores de QM é a sua alta dimensionalidade, o que torna complexa a modelagem de fenômenos moleculares que constituem os processos bioquímicos (ANDONIE, 2010; NING; KARYPIS, 2011). A necessidade de análise de bases de dados com essa característica é uma das motivações para o desenvolvimento de pesquisas em Sistemas de Informação, visto que é fundamental combinar a memória do computador e a eficiência computacional para o reconhecimento de padrões.

Técnicas de redução de dimensionalidade são fundamentais na análise de dados em QM, pois determinam um conjunto de dados com dimensão reduzida que descreve com

\footnotetext{
${ }^{1}$ Do original, em inglês, Structure-Activity Relationships
} 
maior fidelidade o conjunto de dados original, além de possibilitar melhorar o desempenho dos algoritmos de aprendizado em geral (GOODARZI; FREITAS; JENSEN, 2009; BISHOP, 2005). Tais métodos de redução realizam tarefas como: (i) extração de características, em que o espaço do conjunto de dados original é transformado em um espaço de menor dimensão; (ii) seleção de variáveis, etapa na qual são selecionados descritores que representem com maior fidelidade o conjunto original. No presente trabalho foram aplicadas algumas dessas técnicas, como o escore de Fisher, análise de componentes principais $(\mathrm{PCA})^{2}$ e variações da técnica de análise de componentes principais esparsas (SPCA $)^{3}$ (JOLLIFFE, 2002; JOURNEE et al., 2010; ZOU; HASTIE; TIBSHIRANI, 2006; HEIN; BUHLER, 2010).

Além dos métodos de redução de dimensionalidade, técnicas de aprendizado de máquina são fundamentais na análise dos dados químicos pois, a partir desses métodos, é possível descobrir padrões dentro de um conjunto de dados. Em geral, as análises são realizadas por meio de técnicas supervisionadas, em que cada observação do conjunto é associada previamente a um determinado rótulo. Alguns exemplos de técnicas supervisionadas são as redes neurais perceptron multicamadas $(\mathrm{MLP})^{4}$ e as máquinas de vetores de suporte $(\mathrm{SVM})^{5}$ (GERTRUDES et al., 2012).

No presente trabalho, os conjuntos de dados químicos foram analisados por meio de técnicas não supervisionadas, onde não há uma associação prévia de uma observação química a um determinado rótulo. Muitos pesquisadores em QM baseiam-se numa assertiva de que moléculas similares tendem a exibir propriedades químicas similares (BROWN, 2009). Desta forma, neste trabalho foram comparados três métodos de agrupamento de dados: os algoritmos $k$-médias, fuzzy $c$-médias $(\mathrm{FCM})^{6}$ e o modelo de mistura ICA aperfeiçoado (EICAMM) ${ }^{7}$ (XU; WUNSCH-II, 2009; OLIVEIRA; ROMERO, 2008).

Os métodos de redução de dimensionalidade e de agrupamento de dados citados anteriormente serão descritos e discutidos ao longo deste trabalho, uma vez que os mesmos foram investigados e utilizados no processo de análise de dados químicos.

\footnotetext{
${ }^{2}$ Do original, em inglês, Principal Component Analysis

${ }^{3}$ Do original, em inglês, Sparse Principal Component Analysis

${ }^{4}$ Do original, em inglês, Multilayer Perceptron

${ }^{5}$ Do original, em inglês, Support Vector Machines

${ }^{6}$ Do original, em inglês, Fuzzy c-means

${ }^{7}$ Do original, em inglês, Enhanced ICA Mixture Model.
} 


\subsection{Definição do problema}

A alta dimensionalidade dos conjuntos de dados é um dos problemas encontrados por pesquisadores em QM nas análises SAR. Por conta disso, diversas técnicas de redução da dimensionalidade são aplicadas no processo de análise de dados em QM. Neste trabalho, são consideradas as seguintes técnicas de redução de dimensionalidade: escore de Fisher, PCA e variações da técnica SPCA. A técnica escore de Fisher realiza a seleção de variáveis por meio da definição prévia de classes (grupos de compostos com diferentes níveis de atividade biológica) do conjunto de dados em estudo (DUDA; HART; STORK, 2001). É um método simples de implementação e tem sido utilizado com sucesso na análise de dados químicos (MALTAROLLO; MELLO; HONORIO, 2011; WEBER; SILVA, 2008).

A PCA é uma das técnicas de extração de características mais utilizadas na análise de dados devido a sua fácil implementação, além de manter o máximo de informação do conjunto de dados original. A técnica PCA realiza a extração de características por meio da transformação do espaço de dados original para um espaço ortogonal com variáveis não correlacionadas, denominadas componentes principais, e que podem ter dimensão menor do que o conjunto original (JOLLIFFE, 2002; ABDI; WILLIAMS, 2010; DUDA; HART; STORK, 2001). Nessa técnica, cada componente principal é resultado de uma multiplicação entre a matriz do conjunto de dados e uma matriz de autovetores ortogonais, com coeficientes diferentes de zero.

Durante o processo de transformação da técnica PCA, as componentes principais terão contribuições de todas as variáveis do conjunto de dados original. Um problema ao realizar tal transformação é que variáveis com informações não relevantes (variáveis com ruído) ainda serão computadas, podendo acarretar em um desempenho ruim no processo de classificação de dados. Outro problema é que na análise de dados em QM, o valor de cada coeficiente da matriz de autovetores auxilia na descoberta de variáveis realmente importantes na descrição físico-química dos compostos e, uma vez que todos os coeficientes da matriz de autovetores da técnica PCA possuem valores não nulos, a identificação de variáveis relevantes se torna custosa.

Considerando as limitações citadas anteriormente em relação a técnica PCA, diversos autores propuseram outra metodologia para extração de características: a SPCA. Essa técnica realiza a transformação do conjunto de dados a partir de autovetores esparsos, projetando-os em um novo espaço de menor dimensão e com um número menor de variáveis na composição de cada componente principal (HASTIE; TIBSHIRANI; FRIEDMAN, 2009). Nos últimos anos, diversos modelos matemáticos foram propostos para a técnica SPCA, entre eles estão o método de regressão por otimização, método da potência e 
método da potência inversa (ZOU; HASTIE; TIBSHIRANI, 2006; HEIN; BUHLER, 2010; JOURNEE et al., 2010).

Outro problema na análise de dados em QM é encontrar grupos relevantes que permitam identificar novas moléculas candidatas a medicamentos. Essa tarefa pode ser realizada com a aplicação de algoritmos de agrupamento. No presente trabalho, foram utilizadas as técnicas $k$-médias, FCM e EICAMM. O objetivo dessas técnicas é descobrir, sem o conhecimento prévio sobre classes, grupos naturais dentro de um conjunto de dados (JAIN, 2010). De uma forma funcional, esses algoritmos devem encontrar dentro de um conjunto de dados $k$ grupos com base em comparações quantitativas de forma que as semelhanças entre as observações no mesmo grupo sejam as maiores possíveis, enquanto as semelhanças entre observações em diferentes grupos sejam as menores possíveis. Normalmente, para definição de uma partição que seja significativa para o especialista de domínio, os algoritmos de agrupamento são executados de forma independente para diferentes números de grupos.

\subsection{Objetivos}

O principal objetivo deste trabalho foi desenvolver esquemas de análise de dados que tratem o problema da alta dimensionalidade dos dados e que possuam a capacidade de detectar agrupamentos relevantes em conjuntos de dados que são objetos de estudos por pesquisadores da área de Química Medicinal. Considerando os problemas descritos anteriormente, os seguintes objetivos específicos também foram alcançados:

- Análise do desempenho dos algoritmos de agrupamento de dados após uso das técnicas de redução de dimensionalidade, as quais foram aplicadas de formas isolada e combinada aos conjuntos de dados em estudo;

- Análise do desempenho dos algoritmos de agrupamento de acordo com o número de grupos definidos pelo especialista do domínio.

\subsection{Estrutura da dissertação}

O presente trabalho está organizado da seguinte forma: o Capítulo 2 apresenta uma breve descrição das etapas envolvidas durante o processo de descoberta de novos medicamentos, assim como a caracterização dos conjuntos de dados utilizados no processo de 
análise dos resultados. No Capítulo 3 são descritos os métodos de redução de dimensionalidade utilizados neste trabalho. O Capítulo 4 apresenta os métodos de agrupamento de dados e suas aplicações na área de QM. Os experimentos realizados, os resultados obtidos e a discussão dos mesmos são descritos no Capítulo 5. Por fim, no Capítulo 6 serão apresentadas as considerações finais, as limitações e os trabalhos futuros relacionados aos principais tópicos apresentados nessa dissertação. 


\section{Química Medicinal: Planejamento de Substâncias Bioativas}

A descoberta de novos medicamentos utilizados para atender as necessidades de saúde pública é um dos desafios mais importantes da humanidade; além disso, é um processo demorado e dispendioso (YOUNG, 2009). Nos últimos anos, diversas tecnologias foram disponibilizadas para pesquisas em QM, permitindo que os pesquisadores conseguissem sintetizar e testar regularmente milhares, se não centenas de milhares, de novas moléculas para diversas aplicações (BROWN, 2009; YOUNG, 2009).

A área de QM engloba o planejamento racional de novas substâncias bioativas, envolvendo diversas etapas, tais como (i) descrição das moléculas, desde sua constituição atômica até suas características estruturais essenciais para interagir com um determinado alvo biológico; (ii) modificação molecular de compostos; (iii) entendimento (em nível molecular) de processos químicos, além do isolamento de princípios ativos naturais; (iv) elucidação da estrutura química ou sua identificação; (v) validação dos modelos SAR por meio de técnicas matemáticas ou estatísticas, o que permite a proposição de novos compostos (SILVA, 2013).

Nesse capítulo, serão apresentadas algumas características de alvos biológicos, um conceito muito utilizado em QM, assim como os processos empregados no descobrimento ou desenvolvimento de novos candidatos a fármacos. Por fim, serão apresentados quatro conjuntos de compostos que foram utilizados nos experimentos conduzidos no presente trabalho. 


\subsection{Alvo biológico}

Um alvo biológico pode ser uma proteína, receptor ou enzima que ao interagir com um determinado composto modifica o metabolismo do indivíduo, atenuando desordens no organismo (YOUNG, 2009; MALTAROLLO, 2009). No processo de desenvolvimento de novos fármacos, é necessário entender detalhadamente as interações entre a substância e o alvo biológico relacionado com doenças específicas, de forma que o estímulo seja realizado da forma mais eficiente possível (MALTAROLLO, 2009).

A maioria dos fármacos existentes possui um efeito biológico dependente de uma interação específica entre uma molécula (fármaco) e um alvo biológico (proteína ou receptor). Esta interação pode ser descrita pelo modelo chave-fechadura (FISCHER, 1894), como apresentado na Figura 1, em que são representadas as possíveis interações entre uma molécula e um alvo biológico.

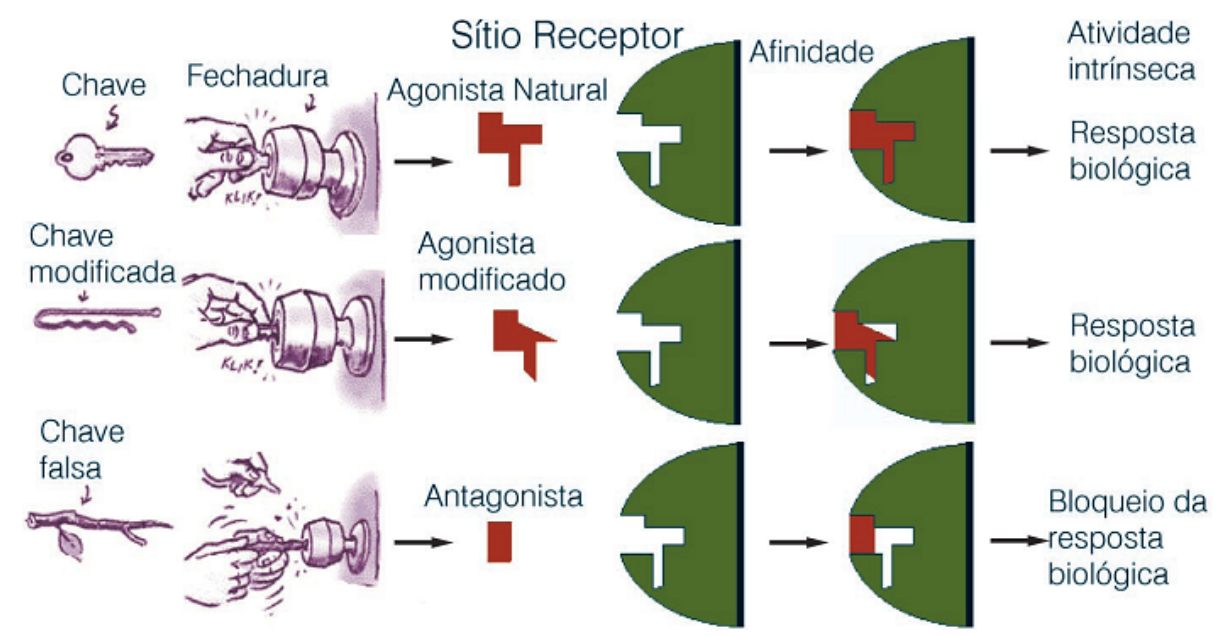

Figura 1 - Possiveis interações entre uma substância bioativa e o seu alvo biológico (VERLI; BARREIRO, 2005).

A primeira parte da Figura 1 apresenta a interação entre um agonista natural ("chave") e o alvo biológico ("fechadura"), realizando de forma eficiente as interações e desencadeando a resposta biológica. Na segunda parte da Figura 1, há interação entre um agonista modificado e o alvo biológico produzindo a resposta biológica, porém com uma eficiência menor que o agonista natural. Por fim, é apresentada uma molécula que durante o processo de interação produz efeito inverso do agonista natural, bloqueando a resposta biológica. Essa molécula é definida como antagonista do alvo biológico (VERLI; BARREIRO, 2005).

Durante o processo de busca por novos medicamentos, os pesquisadores da área de QM analisam se um determinado alvo biológico necessita ter sua resposta biológica ativada ou 
bloqueada. Essa decisão é tomada depois de um estudo detalhado sobre o alvo biológico e sua atuação no organismo. Para quantificar o nível de interação entre uma molécula e o seu alvo biológico, os pesquisadores em QM utilizam índices de atividade biológica, dentre eles podem ser citados valores de $\mathrm{EC}_{50}$ (concentração do composto que ativa em $50 \%$ o alvo biológico) e $\mathrm{IC}_{50}$ (concentração da substância que inibe $50 \%$ da atividade biológica). Esses índices, em geral, são convertidos para sua forma logarítmica ( $\mathrm{pEC}_{50}$ e $\mathrm{pIC}_{50}$ ) e quanto maior o seu valor na base logarítmica, melhor a resposta biológica de uma molécula.

\subsection{Processo de descoberta de medicamentos}

Na área de QM, o processo de descoberta ou desenvolvimento de novos medicamentos geralmente segue um conjunto de etapas comuns. De acordo com a Figura 2, inicialmente é realizada a identificação da doença. Após a identificação da doença, são realizados estudos para identificação de um alvo biológico. A seguir, os pesquisadores identificam moléculas que apresentam afinidade pelo alvo biológico em estudo. Após a identificação das moléculas candidatas a novos fármacos, é realizado um processo de otimização dessas moléculas e são iniciados os testes em animais (testes pré-clínicos). Por fim, as moléculas com resultados promissores nos testes com animais são submetidas a testes em humanos, sendo que as substâncias com melhores resultados nos testes em humanos poderão ser utilizadas como novos medicamentos (YOUNG, 2009).

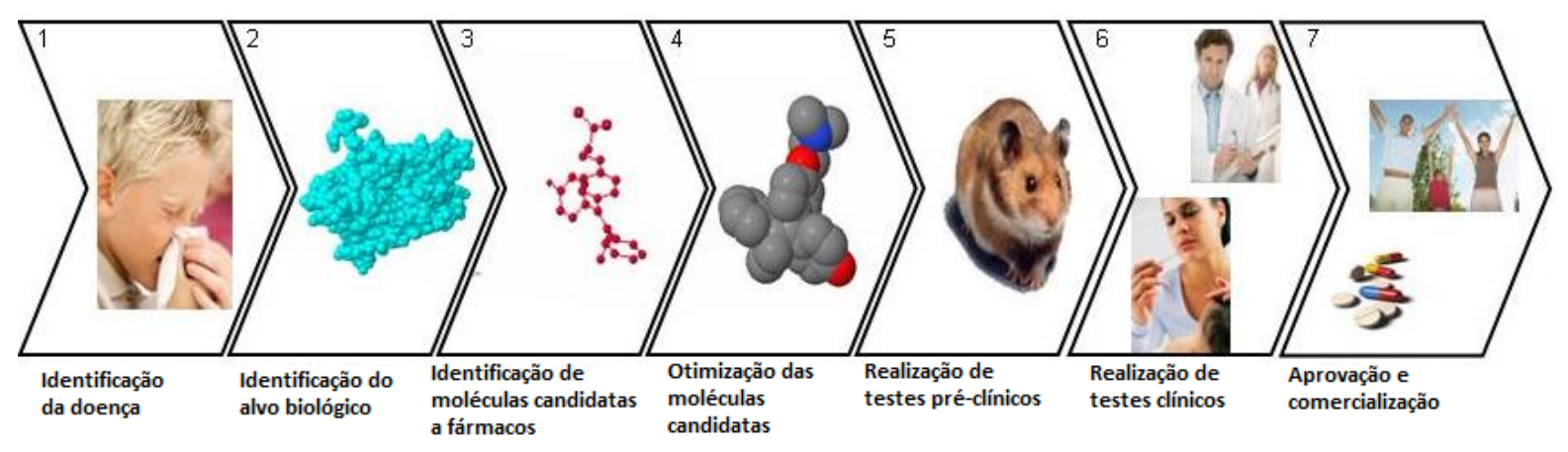

Figura 2 - Processo de descoberta e desenvolvimento de novos medicamentos (Imagem adaptada de: http://www.noesisinformatics.com).

No processo de identificação de novas moléculas candidatas a fármacos (etapa 3, Figura 2), os métodos computacionais podem ser considerados como ferramentas fundamentais. Nesse caso, são realizadas análises sobre as relações entre a estrutura química 
das moléculas e seu potencial de interação com o alvo biológico, as quais são definidas como análises SAR (YOUNG, 2009). O processo de análise SAR pode ser dividido em duas etapas: modelagem molecular e quimiometria. De acordo com a Figura 3, na primeira etapa são selecionadas moléculas com atividade biológica conhecida por meio de consultas a trabalhos na literatura ou por buscas em banco de dados (por exemplo, base de dados $\mathrm{ZINC}^{1}$ ). Após essa escolha, são realizadas transformações dessas moléculas em um conjunto de dados com observações e atributos, os quais irão representar propriedades eletrônicas, estereoquímicas, constitucionais e topológicas de cada molécula. Algumas ferramentas que realizam o cálculo desses atributos incluem os pacotes computacionais GAUSSIAN, SPARTAN e DRAGON .

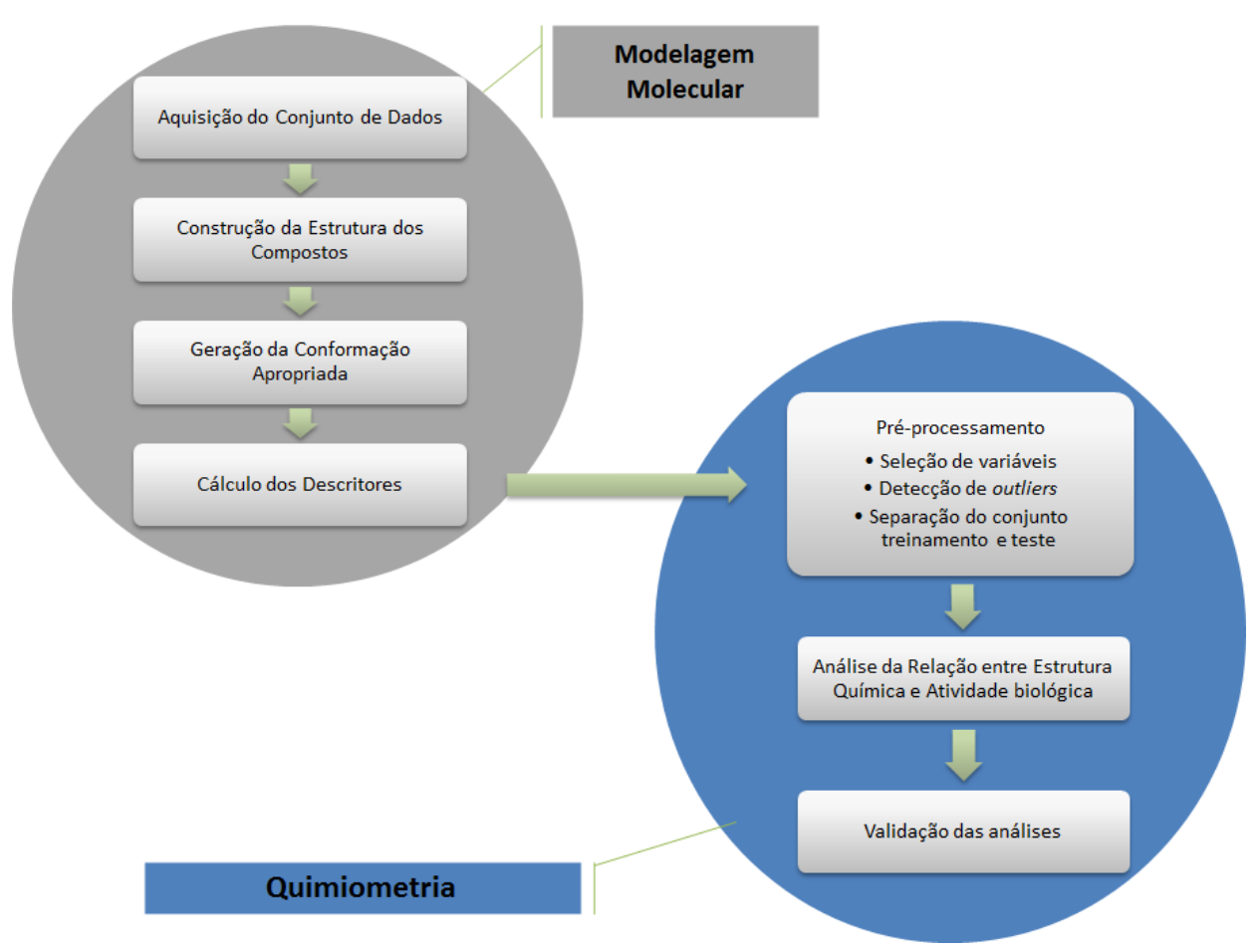

Figura 3 - Etapas envolvidas nas análises SAR (SCIOR et al., 2009).

Com a definição da matriz de observações e atributos, análises multivariadas (também conhecidas como análises quimiométricas) são realizadas e envolvem as seguintes etapas: seleção dos melhores descritores químicos por meio de técnicas de redução de dimensionalidade, verificação de moléculas fora do padrão do conjunto de dados (detecção de outliers), análise das relações entre as moléculas selecionadas e a atividade biológica de cada, além da etapa de validação dos modelos obtidos. Por fim, procede-se com a interpretação dos dados para a compreensão dos possíveis mecanismos de ação/interação molécula-alvo

\footnotetext{
${ }^{1}$ Base de dados disponível em http://zinc.docking.org
} 
biológico, e proposição de alterações na estrutura das moléculas para obtenção de novos compostos com atividade biológica otimizada e com menores efeitos colaterais.

Vale destacar que recentemente, houve um significativo crescimento no número de métodos computacionais robustos utilizados nas análises de dados em QM, tais como redes neurais artificiais e SVM (GERTRUDES et al., 2012). Para que outros métodos computacionais possam ser utilizados na análise de dados na área de QM, na próxima seção serão apresentados alguns conjuntos de dados utilizados durante a realização deste trabalho.

\subsection{Conjuntos de dados estudados}

No desenvolvimento do presente trabalho, foram estudados diversos conjuntos de substâncias bioativas com o objetivo de entender as relações SAR. O primeiro e o segundo conjuntos de dados foram objetos de estudo dos autores Maltarollo e Honório (2012) e Maltarollo, Silva e Honório (2012), utilizados para a geração de modelos estatísticos capazes de descrever moléculas candidatas a fármacos para o tratamento da diabetes mellitus (DM) e síndrome metabólica (SM). A escolha desses conjuntos de dados se deve ao fato do aumento expressivo no número de casos dessas doenças. Uma estimativa indica que, no Brasil, a população portadora da DM em 1995 era de 4,9 milhões de indivíduos e a projeção para 2025 é de 11,6 milhões de pessoas (KING; AUBERT; HERMAN, 1998).

A DM é uma doença caracterizada como o distúrbio crônico do metabolismo de carboidratos, lipídios e proteínas. Outra característica desta enfermidade é a utilização inadequada de glicose pelo organismo, ocasionando a hiperglicemia (quantidade elevada de glicose no sangue). Esta doença pode ser classificada em três principais variantes: tipo 1 (atinge, em sua maioria, crianças e jovens), tipo 2 (adultos) e diabetes gestacional (MALTAROLLO, 2009). As complicações mais frequentes ligadas ao DM ocorrem devido às alterações vasculares, por exemplo, indivíduos portadores de DM tipo 2 apresentam risco de doença cardiovascular duas a quatro vezes maior do que indivíduos não diabéticos.

A SM é um transtorno do metabolismo e está relacionada a um conjunto de fatores de riscos cardiovasculares e obesidade. Estão ligadas a este distúrbio características como resistência à insulina (o que também causa a hiperglicemia), alto índice de ácidos graxos livres, hipertensão arterial e outros distúrbios cardiovasculares. Por possuírem características semelhantes, a DM e a SM possuem o mesmo alvo biológico, o receptor 
PPAR $^{2}$, responsável pelo controle dos níveis de glicose e lipídeos (MALTAROLLO, 2009).

A Tabela 1 apresenta o conjunto de dados contendo 70 compostos, denominado como conjunto $\operatorname{PPAR} \delta$-1, com informações sobre a estrutura química geral, o número do composto e valor de atividade biológica $\left(\mathrm{pEC}_{50}\right)$.

Tabela 1 - Conjunto de dados PPAR $\delta$-1. Compostos relacionados com o tratamento da $D M$ e SM. Estrutura geral e valor de atividade biológica ( $\left.p E C_{50}\right)$.

\begin{tabular}{|c|c|c|}
\hline Molécula & Estrutura Geral & $p E C_{50}$ \\
\hline 1 & & 7,36 \\
\hline 2 & & 8,05 \\
\hline 3 & & 8,38 \\
\hline 4 & & 7,89 \\
\hline 5 & & 8,17 \\
\hline 6 & & 8,18 \\
\hline 7 & & 8,14 \\
\hline 8 & & 7,37 \\
\hline 9 & & 7,25 \\
\hline 10 & & 7,17 \\
\hline 11 & & 6,93 \\
\hline 12 & & 8,34 \\
\hline 13 & & 8,62 \\
\hline 14 & & 8,80 \\
\hline 15 & & 7,60 \\
\hline 16 & & 8,72 \\
\hline 17 & & 8,12 \\
\hline 18 & & 8,57 \\
\hline 19 & & 7,85 \\
\hline 20 & & 7,96 \\
\hline 21 & & 5,65 \\
\hline 22 & & 8,47 \\
\hline 23 & & 8,23 \\
\hline 24 & & 8,42 \\
\hline 25 & & 8,82 \\
\hline 26 & & 8,64 \\
\hline 27 & & 7,37 \\
\hline 28 & & 7,96 \\
\hline 29 & & 8,25 \\
\hline 30 & & 8,66 \\
\hline 31 & & 9,02 \\
\hline
\end{tabular}

\footnotetext{
${ }^{2}$ Do original, em inglês, Peroxisome Proliferator-Activated Receptor
} 
Tabela 1 - continuação

\begin{tabular}{|c|c|c|}
\hline Molécula & Estrutura Geral & $p E C_{50}$ \\
\hline 32 & & 8,80 \\
\hline 33 & & 7,34 \\
\hline 34 & & 7,55 \\
\hline 35 & & 7,92 \\
\hline 36 & & 8,34 \\
\hline 37 & & 8,89 \\
\hline 38 & & 8,92 \\
\hline 39 & & 8,70 \\
\hline 40 & & 8,47 \\
\hline 41 & & 8,64 \\
\hline 42 & & 8,52 \\
\hline 43 & & 8,49 \\
\hline 44 & & 8,22 \\
\hline 45 & & 8,27 \\
\hline 46 & & 9,24 \\
\hline 47 & & 8,57 \\
\hline 48 & & 8,36 \\
\hline 49 & & 7,96 \\
\hline 50 & & 8,60 \\
\hline 51 & & 7,96 \\
\hline 52 & & 8,48 \\
\hline 53 & & 8,54 \\
\hline 54 & & 8,54 \\
\hline 55 & & 8,40 \\
\hline 56 & & 8,89 \\
\hline 57 & & 8,46 \\
\hline 58 & & 8,39 \\
\hline 59 & & 8,66 \\
\hline 60 & & 8,72 \\
\hline 61 & & 8,48 \\
\hline 62 & & 8,40 \\
\hline 63 & & 8,89 \\
\hline 64 & & 8,28 \\
\hline 65 & & 8,16 \\
\hline 66 & & 7,74 \\
\hline 67 & & 8,47 \\
\hline 68 & & 8,36 \\
\hline 69 & & 8,68 \\
\hline 70 & & 6,66 \\
\hline
\end{tabular}


O conjunto de dados apresentado na Tabela 1 foi transformado em uma matriz de observações e atributos de acordo com protocolos da QM. Com tal transformação, foi obtido um conjunto com 70 observações e 653 descritores. Da mesma forma, a Tabela 2 apresenta o conjunto de dados contendo 121 compostos e 653 descritores, denominado como $\operatorname{PPAR} \delta$-2, com informações sobre a estrutura geral, o número do composto e o valor de atividade biológica $\left(\mathrm{pEC}_{50}\right)$.

Tabela 2 - Conjunto de dados PPAR $\delta$-2. Compostos relacionados com o tratamento da $D M$ e SM. Estrutura geral e o valor de atividade biológica $\left(p E C_{50}\right)$.

\begin{tabular}{|c|c|c|}
\hline Molécula & Estrutura Geral & $p E C_{50}$ \\
\hline 1 & & 7,36 \\
\hline 2 & & 8,05 \\
\hline 3 & & 8,38 \\
\hline 4 & & 7,89 \\
\hline 5 & & 8,17 \\
\hline 6 & & 8,18 \\
\hline 7 & & 8,14 \\
\hline 8 & & 7,37 \\
\hline 9 & & 7,25 \\
\hline 10 & & 7,17 \\
\hline 11 & & 6,93 \\
\hline 12 & & 8,34 \\
\hline 13 & & 8,62 \\
\hline 14 & & 8,80 \\
\hline 15 & & 7,60 \\
\hline 16 & & 8,72 \\
\hline 17 & & 8,12 \\
\hline 18 & & 8,57 \\
\hline 19 & & 7,85 \\
\hline 20 & & 7,96 \\
\hline 21 & & 5,65 \\
\hline 22 & & 8,47 \\
\hline 23 & & 8,23 \\
\hline 24 & & 8,42 \\
\hline 25 & & 8,82 \\
\hline 26 & & 8,64 \\
\hline 27 & & 7,37 \\
\hline 28 & & 7,96 \\
\hline 29 & & 8,25 \\
\hline 30 & & 8,66 \\
\hline
\end{tabular}


Tabela 2 - continuação

\begin{tabular}{|c|c|c|}
\hline Molécula & Estrutura Geral & $p E C_{50}$ \\
\hline 31 & & 9,02 \\
\hline 32 & & 8,80 \\
\hline 33 & & 7,34 \\
\hline 34 & & 7,55 \\
\hline 35 & & 7,92 \\
\hline 36 & & 8,34 \\
\hline 37 & & 8,89 \\
\hline 38 & & 8,92 \\
\hline 39 & & 8,70 \\
\hline 40 & & 8,47 \\
\hline 41 & & 8,64 \\
\hline 42 & & 8,52 \\
\hline 43 & & 8,49 \\
\hline 44 & & 8,22 \\
\hline 45 & & 8,27 \\
\hline 46 & & 9,24 \\
\hline 47 & & 8,57 \\
\hline 48 & & 8,36 \\
\hline 49 & & 7,96 \\
\hline 50 & & 8,60 \\
\hline 51 & & 7,96 \\
\hline 52 & & 8,48 \\
\hline 53 & & 8,54 \\
\hline 54 & & 8,54 \\
\hline 55 & & 8,40 \\
\hline 56 & & 8,89 \\
\hline 57 & & 8,46 \\
\hline 58 & & 8,39 \\
\hline 59 & & 8,66 \\
\hline 60 & & 8,72 \\
\hline 61 & & 8,48 \\
\hline 62 & & 8,40 \\
\hline 63 & & 8,89 \\
\hline 64 & & 8,28 \\
\hline 65 & & 8,16 \\
\hline 66 & & 7,74 \\
\hline 67 & & 8,47 \\
\hline 68 & & 8,36 \\
\hline 69 & & 8,68 \\
\hline 70 & & 6,66 \\
\hline
\end{tabular}


2.3 Conjuntos de dados estudados

15

Tabela 2 - continuação

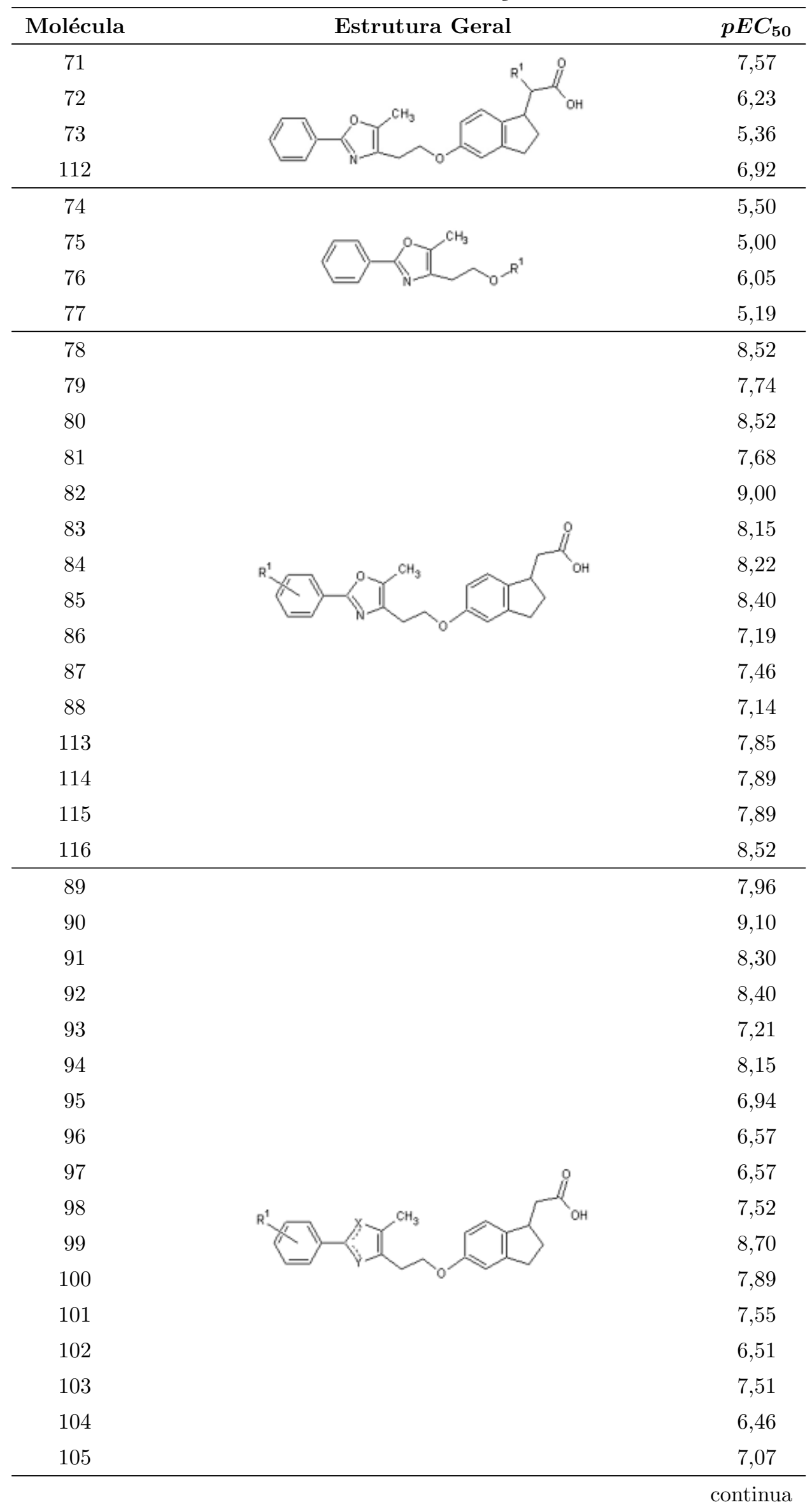


Tabela 2 - continuação

\begin{tabular}{|c|c|c|}
\hline Molécula & Estrutura Geral & $p E C_{50}$ \\
\hline 106 & & 5,00 \\
\hline 107 & & 5,00 \\
\hline 117 & & 8,30 \\
\hline 118 & & 7,33 \\
\hline 119 & & 8,82 \\
\hline 120 & & 6,59 \\
\hline 108 & & 8,15 \\
\hline 109 & & 8,30 \\
\hline 110 & & 7,96 \\
\hline 111 & & 8,00 \\
\hline 121 & & 5,00 \\
\hline
\end{tabular}

O terceiro conjunto de dados apresenta substâncias utilizadas para o tratamento da hipertensão arterial. A hipertensão arterial é uma doença crônica e multifatorial que compromete o equilíbrio entre a contração e o relaxamento dos vasos sanguíneos, ocasionando um aumento na tensão arterial, podendo provocar danos aos órgãos irrigados, além de prejudicar a irrigação tecidual (SILVA, 2013). As moléculas selecionadas para estudo têm como alvo biológico o receptor AT1, que é uma proteína envolvida na regulação de diversos processos fisiopatológicos do sistema cardiovascular (SILVA, 2013). Cada uma das moléculas presente no conjunto de dados possui um nível de atividade biológica determinado pelo valor de $\mathrm{pIC}_{50}$, o qual indica a concentração do composto que inibe em $50 \%$ a atividade do receptor AT1. A Tabela 3 apresenta o conjunto de dados, denominado como conjunto AT1, com informações sobre a estrutura dos compostos e valor de atividade biológica $\left(\mathrm{pIC}_{50}\right)$ 


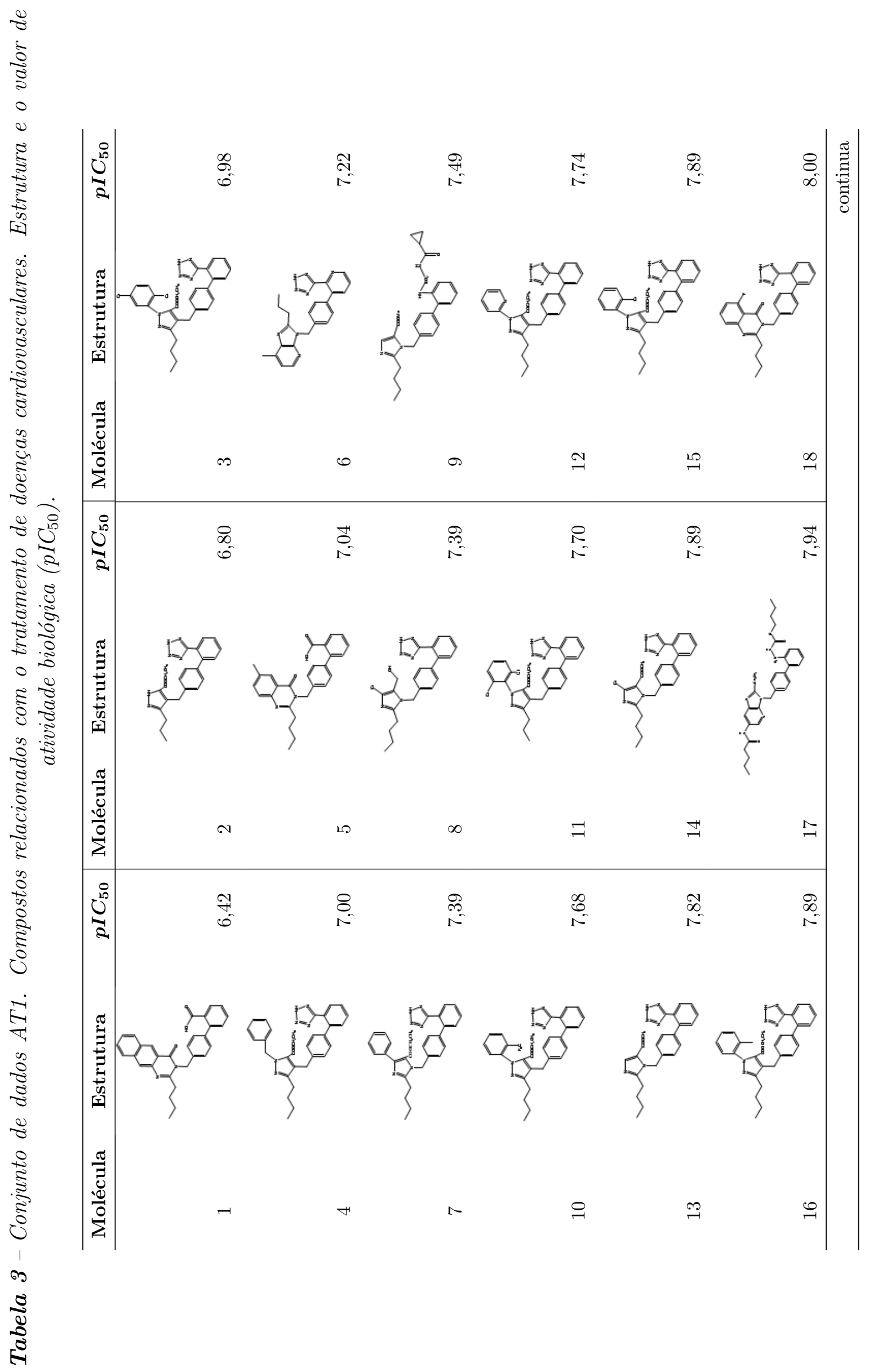




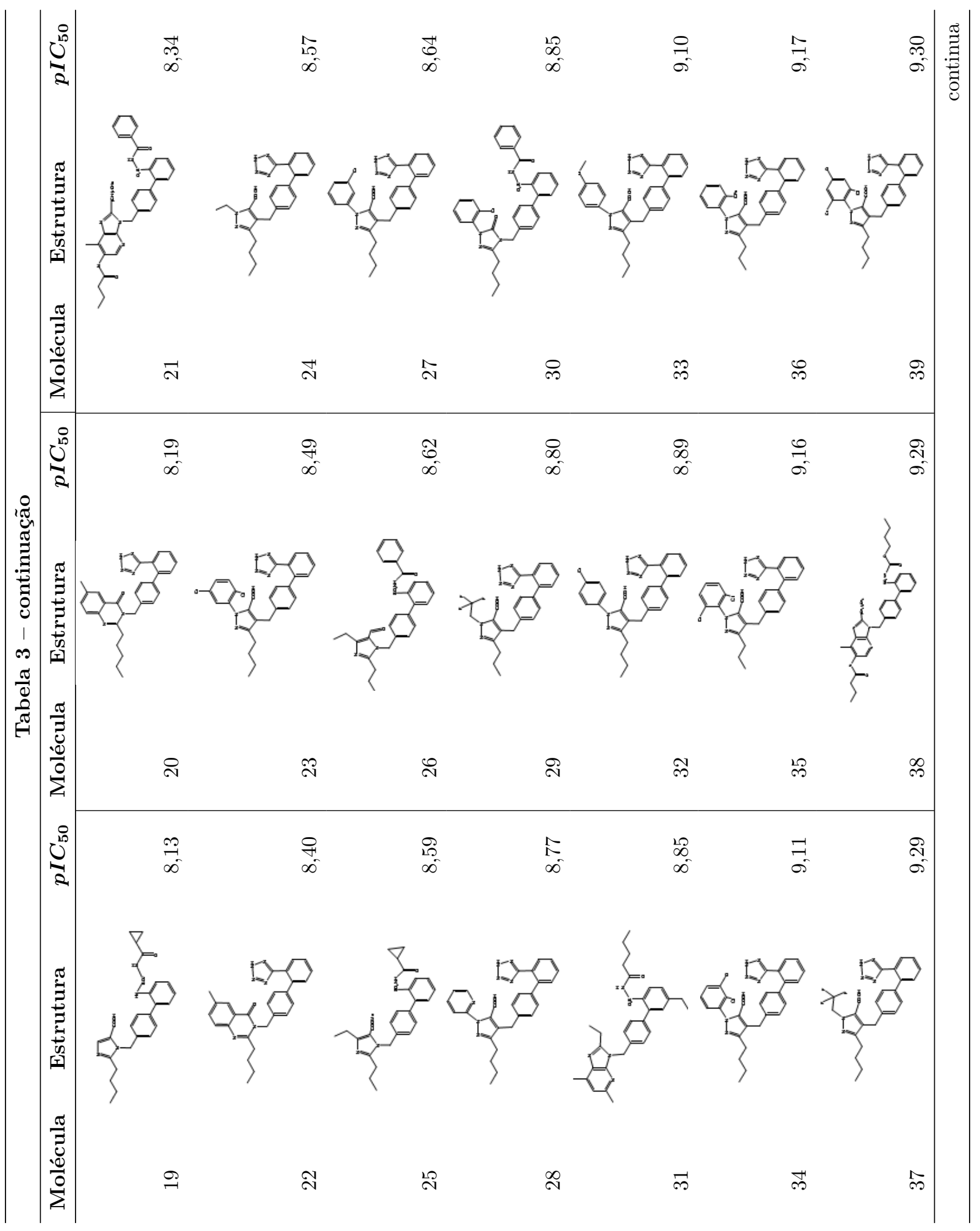




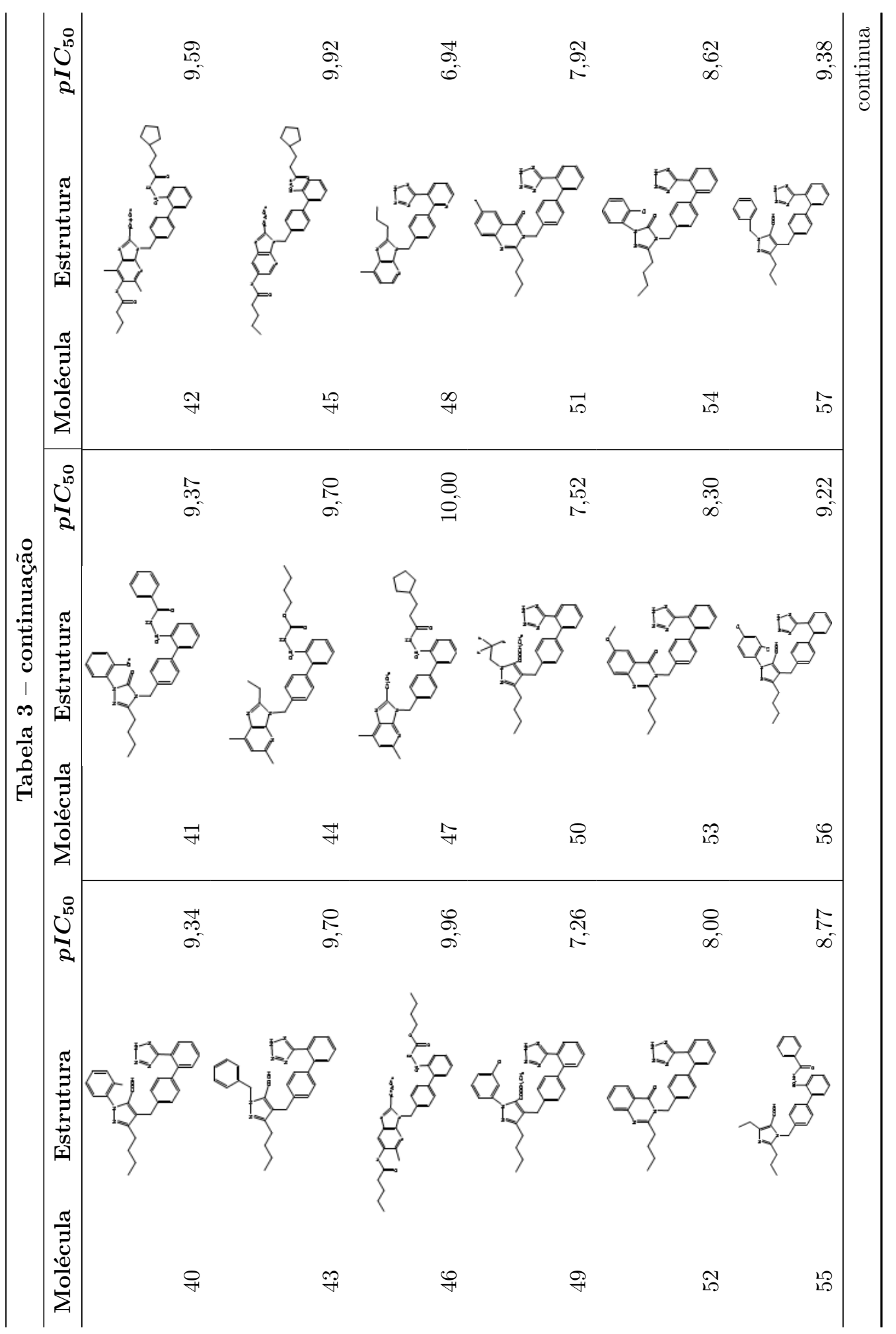




\begin{tabular}{|c|c|c|c|c|c|}
\hline \multicolumn{6}{|c|}{ Tabela 3 - continuação } \\
\hline Molécula & Estrutura & $p I C_{50}$ & Molécula & Estrutura & $p I C_{50}$ \\
\hline \multicolumn{3}{|c|}{ 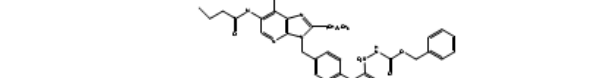 } & \multicolumn{3}{|c|}{ rycions } \\
\hline 58 & & 9,48 & 59 & & 10,00 \\
\hline
\end{tabular}

O conjunto de dados apresentado na Tabela 3 também foi transformado em uma matriz de observações e atributos de acordo com protocolos da QM (SILVA, 2013). Com tal transformação, foi obtido um conjunto contendo 59 observações e 1721 atributos.

O quarto conjunto de dados foi estudado devido ao fato das substâncias bioativas presentes nesse conjunto atuarem como inibidores do receptor $\mathrm{TGF} \beta^{3}$, alvo biológico relacionado com câncer e fibrose (ARAUJO, 2013). A Tabela 4 apresenta o conjunto de dados relacionado com o receptor TGF $\beta$ indicando a estrutura geral dos compostos, assim como o valor de atividade biológica $\left(\mathrm{pIC}_{50}\right)$. O conjunto de dados apresentado na Tabela 4 também foi transformado em uma matriz de observações e atributos de acordo com protocolos da QM. Com tal transformação, foi obtido um conjunto contendo 59 observações e 1719 atributos.

Tabela 4 - Conjunto de dados TGFß. Compostos relacionados com o tratamento do câncer. Estrutura geral e o valor de atividade biológica $\left(p I C_{50}\right)$.

\begin{tabular}{|c|c|c|}
\hline Molécula & Estrutura Geral & $p I C_{50}$ \\
\hline 1 & & 6,97 \\
\hline 2 & & 5,03 \\
\hline 3 & & 6,72 \\
\hline 4 & & 6,94 \\
\hline 5 & & 7,55 \\
\hline 6 & & 7,62 \\
\hline 7 & & 7,32 \\
\hline 8 & & 7,49 \\
\hline 9 & & 7,37 \\
\hline 10 & & 7,57 \\
\hline 11 & & 7,46 \\
\hline 48 & & 7,23 \\
\hline 49 & & 6,62 \\
\hline
\end{tabular}

\footnotetext{
${ }^{3}$ Do original, em inglês, Transforming Growth Factor- $\beta$
} 
Tabela 4 - continuação

\begin{tabular}{|c|c|c|}
\hline Molécula & Estrutura Geral & $p I C_{50}$ \\
\hline 12 & & 6,97 \\
\hline 13 & & 7,62 \\
\hline 14 & & 7,72 \\
\hline 15 & & 7,82 \\
\hline 16 & & 7,92 \\
\hline 17 & & 7,52 \\
\hline 18 & & 7,72 \\
\hline 19 & & 7,38 \\
\hline 20 & & 7,33 \\
\hline 21 & & 7,04 \\
\hline 22 & & 6,91 \\
\hline 23 & & 7,74 \\
\hline 24 & & 6,95 \\
\hline 25 & & 7,31 \\
\hline 26 & & 7,70 \\
\hline 27 & & 7,60 \\
\hline 28 & & 6,26 \\
\hline 29 & & 7,40 \\
\hline 30 & & 6,19 \\
\hline 31 & & 5,43 \\
\hline 50 & & 7,09 \\
\hline 51 & & 7,60 \\
\hline 52 & & 7,40 \\
\hline 32 & & 7,03 \\
\hline 33 & & 7,80 \\
\hline 34 & & 7,66 \\
\hline 54 & & 7,66 \\
\hline 35 & & 6,14 \\
\hline 36 & & 5,93 \\
\hline 37 & & 5,00 \\
\hline 38 & & 5,75 \\
\hline 39 & & 5,99 \\
\hline 40 & & 5,00 \\
\hline 55 & & 5,40 \\
\hline 56 & & 5,90 \\
\hline 41 & & 4,96 \\
\hline 42 & & 5,10 \\
\hline 43 & & 7,52 \\
\hline 57 & & 6,42 \\
\hline
\end{tabular}


Tabela 4 - continuação

\begin{tabular}{ccc}
\hline Molécula & Estrutura Geral & $\boldsymbol{p} \boldsymbol{I}_{\mathbf{5 0}}$ \\
\hline 44 & 7,40 \\
45 & 7,38 \\
\hline
\end{tabular}

\subsection{Considerações finais}

No presente capítulo, foram definidos alguns conceitos primordiais que serão utilizados no decorrer do trabalho, tais como alvo biológico, atividade biológica, além dos conjuntos de dados empregados para realização dos experimentos de redução de dimensionalidade e agrupamento de dados. Também foram apresentados aspectos sobre a descoberta de novos candidatos a fármacos, sendo que tal processo é muito custoso para os pesquisadores em QM e o seu tempo de análise pode ser reduzido com o auxílio de métodos computacionais.

Quanto aos conjuntos de dados químicos, cada um deles foi transformado em uma matriz de observações e descritores (ou atributos), conforme protocolos estabelecidos em QM, a partir da utilização de pacotes computacionais para cálculo de diversas propriedades eletrônicas (como energias de orbitais moleculares), físico-químicas (como área e volume molecular) e diversos descritores topológicos (MALTAROLLO; HONóRIO, 2012; SILVA, 2013). Com tal transformação das moléculas, os dados químicos passaram a representar um conjunto de alta dimensionalidade, tornando custosa a análise dos mesmos pelos pesquisadores em QM. Por conta disso, fez-se necessário o emprego de métodos computacionais para redução da dimensionalidade dos dados, os quais serão apresentados no próximo capítulo. 


\section{Redução de Dimensionalidade}

Atualmente, com o uso de ferramentas computacionais é possível observar e armazenar uma grande quantidade de características (atributos) sobre um determinado fenômeno. Porém, esse alto número de variáveis pode acarretar na imprecisão cometida por métodos de aprendizado de máquina e também no processo de análise estatística de dados. Tal problema é denominado na literatura por problema de "maldição da dimensionalidade" (XU; WUNSCH-II, 2009; BISHOP, 2005; DUDA; HART; STORK, 2001).

A representação do conjunto de dados químicos é um dos problemas dos pesquisadores em QM, uma vez que, para aplicar técnicas de aprendizado de máquina, realizam transformações dos compostos por meio do cálculo de descritores físico-químicos que os representem convenientemente. Essas estruturas podem ser representadas por propriedades físico-químicas e topológicas, assim como por descritores farmacológicos (YOUNG, 2009).

No processo de transformação dos compostos químicos em um conjunto de dados, os diversos pacotes computacionais podem calcular entre centenas e até milhares de descritores químicos (por exemplo, o software DRAGON calcula até 4885 descritores químicos). Além disso, não há garantia de que todos os descritores químicos sejam calculados de forma correta, isto devido a erros no desenho da estrutura do composto. O grande número de descritores calculados e a possível imprecisão no cálculo de alguns desses descritores são motivos primordiais para a aplicação de métodos de redução de dimensionalidade.

O processo de redução de dimensionalidade consiste na projeção de um conjunto de dados no espaço dimensional $\mathbb{R}^{n}$ para um espaço $\mathbb{R}^{m}$, com $m<n$. As duas principais abordagens para redução de dimensionalidade são por meio da seleção de variáveis, que se refere à seleção dos melhores atributos dentro de um conjunto de dados ou por meio da fusão de características, em que novos atributos são gerados a partir de transformações matemáticas realizadas sobre o conjunto de dados original, podendo o novo conjunto ter igual ou menor dimensão do que o conjunto original.

Neste capítulo, serão apresentados os seguintes métodos de redução de dimensiona- 
lidade: escore de Fisher, técnica PCA e técnicas de SPCA. Porém, antes da descrição desses métodos, são apresentados alguns conceitos da álgebra linear, fundamentais para o entendimento das técnicas descritas no presente capítulo.

\subsection{Conceitos iniciais}

Esta seção apresenta conceitos da álgebra linear fundamentais para o entendimento dos métodos de redução de dimensionalidade descritos ao longo do capítulo.

\subsubsection{Propriedades de vetores e matrizes}

\subsubsection{Normas e ortogonalidade}

A norma, ou $\ell$-norma, é uma função $\|$.$\| em que cada ponto de um espaço vetorial \mathbf{x}$ é associado a um número real não negativo (BURDEN; FAIRES, 2005). Dois exemplos são as normas $\ell_{1}$ e $\ell_{2}$ muito utilizadas nas transformações lineares de conjuntos de dados. A norma $\ell_{2}$ (ou norma euclidiana) que é definida por

$$
\|\mathbf{x}\|_{2}=\left\{\sum_{i=1}^{n} x_{i}^{2}\right\}^{\frac{1}{2}}
$$

e a norma $\ell_{1}$, definida por

$$
\|\mathbf{x}\|_{1}=\sum_{i=1}^{n}\left|x_{i}\right|,
$$

representam um conceito usual de distância do vetor $\mathbf{x}$ à origem de um plano cartesiano. Algumas propriedades importantes para a norma são enumeradas a seguir (BURDEN; FAIRES, 2005):

1. $\|\mathbf{x}\| \geq 0$, para todo $\mathbf{x} \in \mathbb{R}^{n}$;

2. $\|\mathbf{x}\|=0$, se, e somente se $\mathbf{x}=0$;

3. $\|\alpha \mathbf{x}\|=|\alpha|\|\mathbf{x}\|$, para todo $\alpha \in \mathbb{R}$ e para todo $\mathbf{x} \in \mathbb{R}^{n}$;

4. $\|\mathbf{x}+\mathbf{y}\| \leq\|\mathbf{x}\|+\|\mathbf{y}\|$, para todo $\mathbf{x}, \mathbf{y} \in \mathbb{R}^{n}$. 
Um vetor $\mathbf{x}$ é considerado unitário caso sua norma seja igual a 1:

$$
\|\mathbf{x}\|=1
$$

Dois vetores a e b são denominados ortogonais caso o produto entre eles tenha valor igual a zero:

$$
\mathbf{a}^{T} \mathbf{b}=0
$$

ou seja, o cosseno do ângulo $\left(90^{\circ}\right)$ formado entre eles é igual a zero.

Uma matriz $\mathbf{Q}$ é considerada ortogonal se a multiplicação desta pela sua matriz transposta tiver como resultado a matriz identidade, ou seja:

$$
\mathbf{Q}^{T} \mathbf{Q}=\mathbf{I}
$$

Algumas propriedades dessa matriz são apresentadas a seguir:

- A inversa da matriz ortogonal $\mathbf{Q}$ é igual a sua transposta $\left(\mathbf{Q}^{-1}=\mathbf{Q}^{T}\right)$;

- O produto de duas matrizes ortogonais é uma matriz ortogonal.

\subsubsection{Transformações lineares}

Dado dois espaços vetoriais $U$ e $V$, uma transformação linear $T$ de $U$ em $V(T: U \rightarrow$ $V)$ é uma aplicação que associa um vetor $\mathbf{x} \in U$ com outro vetor $T \mathbf{x} \in V$, de forma a preservar operações de adição e multiplicação por um escalar (BURDEN; FAIRES, 2005):

$$
\begin{gathered}
T(\mathbf{x}+\mathbf{y})=T \mathbf{x}+T \mathbf{y} \quad \forall \mathbf{x}, \mathbf{y} \in U \\
T(\alpha \mathbf{x})=\alpha T \mathbf{x} \quad \forall \mathbf{x} \in \mathbb{R} .
\end{gathered}
$$

\subsubsection{Autovalores e autovetores}

Os autovalores $(\lambda)$ e autovetores (a) são características obtidas de uma matriz por meio de um processo de transformação linear. Na álgebra linear, os autovalores e autovetores são obtidos por meio de soluções não nulas do sistema:

$$
(\mathbf{Q}-\lambda \mathbf{I}) \mathbf{a}=0
$$

em que I é a matriz identidade (BURDEN; FAIRES, 2005). Existem diversos métodos para determinar autovalores e seus respectivos autovetores. Um desses métodos é a decom- 
posição em valores singulares, que tem sua formulação geral definida na próxima seção.

\subsubsection{Decomposição em valores singulares}

A decomposição em valores singulares $\left(\mathrm{SVD}^{1}\right)$ é uma técnica de fatoração de matrizes que consiste em representar qualquer matriz $\mathbf{X}$ (com $t$ observações e $n$ variáveis) na forma

$$
\mathbf{X}=\mathbf{U D A}^{T}
$$

em que $\mathbf{U}_{t \times t}$ é uma matriz ortogonal com os vetores singulares à esquerda, $\mathbf{A}_{n \times n}^{T}$ é uma matriz ortogonal com os vetores singulares à direita e $\mathbf{D}$ é uma matriz diagonal de valores singulares, apresentados em ordem decrescente $\mathbf{D}=\left\{\lambda_{1}, \ldots, \lambda_{n}\right\}$, em que $\lambda_{1} \geq \lambda_{2} \geq \lambda_{3} \geq, \ldots, \geq \lambda_{n}$ (JOLLIFFE, 2002; BURDEN; FAIRES, 2005).

A técnica SVD é um método que pode ser utilizado no processo de cálculo dos autovetores esparsos, descritos neste trabalho. Maiores detalhes sobre a técnica são encontrados em (JOLLIFFE, 2002; BURDEN; FAIRES, 2005; RODRIGUES, 2011). Na próxima seção é apresentada a técnica do escore de Fisher para seleção de variáveis.

\subsection{Escore de Fisher para seleção de variáveis}

A técnica de escore de Fisher é muito utilizada em reconhecimento de padrões, pois realiza a redução de dimensionalidade por meio da seleção de variáveis que caracterizem ou separem em dois ou mais grupos um determinado conjunto de dados (DUDA; HART; STORK, 2001).

A ideia principal da técnica de escore de Fisher é encontrar um subconjunto de variáveis de tal forma que, no espaço de dados gerado pelas variáveis selecionadas, as distâncias entre as observações de diferentes classes sejam tão grandes quanto possível, enquanto que as distâncias entre as observações na mesma classe sejam as menores possíveis. A seleção das variáveis ocorre por meio da maximização do critério do traço, uma função que pode ser aplicada a diversos métodos de redução de dimensionalidade, pois reflete diretamente as distâncias intra e entre as observações de um conjunto de dados (NIE et al., 2008; GU; LI; HAN, 2011).

Mais especificamente, dados um número $m$ de variáveis para seleção, a classe $k$ de

\footnotetext{
${ }^{1}$ Do original, em inglês, Singular Value Decomposition.
} 
cada observação e o conjunto de dados $\mathbf{X}$ (com $t$ observações e $n$ variáveis), o escore de Fisher realiza a redução de dimensionalidade para um conjunto $\mathbf{Z}$ (com $t$ observações e $m$ variáveis) que satisfaça a função

$$
F(\mathbf{Z})=\operatorname{traço}\left\{\left(\mathbf{S}_{b}\right)\left(\mathbf{S}_{c}+\gamma \mathbf{I}\right)^{-1}\right\}
$$

em que $\gamma$ é um parâmetro de regularização, $\mathbf{S}_{b}$ é denominada matriz de dispersão entre as classes e $\mathbf{S}_{c}$ é denominada matriz total de dispersão, que são computadas, respectivamente, por:

$$
\begin{gathered}
\mathbf{S}_{b}=\sum_{k=1}^{K} t_{k}\left(\boldsymbol{\mu}_{k}-\boldsymbol{\mu}\right)\left(\boldsymbol{\mu}_{k}-\boldsymbol{\mu}\right)^{T} \\
\mathbf{S}_{c}=\sum_{i=1} t\left(\mathbf{z}_{i}-\boldsymbol{\mu}\right)\left(\mathbf{z}_{i}-\boldsymbol{\mu}\right)^{T}
\end{gathered}
$$

em que $\boldsymbol{\mu}_{k}$ e $t_{k}$ são, respectivamente, o vetor de média e o número de observações em cada uma das $k$ classes do conjunto de dados reduzido $(\mathbf{Z})$ e $\boldsymbol{\mu}$ é a média geral do conjunto de dados reduzido.

Uma vez que existem $\left(\begin{array}{l}n \\ m\end{array}\right)$ soluções para o conjunto $\mathbf{Z}$, a seleção de variáveis é um problema de otimização combinatória e acaba se tornando difícil para resolução. Para simplificar esse problema, a heurística mais utilizada é a de computar um peso para cada uma das variáveis do conjunto $\mathbf{X}\left(\mathbf{x}^{j}, j=1, \ldots, n\right)$, de acordo com o critério $F$ (GU; LI; HAN, 2011). Nesse caso, o problema é reduzido para somente $\left(\begin{array}{l}n \\ 1\end{array}\right)=n$ candidatos à solução do problema. Considerando $\mu_{k}^{j}$ a média da $k$-ésima classe correspondente à $j$ ésima variável e que $\sigma^{j}$ é o desvio padrão da $j$-ésima variável, computa-se o peso de cada variável por meio da equação:

$$
F\left(\mathbf{x}^{j}\right)=\frac{\sum_{k=1}^{K} t_{k}\left(\mu_{k}^{j}-\mu^{j}\right)^{2}}{\left(\sigma^{j}\right)^{2}} .
$$

Após o cálculo do escore de Fisher para cada variável, são selecionadas as $m$ variáveis com maiores índices.

O método de escore de Fisher tem sido utilizado em diversos trabalhos em QM (WEBER; SILVA, 2008; MALTAROLLO, 2009). Porém, devido à sua característica supervisionada (definição prévia das classes do conjunto de dados no processo de análise), é possível que este método de seleção de variáveis influencie diretamente o resultado obtido por meio de métodos de aprendizado não supervisionado. Por isso, faz-se necessária a análise de outros métodos de redução de dimensionalidade, em especial aqueles que não utilizam informações de rótulos de classe em suas formulações. Na próxima seção, é descrita a técnica PCA, um método não supervisionado de redução de dimensionalidade e um dos 
mais utilizados na literatura.

\subsection{Análise de componentes principais (PCA)}

A análise de componentes principais (PCA) é uma das mais antigas técnicas de análise de dados multivariados (JOLLIFFE, 2002). A ideia central desse método é reduzir a dimensionalidade do conjunto de dados original, retendo o máximo de variabilidade possível desse conjunto. A redução é obtida por meio de uma transformação linear para a obtenção de um novo conjunto de variáveis, denominadas componentes principais (PC), não correlacionadas, e que são ordenadas de forma que as primeiras componentes principais retenham o máximo de variabilidade possível do conjunto de dados original (JOLLIFFE, 2002; DUDA; HART; STORK, 2001).

De acordo com Abdi e Williams (2010), as quatro principais características da técnica PCA são: (i) extrair as informações mais importantes do conjunto de dados; (ii) compactar o conjunto de dados original, armazenando somente informações importantes; (iii) simplificar a descrição de um conjunto de dados; (iv) permitir a análise da estrutura das observações e das variáveis.

Uma série de estudos em QM apresenta o uso da técnica de PCA na análise dos seus conjuntos de dados. Cormanich, Goodarzi e Freitas (2009) utilizam a técnica PCA na extração de características de substâncias com potencial afinidade contra o câncer, para projeção e classificação de novos compostos químicos a partir dos padrões obtidos.

No trabalho de Koul et al. (2011), que avalia compostos para tratamento da tuberculose, é aplicada a técnica de PCA para projeção desses dados no espaço bidimensional, a fim de verificar relações entre os compostos químicos e a atividade biológica. Em estudos realizados por Yang et al. (2008), foi aplicada a PCA para redução de dimensionalidade e projeção de compostos químicos com o intuito de obter características importantes relacionadas com atividade anti HIV-1.

O algoritmo PCA é descrito da seguinte forma: a partir de um conjunto de dados $\mathbf{X}$, combinações lineares são geradas para produzirem PC's representadas por $\mathbf{z}_{1}, \mathbf{z}_{2}, \ldots, \mathbf{z}_{n}$, tal que $\operatorname{var}\left(\mathbf{z}_{1}\right) \geq \operatorname{var}\left(\mathbf{z}_{2}\right) \geq \ldots \geq \operatorname{var}\left(\mathbf{z}_{n}\right)$. Para que essa transformação linear ocorra, determina-se suas bases ortogonais que são os autovetores $\mathbf{A}=\left[\mathbf{a}_{1}, \mathbf{a}_{2}, \ldots, \mathbf{a}_{n}\right]$ obtidos a partir da matriz de correlação dos dados. Esses autovetores estão ordenados de acordo com seus respectivos autovalores $\Delta=\left\{\lambda_{1} \geq \lambda_{2} \geq \ldots \geq \lambda_{n}\right\}$ (JOLLIFFE, 2002). Com base 
nos autovetores, cada PC é obtida por meio da seguinte equação:

$$
\mathbf{z}_{i}=\mathbf{X} \mathbf{a}_{i}
$$

em que cada $\mathbf{z}_{i}$ representa a $i$-ésima componente principal e $\mathbf{a}_{i}$ é o $i$-ésimo autovetor classificado por ordem decrescente dos autovalores.

Uma particularidade da técnica PCA é que cada autovalor representa a variância contida em cada componente principal $\left(\lambda_{i}=\operatorname{var}\left(\mathbf{z}_{i}\right)\right)$ e com isso é possível organizar cada autovalor $\left(\lambda_{i}\right)$ de forma decrescente para manter o máximo de variabilidade nas primeiras componentes. A formação da primeira componente principal é denotada por:

$$
\mathbf{z}_{1}=\mathbf{x}_{1} a_{11}+\mathbf{x}_{2} a_{12}+\ldots+\mathbf{x}_{n} a_{1 n}
$$

que possuirá a máxima variação, com a condição de que

$$
a_{11}^{2}+a_{12}^{2}+\ldots+a_{1 n}^{2}=1
$$

e que $\operatorname{var}\left(\mathbf{z}_{1}\right)$ seja a maior possível. A segunda componente principal será representada por:

$$
\mathbf{z}_{2}=\mathbf{x}_{1} a_{21}+\mathbf{x}_{2} a_{22}+\ldots+\mathbf{x}_{n} a_{2 n}
$$

que irá possui a segunda maior variação, com a condição de que

$$
a_{21}^{2}+a_{22}^{2}+\ldots+a_{2 n}^{2}=1
$$

e que $\mathbf{z}_{2}$ não tenha correlação com $\mathbf{z}_{1}$. A terceira componente principal será representada por:

$$
\mathbf{z}_{3}=\mathbf{x}_{1} a_{31}+\mathbf{x}_{2} a_{32}+\ldots+\mathbf{x}_{n} a_{3 n}
$$

que irá possuir a terceira maior variação, com a condição de que

$$
a_{31}^{2}+a_{32}^{2}+\ldots+a_{3 n}^{2}=1
$$

e que $\mathbf{z}_{3}$ não tenha correlação com $\mathbf{z}_{1}$ e $\mathbf{z}_{2}$. Este cálculo é realizado até que sejam geradas as $n$ componentes principais.

A redução de dimensionalidade utilizando o método PCA dá-se por meio da análise dos autovalores (variância) de cada componente. Neste caso, seleciona-se como bases da transformação, os autovetores associados aos $m$ maiores autovalores $(m<n)$. O valor de $m$, portanto, está relacionado à variância que será retida no novo espaço vetorial.

A técnica PCA também é aplicada em QM para estimar a relevância de cada uma das variáveis do conjunto original, por meio da análise dos coeficientes da matriz de autove- 
tores utilizada na transformação dos dados (MALTAROLLO, 2009). Em cada autovetor, os coeficientes possuem geralmente valores não nulos e a soma de todos tem valor igual a 1 (ver, por exemplo, Equações 3.15, 3.17 e 3.19). Tal regra faz com que: (i) variáveis coletadas incorretamente (variáveis ruidosas) tenham uma representação dentro do espaço de componentes principais; (ii) variáveis com maior poder descritivo percam relevância dentro do espaço das componentes principais. Para superar essas limitações, foram propostos novos métodos para redução de dimensionalidade que se baseiam na técnica PCA mas, no entanto, desconsideram variáveis com coeficientes irrelevantes. Essa técnica é conhecida como análise de componentes principais esparsas e será apresentada na próxima seção.

\subsection{Análise de componentes principais esparsas (SPCA)}

A PCA é uma ferramenta consolidada no processo de redução de dimensionalidade, já que realiza a transformação linear de um conjunto de dados para um novo conjunto de variáveis denominadas componentes principais. As componentes principais são, em geral, combinações lineares de todas as variáveis do conjunto de dados original e isto faz com que todos os coeficientes de uma base de transformação possuam valores diferentes de zero. No entanto, em algumas aplicações, as variáveis originais tem algum significado físico e, devido a isso, a técnica PCA seria ainda mais interessante caso cada componente principal fosse gerada considerando apenas algumas variáveis do conjunto original (JOURNEE et al., 2010).

Com o desafio de encontrar uma transformação em que um número pequeno de variáveis seja utilizado no processo de transformação linear, foram desenvolvidas as técnicas de análise SPCA. Essa técnica tem por objetivo determinar, a partir de um grau de esparsidade, um autovetor que possua poucos coeficientes não nulos. O grau de esparsidade pode ser definido como o número de coeficientes iguais a zero presentes na base de transformação (SHEN; HUANG, 2008). Uma definição formal para a técnica SPCA pode ser descrita da seguinte forma: a partir do conjunto de dados $\mathbf{X}$ (com $t$ observações e $n$ variáveis), do número $m$ de componentes principais e do grau de esparsidade $(\gamma)$, a tarefa é encontrar uma matriz de autovetores $\mathbf{A}$ (com $n$ linhas e $m$ colunas) esparsa.

Diversos métodos foram desenvolvidos para o cálculo de autovetores esparsos, sendo que a maioria desses métodos trata a técnica de SPCA como um problema de otimização de função. Em D'Aspremont et al. (2007), foi desenvolvido um método de relaxamento 
semidefinido para a técnica SPCA, além da aplicação de um algoritmo guloso que calcula um conjunto completo de soluções para qualquer número de coeficientes não nulos dos autovetores. Esse método foi aplicado com sucesso na análise e agrupamento de dados biológicos (LUSS; D'ASPREMONT, 2010).

Os autores Shen e Huang (2008) desenvolveram um método denominado PCA esparsa via SVD regularizado ${ }^{2}$, em que realizam o cálculo dos autovetores esparsos combinando a técnica SVD e a aproximação por baixo posto. Os autores Qi, Luo e Zhao (2013) propuseram um método de otimização de gradiente e regularização por meio de combinação das normas $\ell_{1}$ e $\ell_{2}$ para obtenção de autovetores esparsos. Por fim, os autores (LU; ZHANG, 2012) propuseram um método de Lagrange aumentado também para obtenção de uma matriz de autovetores com padrão esparso.

Neste trabalho, foram estudados os seguintes métodos de análise SPCA: (i) análise SPCA via otimização de regressão (SPCA-ZOU), proposta por Zou, Hastie e Tibshirani (2006), que trata o problema de autovetores esparsos como um problema de otimização de regressão; (ii) a técnica SPCA por meio do método da potência, via penalização pela norma $\ell_{1}(\mathrm{GP})^{3}$, proposto por Journee et al. (2010) e (iii) a técnica SPCA pelo método da potência inversa (IPM) ${ }^{4}$, proposto por Hein e Buhler (2010). Os dois últimos realizam a otimização de gradiente para obtenção de um padrão de esparsidade que será aplicado para o cálculo da matriz de transformação esparsa. Nas próximas seções, esses métodos são descritos com maiores detalhes.

\subsubsection{Análise de componentes principais esparsas por meio de regressão (SPCA-ZOU)}

A técnica SPCA-ZOU, proposta por Zou, Hastie e Tibshirani (2006), baseia-se na ideia de que a técnica PCA pode ser escrita como um problema de regressão via otimização que penaliza alguns coeficientes da matriz de autovetores para obtenção de bases de transformações esparsas. O modelo de regressão utilizado no cálculo da SPCA-ZOU é originário da técnica de mínimos quadrados ordinários $(\mathrm{OLS})^{5}$, em que uma variável independente $\mathbf{z}$ é aproximada por uma combinação linear das variáveis dependentes em X (HASTIE; TIBSHIRANi; FRIEDMAN, 2009). Neste caso, os coeficientes da transformação

\footnotetext{
${ }^{2}$ Do original, em inglês, Sparse PCA via Regularized SVD.

${ }^{3}$ Do original, em inglês, Generalized Power Method.

${ }^{4}$ Do original, em inglês, Inverse Power Method.

${ }^{5}$ Do original, em inglês, Ordinal Least Squares.
} 
de $\mathbf{X}$ são dados pelo vetor a, que por sua vez é estimado por:

$$
\hat{\mathbf{a}}_{O L S}=\arg \min _{\mathbf{a}}\|\mathbf{z}-\mathbf{X} \mathbf{a}\|^{2}
$$

em que o termo $\|\mathbf{z}-\mathbf{X a}\|^{2}$ representa o erro de reconstrução dos dados originais.

Ao modelo OLS foi adicionada uma restrição que permite a obtenção do vetor estimado â com coeficientes iguais a zero. Tal modelo é denominado por regressão ridge, obtido por:

$$
\hat{\mathbf{a}}_{R I D G E}=\arg \min _{\mathbf{a}}\|\mathbf{z}-\mathbf{X a}\|^{2}+\gamma\|\mathbf{a}\|_{2}^{2},
$$

em que $\gamma$ representa o grau de esparsidade. Quanto maior o grau de esparsidade, maior será o número de coeficientes transformados em zero. Uma variação da regressão ridge inclui a norma $\ell_{1}$ como forma de penalização dos coeficientes da base de transformação, sendo denominada por método de regressão LASSO (Least Absolute Shrinkage Selection Operator) que é determinado por:

$$
\hat{\mathbf{a}}_{L A S S O}=\arg \min _{\mathbf{a}}\|\mathbf{z}-\mathbf{X a}\|^{2}+\gamma\|\mathbf{a}\|_{1}
$$

Apesar de garantir a esparsidade da base de transformação, o método LASSO possui algumas limitações, sendo uma delas a de que esse método realiza a seleção das variáveis limitando-se ao número de observações, isto é, para o caso em que $n \gg t$, ocorrerá a seleção de somente $t$ variáveis. Por conta disso, foi definido um novo modelo de regressão denominado elastic net (EN), que combina as penalizações dos modelos de regressão ridge e LASSO (normas $\ell_{2}$ e $\ell_{1}$ ) para obtenção da base de transformação no caso $n \gg t$ (HASTIE; TIBSHIRANI; FRIEDMAN, 2009; ZOU; HASTIE; TIBSHIRANI, 2006). O modelo EN é definido por:

$$
\hat{\mathbf{a}}_{E N}=\arg \min _{\mathbf{a}}\|\mathbf{z}-\mathbf{X} \mathbf{a}\|^{2}+\gamma\|\mathbf{a}\|_{2}^{2}+\gamma\|\mathbf{a}\|_{1} .
$$

De acordo com Zou, Hastie e Tibshirani (2006), tanto a técnica PCA quanto a técnica SPCA-ZOU podem ser descritas com base nos modelos de regressão apresentados anteriormente. Para a técnica PCA, é tomada por base a Equação 3.21, em que a matriz $\hat{\mathbf{A}}$ com $m$ autovetores de norma unitária pode ser estimada independentemente do grau de esparsidade $\gamma$. Tal matriz de transformação é obtida por:

$$
(\hat{\mathbf{B}}, \hat{\mathbf{A}})=\arg \min _{\mathbf{B}, \mathbf{A}} \sum_{i=1}^{t}\left\|\mathbf{x}_{i}-\mathbf{B} \mathbf{A}^{T} \mathbf{x}_{i}\right\|^{2}+\gamma \sum_{j=1}^{m}\left\|\mathbf{a}_{j}\right\|^{2},
$$

sujeito a

$$
\mathbf{B}^{T} \mathbf{B}=\mathbf{I}
$$


Para fins didáticos, é realizada uma breve descrição da função apresentada na Equação (3.24). Em primeiro lugar, a expressão $\mathbf{A}^{T} \mathbf{x}_{i}$ transforma as variáveis da observação $\mathbf{x}_{i}$ para o espaço das componentes principais de A. Após essa transformação, a expressão $\mathbf{B A}^{T} \mathbf{x}_{i}$ transforma novamente para o espaço original a componente obtida pela expressão $\mathbf{A}^{T} \mathbf{x}_{i}$. A ortogonalidade de $\mathbf{B}$ faz com que $\mathbf{A}$ também tenha propriedade ortogonal. $\mathrm{O}$ termo $\sum_{i=1}^{t}\left\|\mathbf{x}_{i}-\mathbf{B A}^{T} \mathbf{x}_{i}\right\|^{2}$ representa o erro de reconstrução de cada observação. No caso da técnica PCA, para que os $m$ autovetores sejam obtidos, é considerada a igualdade entre as matrizes $\mathbf{B}$ e $\mathbf{A}$.

Na técnica de análise esparsa SPCA-ZOU, o método para a obtenção da matriz de autovetores esparsa é baseado na Equação (3.23). Para estimar a matriz esparsa A com $m$ autovetores, foi proposta a função 3.25 determinada por:

$$
(\hat{\mathbf{B}}, \hat{\mathbf{A}})=\arg \min _{\mathbf{B}, \mathbf{A}} \sum_{i=1}^{t}\left\|\mathbf{x}_{i}-\mathbf{B} \mathbf{A}^{T} \mathbf{x}_{i}\right\|^{2}+\gamma \sum_{j=1}^{m}\left\|\mathbf{a}_{j}\right\|^{2}+\gamma \sum_{j=1}^{m}\left\|\mathbf{a}_{j}\right\|_{1}
$$

sujeito a

$$
\mathbf{B}^{T} \mathbf{B}=\mathbf{I}_{m \times m}
$$

De uma forma mais específica, a partir do conjunto de dados $\mathbf{X}$, do número $m$ de autovetores e do grau de esparsidade $(\gamma)$, a matriz de autovetores A pode ser estimada minimizando a função apresentada na Equação (3.25). Nessa função, os parâmetros A e $\mathbf{B}$ são as $n \times m$ matrizes de autovetores utilizadas no processo de otimização. Para que a matriz de autovetores esparsa seja estimada, faz-se necessária a atualização de $\mathbf{B}$ com base em A e vice-versa até que ocorra a convergência da função. Os termos de penalização do método elastic net (normas $\ell_{2}$ e $\ell_{1}$ ), representados respectivamente por $\gamma \sum_{j=1}^{m}\left\|\mathbf{a}_{j}\right\|^{2}$ e $\sum_{j=1}^{m} \gamma\left\|\mathbf{a}_{j}\right\|_{1}$, impõem a esparsidade em cada autovetor da matriz de transformação $\mathbf{A}$. O grau de esparsidade deve ser escolhido previamente e pode ter o mesmo valor para todos as PCs.

Na Equação (3.25), diferentemente da Equação (3.23), é realizada a estimativa de várias bases de transformação ao invés de estimar um único vetor de coeficientes. Além disso, este problema tem duas matrizes de coeficientes desconhecidos A e B. Para minimização do critério SPCA-ZOU utiliza-se o Algoritmo 1. Em primeiro lugar, assume-se que $\mathbf{B}$ é conhecido. Com isso, é possível estimar A de duas formas: (i) por meio da resolução de $m$ regressões elastic net (Equação 3.23)(ZOU; HASTIE; TIBSHIRANI, 2006); (ii) por meio do operador de limiarização determinado por

$$
\mathbf{a}_{j}=\max \left\{0,\left|\mathbf{b}_{j}^{T} \mathbf{X}^{T} \mathbf{X}\right|-\frac{\gamma}{2}\right\} \operatorname{sinal}\left(\mathbf{b}_{j}^{T} \mathbf{X}^{T} \mathbf{X}\right) .
$$


O último é utilizado principalmente no caso em que o número de variáveis é muito maior que o número de observações do conjunto $(n \gg t)$.

Por outro lado, se $\mathbf{A}$ for conhecida, B pode ser estimada por meio da técnica SVD (se $\mathbf{X}^{T} \mathbf{X A}=\mathbf{U D V}^{T}$, então $\mathbf{B}=\mathbf{A V}^{T}$ ). Uma vez que as matrizes são desconhecidas, uma suposição inicial é feita e A e $\mathbf{B}$ são estimadas alternadamente até a convergência. Uma opção padrão é inicializar a matriz $\mathbf{B}$ com os $m$ primeiros autovetores obtidos por meio da técnica PCA.

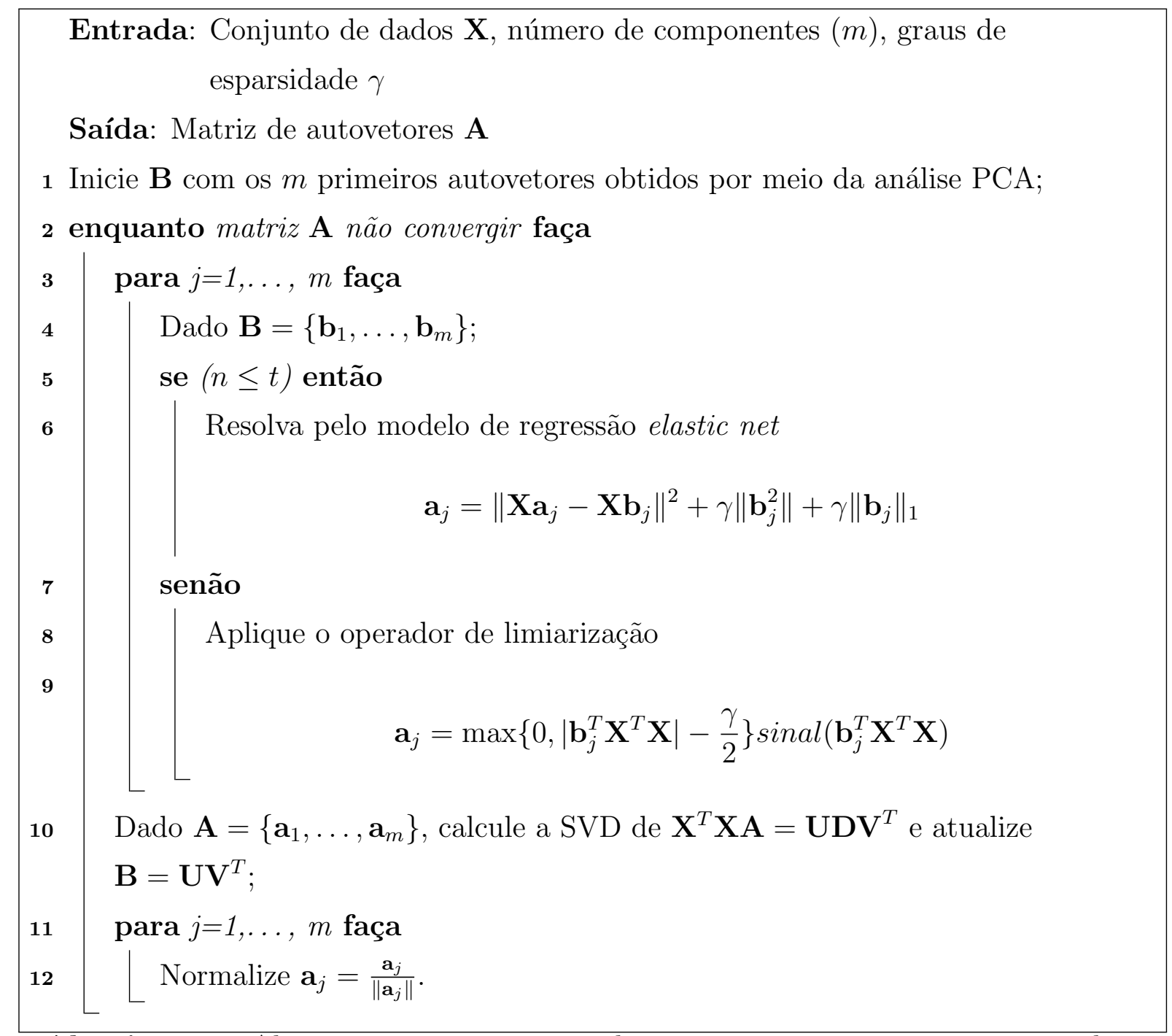

Algoritmo 1: Algoritmo para estimação dos autovetores esparsos, por meio da técnica SPCA-ZOU.

Após a técnica SPCA-ZOU, novos métodos foram desenvolvidos para realização da análise SPCA. Tais métodos realizam adaptações de métodos já existentes para obtenção de autovetores esparsos. O próximo a ser apresentado é o método de análise de componentes principais esparsas GP. 


\subsubsection{Análise de componentes principais esparsas por meio do método da potência, via penalização pela norma $\ell_{1}(\mathrm{GP})$}

A análise de componentes principais esparsas por meio do método da potência, via penalização pela norma $\ell_{1}(\mathrm{GP})$, faz parte de um conjunto de técnicas propostas por Journee et al. (2010) para obtenção de bases de transformações esparsas. Tal método realiza o cálculo de um único autovetor esparso e aplica um esquema de deflação no caso em que seja necessário calcular um número maior de autovetores.

Inicialmente é apresentado o método da potência, que realiza de forma iterativa a aproximação de autovalores e autovetores. Para isso, é assumido que uma matriz quadrada $\mathbf{B}^{n \times n}$ possua um autovalor dominante com seu respectivo autovetor (BURDEN; FAIRES, 2005). Logo após, é escolhido um vetor inicial $\mathbf{a}_{0}$ não nulo, que irá convergir para o autovetor dominante de $\mathbf{B}$. Tal autovetor é obtido por meio da sequência

$$
\begin{gathered}
\mathbf{a}_{1}=\mathbf{B} \mathbf{a}_{0} \\
\mathbf{a}_{2}=\mathbf{B} \mathbf{a}_{1}=\mathbf{B}\left(\mathbf{B} \mathbf{a}_{0}\right)=\mathbf{B}^{2} \mathbf{a}_{0} \\
\mathbf{a}_{3}=\mathbf{B} \mathbf{a}_{2}=\mathbf{B}\left(\mathbf{B}^{2} \mathbf{a}_{0}\right)=\mathbf{B}^{3} \mathbf{a}_{0} \\
\vdots \\
\mathbf{a}_{r}=\mathbf{B} \mathbf{a}_{r-1}=\mathbf{B}\left(\mathbf{B}^{r-1} \mathbf{a}_{0}\right)=\mathbf{B}^{r} \mathbf{a}_{0}
\end{gathered}
$$

Para valores suficientes de $r$, e realizando a devida normalização dos vetores, é possível obter uma boa estimativa do autovetor dominante de $\mathbf{B}$ (neste caso, $\mathbf{a}_{r}$ ). Assumindo ainda que não é conhecido o autovalor dominante, o Teorema 1 determina a formulação para obtenção do mesmo a partir do autovetor dominante. Tal teorema é conhecido como teorema de Rayleigh (BURDEN; FAIRES, 2005). No caso em que o método da potência obtém uma boa estimativa do autovetor dominante, o coeficiente de Rayleigh provê uma boa aproximação para o autovalor dominante.

Teorema 1 Caso a seja o autovetor dominante de uma matriz $\mathbf{B}$, então seu autovalor correspondente será determinado por:

$$
\lambda=\frac{\mathbf{a}^{T} \mathbf{B} \mathbf{a}}{\mathbf{a}^{T} \mathbf{a}}
$$

Os autores Journee et al. (2010) transformaram o método da potência em um problema de otimização para que fosse possível obter um autovetor esparso. Em primeira instância, dado o conjunto $\mathbf{X}$ (com $t$ observações, $n$ variáveis) e um grau de esparsidade 
$\gamma$, é calculado um autovetor dominante $\mathbf{p}$ (de tamanho $t$ ) que satisfaça o Teorema 1. Tal autovetor pertence ao espaço Euclidiano $S^{b}$, obtido por meio da otimização de um método de gradiente ascendente (JOURNEE et al., 2010; HYVARINEN; KARHUNEN; OJA, 2001), determinado por:

$$
\mathbf{p}^{r+1} \leftarrow \sum_{i=1}^{n} \max \left\{0,\left|\mathbf{x}_{i}^{T} \mathbf{p}^{r}\right|-\gamma\right\} \operatorname{Sinal}\left(\mathbf{x}_{i}^{T} \mathbf{p}^{r+1}\right) \mathbf{x}_{i}
$$

Para que essa otimização seja realizada, o vetor $\mathbf{p}^{0}$ é iniciado com a variável de maior norma euclidiana, denotada matematicamente por:

$$
\mathbf{p}^{0}=\frac{\mathbf{x}_{i^{\star}}}{\left\|\mathbf{x}_{i^{\star}}\right\|}, \quad i^{\star}=\arg \max _{i}=\left\|\mathbf{x}_{i}\right\|
$$

A partir do autovetor p é possível resolver a função apresentada na Equação (3.31), a qual irá determinar quais coeficientes terão valores não nulos no autovetor esparso. Tal função é determinada por:

$$
\phi_{\ell_{1}}^{2}(\gamma)=\max _{\mathbf{p} \in S^{b}} \sum_{i=1}^{n} \max \left\{0,\left|\mathbf{x}_{i}^{T} \mathbf{p}\right|-\gamma\right\}^{2} .
$$

Com base nessa função, é construído um padrão de esparsidade q, de tamanho $n$, indicando quais os coeficientes que terão valores não nulos dentro do autovetor esparso. As etapas para determinação do padrão de esparsidade são descritas no Algoritmo 2.

Entrada: Conjunto de dados $\mathbf{X}$, grau de esparsidade $\gamma$, critério de convergência $\epsilon$. Saída: Padrão de esparsidade $\mathbf{q}$

1 Para a primeira iteração, inicie $\mathbf{p}$ com o vetor da variável de maior norma euclidiana

$$
\mathbf{p}^{0}=\frac{\mathbf{x}_{i^{*}}}{\left\|\mathbf{x}_{i^{*}}\right\|_{2}}, i^{*}=\arg \max _{i}\left\|\mathbf{x}_{i^{*}}\right\|_{2}
$$

\section{repita}

$\mathbf{2} \quad \mathbf{p}^{r+1} \leftarrow \sum_{i=1}^{n} \max \left\{0,\left|\mathbf{x}_{i}^{T} \mathbf{p}^{r}\right|-\gamma\right\} \operatorname{Sinal}\left(\mathbf{x}_{i}^{T} \mathbf{p}^{r+1}\right) \mathbf{x}_{i} ;$

$3 \quad \mathbf{p}^{r+1} \leftarrow \frac{\mathbf{p}^{r+1}}{\left\|\mathbf{p}^{r+1}\right\|_{2}} ;$

4 até $\left\|\mathbf{p}^{r+1}\right\|-\left\|\mathbf{p}^{r}\right\| \leq \epsilon$;

$\mathbf{5}$ Construa o vetor $\mathbf{q} \in\{0,1\}^{n}$ em que $\left\{\begin{array}{ll}q_{i}=1, & \text { se }\left|\mathbf{x}_{i}^{T} \boldsymbol{\mu}\right|>\gamma \\ q_{i}=0, & \text { caso contrário. }\end{array}\right.$;

Algoritmo 2: Algoritmo utilizado para estimar o padrão de esparsidade (q). 
Com o padrão de esparsidade obtido, é realizada uma etapa de pós-processamento em que, de fato, é calculado o maior autovetor esparso da matriz de dados $\mathbf{X}$. Esse processo pode ser ilustrado pelo exemplo dado a seguir:

- Considere a matriz de dados $\mathbf{X}$ :

\begin{tabular}{c|ccc}
\hline \multirow{2}{*}{ Observação } & \multicolumn{3}{|c}{ Variáveis } \\
\cline { 2 - 4 } & $\mathbf{x}_{1}$ & $\mathbf{x}_{2}$ & $\mathbf{x}_{3}$ \\
\hline 1 & $-0,39$ & 0,84 & 0,21 \\
2 & 1,36 & $-1,14$ & 0,88 \\
3 & 0,03 & $-0,54$ & $-1,43$ \\
4 & $-1,00$ & 0,84 & 0,34 \\
\hline
\end{tabular}

A partir da matriz de dados $\mathbf{X}$ e com um padrão de esparsidade $(\gamma=0,2)$ é obtido um padrão de esparsidade $\mathbf{q}$ com a seguinte informação:

$$
\mathbf{q}=\left[\begin{array}{l}
1 \\
1 \\
0
\end{array}\right]
$$

Com base nesse autovetor, são selecionadas as variáveis em que o valor do coeficiente do padrão de esparsidade seja igual a $1\left(q_{i}=1, i=1, \ldots, n\right)$. Após essa identificação, é gerado um conjunto de dados $\mathbf{X}^{\star}$, contendo somente as variáveis selecionadas, e um autovetor $\mathbf{a}^{\star}$ é estimado por meio da técnica PCA. Considerando o padrão q no exemplo, tem-se que as variáveis $\mathbf{x}_{1}$ e $\mathbf{x}_{2}$ terão coeficientes diferentes de zero e, portanto, o conjunto $\mathbf{X}^{\star}$ será representado por:

\begin{tabular}{c|cc}
\hline \multirow{2}{*}{ Observação } & \multicolumn{2}{|c}{ Variáveis } \\
\cline { 2 - 3 } & $\mathbf{x}_{1}$ & $\mathbf{x}_{2}$ \\
\hline 1 & $-0,39$ & 0,84 \\
2 & 1,36 & $-1,14$ \\
3 & 0,03 & $-0,54$ \\
4 & $-1,00$ & 0,84 \\
\hline
\end{tabular}

A partir do conjunto de dados $\mathbf{X}^{\star}$, obtém-se o autovetor $\mathbf{a}^{\star}$, calculado pela técnica PCA:

$$
\mathbf{a}^{\star}=\left[\begin{array}{l}
0,71 \\
0,71
\end{array}\right] \text {. }
$$


Por fim, é definido o vetor de transformação esparso a combinando o vetor com o padrão de esparsidade $\mathbf{q}$ e o vetor $\mathbf{a}^{\star}$. No exemplo, é obtido um vetor $\mathbf{a}$, com a seguinte forma:

$$
\mathbf{a}=\left[\begin{array}{c}
0,71 \\
0,71 \\
0
\end{array}\right] .
$$

Todo o processo descrito anteriormente é denominado renormalização vetorial. Tal processo recupera uma restrição da técnica PCA de que um autovetor possua norma euclidiana igual a 1 (MOGHADDAM; WEISS; AVIDAN, 2005).

No caso onde há um número maior de componentes a ser computado $(m>1)$, faz-se necessário aplicar um método de deflação à matriz de dados $\mathbf{X}$, gerando um novo conjunto $\mathbf{X}^{\prime}$ em que a informação já calculada para o primeiro autovetor esparso tenha sido retirada. Tal deflação é obtida minimizando a função

$$
F\left(\mathbf{X}^{\prime}\right)=\min \left\|\mathbf{X}^{\prime}-\mathbf{v a}^{T}\right\|_{F},
$$

em que $\mathbf{v}=\mathbf{X a}$ é o vetor que resolve a Equação (3.32).

Na próxima seção, será apresentado um método com formulação da potência inversa para obtenção de autovetores esparsos.

\subsubsection{Análise de componentes principais esparsas por meio do método da potência inversa (IPM)}

A análise de componentes principais esparsas por meio do método da potência inversa (IPM) é uma outra técnica proposta para obtenção de autovetores esparsos. Tal técnica foi construída após desenvolvimento de novas formulações matemáticas, pelos autores Hein e Buhler (2010), para resolução de problemas de autovetores.

Inicialmente é apresentado o método da potência inversa. Esse método realiza a aproximação do autovalor $(\lambda)$ e seu respectivo autovetor (a) de uma matriz quadrada $\mathbf{B}$ a partir do esquema iterativo

$$
\begin{gathered}
\mathbf{y}^{r+1}=(\mathbf{B}-\sigma \mathbf{I})^{-1} \mathbf{a}^{r} \\
\mathbf{a}^{r+1}=\frac{\mathbf{y}^{r+1}}{\left\|\mathbf{y}^{r+1}\right\|_{2}} \\
\lambda^{r+1}=\mathbf{a}_{r+1}^{T} \mathbf{B} \mathbf{a}_{r+1},
\end{gathered}
$$

em que $\mathbf{B}=\mathbf{X}^{T} \mathbf{X}$ e $\sigma$ representa uma constante de regularização. O método da potência inversa é utilizado especialmente para o cálculo do último autovalor $\left(\lambda_{n}\right)$ de uma matriz 
quadrada. Maiores detalhes sobre esse método são encontados em (BURDEN; FAIRES, 2005; DEMMEL, 1997).

Para formulação do método de análise esparsa IPM, inicialmente é realizada a transformação da técnica PCA em um problema de otimização, determinado pela função

$$
F(\mathbf{a})=\arg \min _{\mathbf{a} \in \mathbb{R}^{n}} \frac{\|\mathbf{a}\|_{2}}{\|\mathbf{X a}\|_{2}} .
$$

A fim de garantir esparsidade no autovetor estimado pela Equação (3.34), os autores Hein e Buhler (2010) incorporaram o grau de esparsidade $(\gamma)$ e as normas $\ell_{1}$ e $\ell_{2}$ resultando na função

$$
F(\mathbf{a})=\arg \min _{\mathbf{a} \in \mathbb{R}^{n}} \frac{(1-\gamma)\|\mathbf{a}\|_{2}+\gamma\|\mathbf{a}\|_{1}}{\|\mathbf{X a}\|_{2}}
$$

Mais especificamente, a partir do conjunto de dados $\mathbf{X}$, do grau de esparsidade $(\gamma)$ e de um valor de convergência $(\epsilon)$, o método IPM realiza a estimativa do autovetor e autovalor da Equação (3.35). O processo utilizado para cálculo desses valores é apresentado no Algoritmo 3.

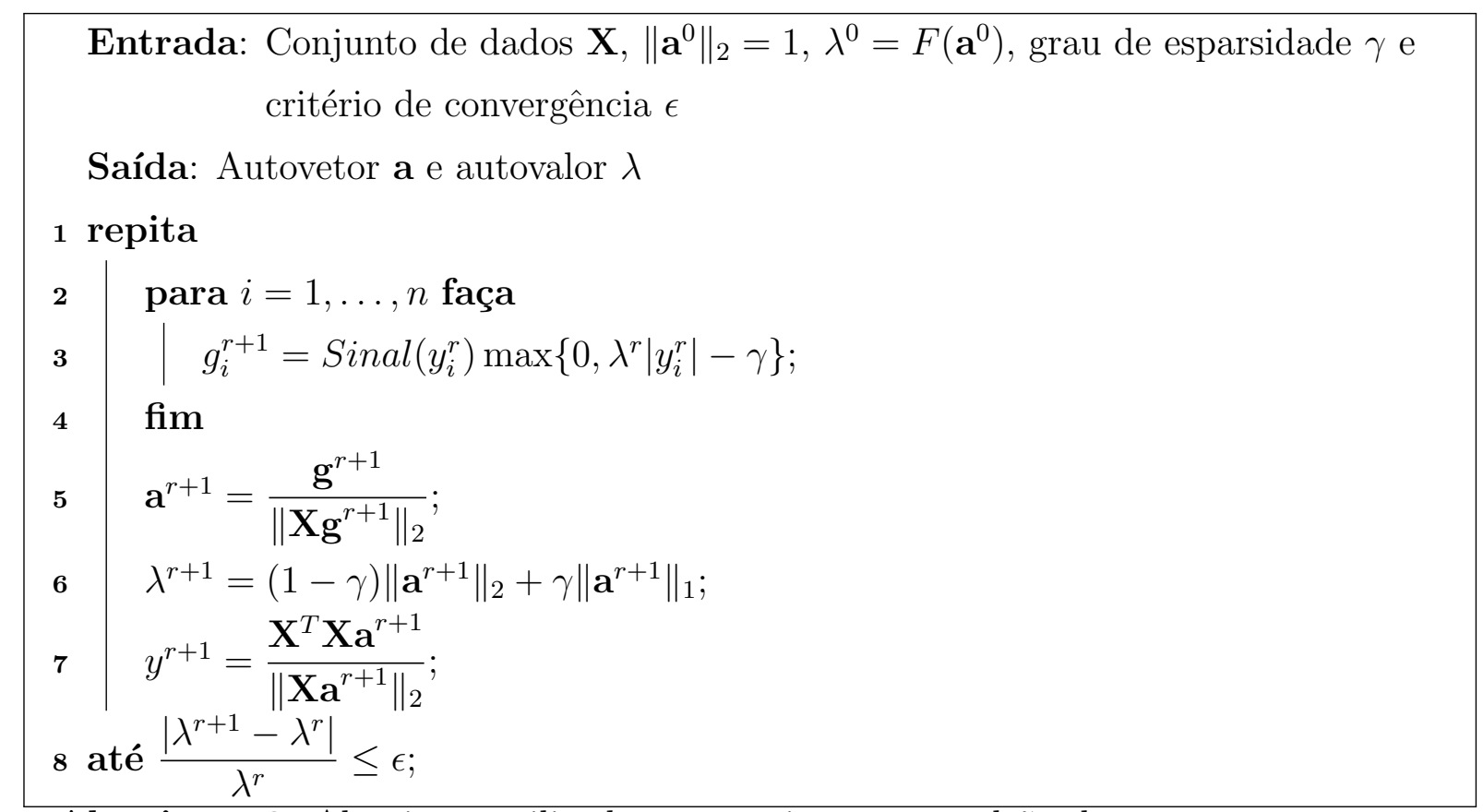

Algoritmo 3: Algoritmo utilizado para estimar um padrão de autovetor esparso por meio do método IPM.

Para garantir que o autovetor a possua norma euclidiana igual a 1, é realizada a etapa de pós processamento do autovetor, em que são recomputados os coeficientes do autovetor com valores diferentes de zero. Tal processo é denominado renormalização vetorial, o qual foi apresentado com maiores detalhes na Seção 3.4.2. 
No caso da necessidade de computar um número grande de componentes principais $(m>1)$, faz-se necessária a aplicação do esquema de deflação ao conjunto de dados, retirando a informação já calculada para o primeiro autovetor esparso. Tal método de deflação foi descrito com maiores detalhes na seção anterior.

\subsection{Considerações finais}

Neste capítulo, foram apresentadas as técnicas de redução de dimensionalidade utilizadas no processo de análise dos conjuntos de dados químicos estudados no presente trabalho. Tais técnicas incluem, principalmente, as que têm por base a extração de características do conjunto de dados, tais como as técnicas PCA e SPCA. Quanto às técnicas de seleção de variáveis, foi apresentada a técnica de escore de Fisher que é supervisionada e realiza a seleção das melhores variáveis do conjunto de dados.

Com a aplicação da redução de dimensionalidade, foi possível obter uma melhoria significativa na etapa de agrupamento dos compostos químicos. Na próxima seção, os algoritmos de agrupamento de dados são apresentados com maiores detalhes. 


\section{Métodos de Agrupamento de Dados}

O objetivo dos algoritmos de agrupamento é descobrir, sem o conhecimento prévio sobre classes, grupos naturais dentro de um conjunto de dados (JAIN, 2010). Uma definição operacional de agrupamento pode ser descrita como: dado um conjunto com $t$ observações, deve-se encontrar $k$ grupos com base em comparações quantitativas de forma que as semelhanças entre as observações no mesmo grupo sejam as maiores possíveis, enquanto as semelhanças entre observações em diferentes grupos sejam as menores possíveis.

Os algoritmos de agrupamento são classificados em hierárquicos e particionais (XU; WUNSCH-II, 2009; JAIN, 2010). Os algoritmos hierár-quicos consideram os vizinhos locais para o agrupamento e têm a vantagem de facilitar a interpretação gráfica dos dados. No entanto, por considerar apenas vizinhos locais, essas técnicas não podem incorporar conhecimento a priori sobre a forma global ou o tamanho dos agrupamentos. Já os algoritmos particionais apoiam-se no cálculo de funções objetivo, distâncias ou distribuições probabilísticas para determinar seus grupos. Essas técnicas de agrupamento têm a vantagem de incorporar conhecimento por meio das medidas de distância apropriadas ou de uma função objetivo (WILSON; BOOTS; MILLWARD, 2002).

Downs e Barnard (2003) discutem vários métodos de agrupamento utilizados em QM para a triagem de moléculas. Segundo esses autores, os principais métodos utilizados nas análises químicas são os algoritmos hierárquicos. Varin et al. (2008) comparam métodos de agrupamento hierárquico para dados de receptores $5-\mathrm{HT}_{4}$, alvo relacionado com doenças do sistema nervoso, e mostram o poder desses métodos para classificar eficientemente dados químicos em termos de similaridade molecular e atividade biológica.

Lounkine et al. (2011) introduzem uma abordagem de agrupamento de dados combinando modelagem Bayesiana com similaridade molecular, apresentando uma nova maneira de análise SAR em grandes e diversificados conjuntos de dados químicos. Rivera-Borroto et al. (2011) aplicam métodos de agrupamento hierárquico em análises SAR, obtendo bons índices de validação que se aproximam dos valores obtidos por técnicas supervisionadas 
como as máquinas de vetores de suporte (SVM) e redes neurais artificiais.

Para a tarefa de agrupamento dos conjuntos de dados descritos no Capítulo 2, são apresentadas três técnicas: o algoritmo $k$-médias, o algoritmo FCM e o método EICAMM. Com um método simples de cálculo e de entendimento, o algoritmo $k$-médias tem sido muito utilizado em problemas de QM. Um exemplo de aplicação de tal algoritmo foi apresentado por Souto et al. (2008). Nesse trabalho, os autores verificaram um bom desempenho de classificação do algoritmo quando aplicado aos dados (moléculas) com potencial anti câncer.

Para análise de um conjunto de moléculas, Roy e Ghosh (2009) obtiveram bons resultados de classificação com a combinação dos métodos k-médias e Mínimos Quadrados Parciais na análise de toxicidade de compostos aromáticos obtidos da Tetrahymena pyriformis (protozoário responsável por contaminações na água). Silva et al. (2008) utilizaram o método de aprendizado $k$-médias para classificação de um conjunto de dados contendo 30 canabinóides em três categorias (psicoativos, moderadamente psicoativos e psicoinativos), obtendo bons resultados na classificação destes compostos.

Assim como o método $k$-médias, alguns trabalhos também aplicam o método fuzzy c-médias para dados químicos. Prokhorov et al. (2011) aplicaram o FCM para otimizar a seleção de descritores químicos na análise SAR de moléculas odorantes, glicosiladas e compostos tóxicos. Zoladek et al. (2010) utilizaram o FCM para análise de mudanças químicas em células dendríticas por meio de imagens geradas a partir de espectroscopia, verificando-se que o uso do algoritmo possibilitou identificar, eficientemente, concentrações de compostos químicos responsáveis por sua ativação no organismo. Yan et al. (2008) aplicaram o FCM na análise de relações entre as propriedades físico-químicas e farmacocinéticas responsáveis por ações biológicas relacionadas com doenças hepáticas.

O último método que será utilizado neste trabalho para o agrupamento das substâncias em estudo é o EICAMM, método de classificação de dados não supervisionado que baseiase na probabilidade de pertinência de cada elemento a uma determinada classe. Essa técnica foi aplicada, inicialmente, no processo de segmentação de imagens e apresentou resultados superiores aos métodos $k$-médias e Modelo de Misturas ICA (ICAMM) ${ }^{1}$ na classificação não supervisionada de dados (OLIVEIRA; ROMERO, 2008; RIBEIRO et al., 2013). Nas próximas seções deste trabalho, os algoritmos $k$-médias, FCM e EICAMM serão apresentados com maiores detalhes.

\footnotetext{
${ }^{1}$ Do original, em inglês, ICA Mixture Model.
} 


\subsection{Algoritmo $k$-médias}

O k-médias, proposto por Steinhaus (1956), é um método simples de agrupamento que realiza a partição do conjunto de dados em $k$ grupos por meio do cálculo de distâncias entre observações e os centros de cada um dos $k$ grupos. Historicamente, o $k$-médias é um dos mais importantes algoritmos aplicados no processo de mineração de dados (JAIN, 2010).

Em uma forma particular, a partir do conjunto $\mathbf{X}$ (com $t$ observações e $n$ variáveis), em que cada observação é representada por $\mathbf{x}_{i}(i=1, \ldots, t)$, e do número $k$ de grupos, o algoritmo $k$-médias encontra uma partição $\mathbf{C}=\left\{\mathbf{C}_{j}, j=1, \ldots, k\right\}$, em que $\mathbf{C}_{j} \neq \mathbf{C}_{l}$ $(j, l=1, \ldots, k)$, de modo que o erro quadrado entre a média empírica de um grupo e as observações dentro desse grupo sejam a mínima possível.

Seja $\boldsymbol{\mu}_{j}$ a média (centróide) de um grupo $\mathbf{C}_{j}$, o erro quadrático entre $\boldsymbol{\mu}_{j}$ e as observações presentes no grupo $\mathbf{C}_{j}$ é definido por:

$$
J\left(\mathbf{C}_{j}\right)=\sum_{\mathbf{x}_{i} \in \mathbf{C}_{j}}\left\|\mathbf{x}_{i}-\boldsymbol{\mu}_{j}\right\|^{2}
$$

A finalidade do método consiste, portanto, em minimizar a soma dos erros quadráticos sobre todos os $k$ grupos do conjunto, resultando na função objetivo:

$$
J(\mathbf{C})=\sum_{k=1}^{K} \sum_{\mathbf{x}_{i} \in \mathbf{c}_{k}}\left\|\mathbf{x}_{i}-\boldsymbol{\mu}_{k}\right\|^{2} .
$$

Para minimizar a Equação (4.2), o algoritmo $k$-médias realiza a execução das seguintes etapas: (i) inicialização de um centróide para cada um dos $k$ grupos $\left(\boldsymbol{\mu}_{k}\right)$, que pode ser realizada com base em valores escolhidos aleatoriamente sobre as observações do conjunto de dados; (ii) geração de uma partição atribuindo cada observação ao grupo de centro mais próximo; (iii) atualização dos centros dos $k$ grupos, por meio do cálculo da média empírica das observações contidas em cada um deles. As etapas (ii) e (iii) são repetidas até que não ocorram mudanças nas configurações do agrupamento.

O algoritmo $k$-médias requer três parâmetros para seu funcionamento: número de grupos $(k)$, a inicialização do centros dos grupos, e a métrica de distância utilizada. De acordo com Jain (2010), a escolha mais importante é o valor de $k$, sendo que há uma série de heurísticas disponíveis para a sua escolha. Normalmente, o algoritmo $k$-médias é executado de forma independente para diferentes valores de $k$ e a partição que parece ser a mais significativa para o especialista de domínio é selecionada. Por fim, no algoritmo $k$-médias é normalmente utilizada a métrica euclidiana para calcular a distância entre os 
pontos e os centros de cada grupo.

Tendo como base o $k$-médias, vários outros algoritmos foram desenvolvidos, como ISODATA, $k$-medóides, FCM, entre outros (JAIN, 2010). Na próxima seção, será apresentado o método FCM, que pode ser considerado uma generalização do algoritmo $k$-médias para partições fuzzy.

\subsection{Algoritmo fuzzy $c$-médias (FCM)}

Conforme definido no início do presente capítulo, a tarefa de agrupamento é o processo de agrupar dados de um conjunto, de forma que a similaridade entre as observações de um grupo é maximizada, enquanto a similaridade entre observações de grupos diferentes é minimizada. Porém, em alguns casos, separar dados em grupos pode exigir a consideração de fatores de incerteza e imprecisão, já que algumas observações podem se caracterizar como similares a mais de um grupo. O tratamento desses fatores pode ser realizado por meio da transformação do processo de agrupamento clássico em um processo fuzzy (XU; WUNSCH-II, 2009; PERES et al., 2012). Nesse caso, é gerada uma matriz de pertinência $\mathbf{C}$ com seus coeficientes denominados por coeficientes de pertinência $\left(c_{i j} \in[0,1]\right)$, que indicam o nível de associação de uma $j$-ésima observação a um $i$-ésimo grupo fuzzy.

O algoritmo fuzzy c-médias (FCM), proposto por Dunn (1973) e reformulado por Bezdek (1981), é uma extensão do algoritmo $k$-médias que permite a geração de uma matriz de pertinência fuzzy durante o processo de agrupamento de dados. Mais especificamente, a partir do número de $k$ grupos ( $k=c$, variável do $c$ médias) e do conjunto $\mathbf{X}$ (com $t$ observações e $n$ variáveis, em que x é uma observação), o algoritmo FCM encontra uma matriz de pertinência $\mathbf{C}$ (com $t$ linhas e $k$ colunas) por meio da minimização de uma função que reflete as distâncias entre as observações e os centros dos grupos as quais essas observações pertencem com algum grau de pertinência (XU; WUNSCH-II, 2009). Tal função é dada por:

$$
J(\mathbf{C}, \mathbf{U})=\sum_{i=1}^{k} \sum_{j=1}^{t}\left(c_{i j}\right)^{m}\left\|\boldsymbol{\mu}_{i}-\mathbf{x}_{j}\right\| .
$$

Cada coeficiente $c_{i j}$ da matriz de pertinência é atualizado mantendo o índice $i$ no grupo ao qual se quer calcular a pertinência do dado $j$, enquanto varia o índice $l$ em todos os grupos. Isso significa que a pertinência de uma observação $j$ a um grupo $i$ é dependente das relações desse dado com todos os demais grupos. A atualização é definida 
pela Equação

$$
c_{i j}^{r+1}=\frac{1}{\sum_{l=1}^{k}\left(\frac{\left\|\boldsymbol{\mu}_{l}-\mathbf{x}_{j}\right\|}{\left\|\boldsymbol{\mu}_{i}-\mathbf{x}_{j}\right\|}\right)^{\frac{1}{1-m}}},
$$

sendo que as exceções a seguir devem ser tratadas:

$$
c_{i j}^{r+1}=\left\{\begin{array}{l}
1 \quad \text { se }\left\|\boldsymbol{\mu}_{i}-\mathbf{x}_{j}\right\|=0 \\
0 \quad \text { se }\left\|\boldsymbol{\mu}_{l}-\mathbf{x}_{j}\right\|=0, \quad(l \neq i \text { e } 1 \leq l, i \leq k) .
\end{array}\right.
$$

O termo $m$ é um número real positivo, tal que $m \in(1, \infty)$, utilizado como parâmetro de "fuzzificação". Esse parâmetro realiza a ponderação dos coeficientes da matriz de pertinência C. A variável $r$ representa um contador de iterações, iniciado em 1 e utilizado durante o processo de minimização da função apresentada na Equação (4.3).

Ainda com referência a função apresentada na Equação (4.3), o termo $\left\|\boldsymbol{\mu}_{i}-\mathbf{x}_{j}\right\|$ representa a distância entre uma observação $\mathbf{x}_{j}$ e o centróide representante da $i$-ésima partição fuzzy $\boldsymbol{\mu}_{i}$. Em geral, a distância Euclidiana é utilizada para determinar a proximidade entre observações e grupos. Por fim, o termo U é uma matriz de centróides dos grupos fuzzy (com $k$ linhas e $n$ colunas), sendo cada $\boldsymbol{\mu}_{i}$ um vetor do $i$-ésimo centro do grupo fuzzy. Essa matriz é atualizada com base na relação entre as observações e as suas pertinências, por meio da equação:

$$
\boldsymbol{\mu}_{i}^{r}=\frac{\sum_{j=1}^{t}\left(c_{i j}^{r}\right)^{m} \mathbf{x}_{j}}{\sum_{j=1}^{t}\left(c_{i j}^{r}\right)^{m}}, \quad(i=1, \ldots, k ; j=1, \ldots, t) .
$$

Resumidamente, a partir do número de grupos $(k)$, do valor do parâmetro de fuzzyficação $(m)$ e um número máximo de iterações $(r)$, o algoritmo FCM realiza a atualização da matriz de pertinência $(\mathbf{C})$ e da matriz de centróides $\mathbf{U}$ até que um valor mínimo de erro seja alcançado. O erro $\epsilon$ usado como condição de parada do algoritmo é um limite inferior para a alteração dos vetores dos centróides: alterações muito pequenas indicam que as mudanças ocorridas nos grupos em formação no algoritmo não alteram, significativamente, a formação de cada grupo, indicando que o processo encontrou um ponto de mínimo. Informações complementares sobre o método FCM são encontradas em diversas fontes na literatura (PERES et al., 2012; BEZDEK, 1981; XU; WUNSCH-II, 2009).

Algoritmos como o fuzzy $c$-médias e o $k$-médias possuem uma desvantagem: utilizam medidas de distância para alocar os elementos em seus grupos, o que lhes conferem a sensibilidade à presença de outliers (XU; WUNSCH-II, 2009; YANYUN et al., 2011). Uma outra técnica de agrupamento que não se baseia no cálculo de métricas de distância será apresentada a seguir. 


\subsection{Modelo de misturas ICA aperfeiçoado}

O modelo de misturas ICA (ICAMM)2 tem como meta superar uma limitação da técnica de análise de componentes independentes (ICA) ${ }^{3}$ que assume que as fontes geradoras de um conjunto de dados são independentes (HYVARINEN; KARHUNEN; OJA, 2001). No método ICAMM, essa suposição foi relaxada usando o conceito estatístico de modelos de misturas.

De acordo com Lee, Lewicki e Sejnowski (2000), no método ICAMM, cada classe é descrita por uma combinação linear independente de fontes não gaussianas. O método de classificação não supervisionado estima a matriz de bases e o vetor de bias (parâmetros do modelo) para cada classe por meio do algoritmo infomax (HYVARINEN; KARHUNEN; OJA, 2001) e, por fim, aplica o teorema de Bayes para associar uma observação à classe com maior probabilidade a posteriori. As regras para o processo de estimativa foram derivadas por uma técnica de otimização de gradiente, com o objetivo de maximizar a função de log-verossimilhança do conjunto de dados.

Apesar das características promissoras do método ICAMM, algumas limitações foram apontadas por Oliveira e Romero (2008). A primeira limitação é que o seu aprendizado é baseado numa técnica de otimização por gradiente e, assim, ele pode ser afetado entre outros fatores, por alguns problemas associados com esse tipo de abordagem. Além disso, Oliveira e Romero (2008) apresentaram que alguns aspectos dessa formulação e implementação poderiam ser incrementadas com o objetivo de tornar o método eficiente, como a incorporação de algumas características de métodos de otimização não lineares ao processo de aprendizado. Nesse caso, o método de Levenberg-Marquardt foi incorporado ao algoritmo de aprendizado para garantir e melhorar a convergência do modelo. Por fim, uma formulação alternativa do modelo generativo da ICA também foi proposta. Tais melhorias no método ICAMM deram origem ao modelo de misturas ICA aperfeiçoado (EICAMM) (OLIVEIRA; ROMERO, 2008).

O procedimento para estimar os parâmetros da distribuição para cada grupo tem por objetivo maximizar a função de log-verossimilhança dada por:

$$
p(\mathbf{X} \mid \boldsymbol{\theta})=\prod_{i=1}^{T} p\left(\mathbf{x}_{t} \mid \boldsymbol{\theta}\right),
$$

em que $\mathbf{X}=\left\{\mathbf{x}_{1}, \ldots, \mathbf{x}_{T}\right\}$ é o conjunto de entrada, $\boldsymbol{\theta}=\left\{\boldsymbol{\theta}_{1}, \ldots, \boldsymbol{\theta}_{k}\right\}$ são parâmetros desconhecidos para cada $p\left(\mathbf{x} \mid \mathbf{C}_{k}, \boldsymbol{\theta}_{k}\right)$, em que cada $\mathbf{C}_{k}$ denota um grupo $k$. É assumido

\footnotetext{
${ }^{2}$ Do original, em inglês, ICA Mixture Model

${ }^{3}$ Do original, em inglês, Independent Component Analysis
} 
que o número $k$ é conhecido a priori.

No modelo EICAMM, o conjunto de dados para cada grupo é definido por

$$
\mathbf{x}_{t}=\mathbf{A}_{k}\left(\mathbf{s}_{k}+\mathbf{b}_{k}\right)
$$

em que $\mathbf{A}_{k}$ é uma matriz $N \times N$ e $\mathbf{b}_{k}$ é o vetor de bias para o $k$-ésimo grupo.

O método EICAMM é utilizado para classificar dados não rotulados por meio de um processo de estimativa dos parâmetros $\boldsymbol{\theta}_{k}=\left(\mathbf{A}_{k}, \mathbf{b}_{k}\right)$ e o cálculo das probabilidades de classe para cada observação. Esse método de aprendizado iterativo, que realiza a subida de gradiente em direção à função de log-verossimilhança, pode ser resumido nas seguintes etapas:

1. Calcule a log-verossimilhança para cada grupo, de acordo com

$$
\log p\left(\mathbf{x}_{t} \mid \mathbf{C}_{k}, \boldsymbol{\theta}_{k}\right)=\log p\left(\mathbf{s}_{k}\right)-\log \operatorname{det}\left(\mathbf{A}_{k}\right)
$$

em que $\mathbf{s}_{k}=\left(\mathbf{A}_{k}^{-1} \mathbf{x}_{t}\right)-\mathbf{b}_{k}$. Assumindo que $\mathbf{A}$ é uma matriz ortogonal, é aplicada a regra da ortogonalidade em que $\mathbf{A}^{T}=\mathbf{A}^{-1}$, o que simplifica o processo de cálculo nesta etapa;

2. Calcule a probabilidade para cada classe, dado o vetor de dados $\mathbf{x}_{t}$ por meio da equação

$$
p\left(\mathbf{C}_{k} \mid \mathbf{x}_{t}, \boldsymbol{\theta}\right)=\frac{p\left(\mathbf{x}_{t} \mid \mathbf{C}_{k}, \boldsymbol{\theta}_{k}\right) p\left(\mathbf{C}_{k}\right)}{\sum_{k} p\left(\mathbf{x}_{t} \mid \mathbf{C}_{k}, \boldsymbol{\theta}_{k}\right) p\left(\mathbf{C}_{k}\right)} ;
$$

3. Atualize a matriz de bases por meio da equação:

$$
\Delta \mathbf{A}_{k} \propto p\left(\mathbf{C}_{k} \mid \mathbf{x}_{t}, \theta\right)(\mathbf{H}+\mu \mathbf{I})^{-1} \mathbf{A}_{k}\left(\mathbf{I}-\mathbf{K} \tanh \left(\mathbf{s}_{k}\right) \mathbf{s}_{k}^{T}-\mathbf{s}_{k} \mathbf{s}_{k}^{T}\right)^{T},
$$

em que $\mathbf{H}$ representa a matriz hessiana, com informações de segunda derivada da função de log-verossimilhança, obtida por meio do método de Levenberg-Maquardt; $\mu$ representa uma constante no intervalo $(0,1)$; K representa uma matriz diagonal $N$-dimensional composta por $k^{\prime} s$ calculados por:

$$
k_{i}=\operatorname{sinal}\left(\operatorname{curtose}\left(s_{i, t}\right)\right)
$$

4. Atualize o vetor de bias de cada classe por meio da equação:

$$
\Delta \mathbf{b}_{k} \propto-2 \tanh \left(\mathbf{s}_{k}\right)
$$


5. Ortogonalize a matriz de base $\mathbf{A}_{k}$, por meio da equação

$$
\mathbf{A}_{k}=\mathbf{A}_{k}\left(\mathbf{A}_{k}^{T} \mathbf{A}_{k}\right)^{1 / 2}
$$

6. Estime a função de log-verossimilhança, em que o termo $\log p\left(\mathbf{s}_{k}\right)$ é dado por

$$
\log p\left(\mathbf{s}_{k}\right) \propto-\sum_{i=1}^{N}\left(k_{i} \log \left(\cosh \mathbf{s}_{k . i}\right)-\frac{\mathbf{s}_{k, i}^{2}}{2}\right) .
$$

O algoritmo de aprendizado EICAMM converge quando a mudança de valor da logverossimilhança entre duas sucessivas iterações for menor do que uma pequena constante pré determinada (por exemplo, valores iguais a 0,1 ou 0,001 ).

O processo de classificação consiste em processar cada observação com os parâmetros $\mathbf{A}_{k}$ e $\mathbf{b}_{k}$. Em seguida, as probabilidades condicionais de cada grupo $p\left(\mathbf{C}_{k} \mid \mathbf{x}_{t}, \boldsymbol{\theta}\right)$ são calculadas para todos os $k$ grupos e o rótulo da observação é associado para o grupo de maior probabilidade.

De acordo com Theodoridis e Koutroumbas (2003), uma característica comum dos algoritmos de agrupamento é a imposição de estruturas de agrupamento no conjunto de dados X, mesmo que tal conjunto não possua essa estrutura. Isso se deve a parâmetros apresentados de forma incorreta aos algoritmos de agrupamento (por exemplo, o número de $k$ grupos) levando a interpretação equivocada dos grupos gerados. É necessária, então, uma análise cuidadosa dos resultados obtidos pela aplicação dos algoritmos de agrupamento e isso é realizado por meio dos métodos de validação de agrupamentos, os quais serão apresentados a seguir.

\subsection{Validação de agrupamentos}

Por conta do grande número de técnicas para análise de agrupamentos existentes e das diversas partições que estas podem impor sobre um conjunto de dados, os critérios de validação são necessários para verificar a qualidade da partição encontrada sobre as observações, além de serem utilizados para indicar o número adequado de agrupamentos que existem no conjunto de dados (THEODORIDIS; KOUTROUMBAS, 2003).

É possível encontrar na literatura diversos métodos para investigar a qualidade dos agrupamentos de dados (THEODORIDIS; KOUTROUMBAS, 2003; XU; WUNSCH-II, 2009). Alguns métodos são dependentes do conhecimento prévio das classes (métodos de validação externa). Outros são dependentes somente das observações ou do número de agrupamen- 
tos encontrados (métodos de validação interna) (XU; WUNSCH-II, 2009).

Os índices calculados pelos métodos de validação externa podem ser vistos como critérios que permitem o uso dos rótulos dos dados para validar o desempenho dos algoritmos de agrupamento (XU; WUNSCH-II, 2009). O índice computado pelo método de Rand compara os resultados obtidos pela técnica de agrupamento com um conjunto de classes definidas a priori (geralmente por especialistas do domínio). Nesse caso, denotando por $\mathbf{C}$ a partição obtida automaticamente e por $\mathbf{P}$ a partição definida a priori, são computados inicialmente quatro valores distintos para todos os possíveis pares de observação no conjunto de dados $\mathbf{X}$ :

- $a$ : o número de pares de observações que pertencem às mesmas classes em $\mathbf{P}$ e aos mesmos grupos em $\mathbf{C}$;

- $b$ : o número de pares de observações que pertencem às mesmas classes em $\mathbf{P}$ e a diferentes grupos em $\mathbf{C}$;

- c: o número de pares de observações que pertencem a diferentes classes em $\mathbf{P}$ e aos mesmos grupos em $\mathbf{C}$;

- $d$ : o número de pares de observações que pertencem a diferentes classes em $\mathbf{P}$ e a diferentes grupos em $\mathbf{C}$.

A partir dos valores computados, o índice de Rand é calculado por:

$$
\text { Rand }=\frac{a+d}{a+b+c+d} .
$$

De acordo com a Equação (4.16), os termos $a$ e $d$ são medidas de acordos, enquanto os termos $b$ e $c$ são medidas de discordâncias. É possível observar que: (i) o índice de Rand tem intervalo entre [0,1]; (ii) o índice de Rand terá valor igual a zero se, e somente se $\mathbf{C}$ for completamente inconsistente (por exemplo, $a=d=0$ ); (iii) o índice de Rand terá valor igual a 1 se, e somente se a partição sob avaliação coincide exatamente com a partição de referência (por exemplo, $b=c=0$ ou $\mathbf{P}=\mathbf{C}$ ). 


\subsection{Considerações finais}

Neste capítulo, foram apresentados trabalhos que utilizam os métodos de agrupamento de dados no processo de descoberta de novos medicamentos. Também foram apresentados os algoritmos de agrupamento de dados $k$-médias, FCM e EICAMM, os quais foram utilizados nos experimentos conduzidos no presente trabalho. Além desses algoritmos, foi descrito também o método para validação das partições geradas pelos mesmos (índice de Rand).

No próximo capítulo, serão apresentados os experimentos conduzidos com os diversos esquemas de análise exploratória de dados, que combinou as técnicas de agrupamento de dados e de redução de dimensionalidade. 


\section{$5 \quad$ Resultados Experimentais}

Neste capítulo, são apresentados e discutidos os resultados dos experimentos realizados neste trabalho que visaram a tratar o problema da alta dimensionalidade e obtenção de agrupamentos relevantes considerando moléculas candidatas a novos medicamentos.

Inicialmente, diversos esquemas de análise exploratória e algoritmos de agrupamento foram aplicados sobre o conjunto de dados PPAR $\delta$-1 e a avaliação dos mesmos foi realizada empregando o índice de Rand. Após análises preliminares realizadas sobre esse conjunto de dados, serão apresentados resultados e discussões envolvendo aplicações em outros conjuntos de dados químicos $(\operatorname{PPAR} \delta-2, \operatorname{AT} 1$ e TGF $\beta)$, os quais também são objetos de estudo deste trabalho. Antes da discussão dos experimentos conduzidos, serão apresentados alguns aspectos de implementação das técnicas utilizadas, conforme descrito na próxima seção.

\subsection{Detalhes de implementação}

Os experimentos realizados com todos os conjuntos de dados, apresentados no Capítulo $2(\operatorname{PPAR} \delta$-1, PPAR $\delta$-2, AT1 e TGF $\beta$ ), foram conduzidos no software MATLAB (versão R2009a). Para a técnica de redução de dimensionalidade PCA e os métodos de agrupamento $k$-médias e FCM, foram utilizadas funções nativas desse software ${ }^{1}$. O método de agrupamento EICAMM foi implementado e fornecido pelos autores Oliveira e Romero (2008).

O código da técnica de análise esparsa $\mathrm{IPM}^{2}$ foi disponibilizado pelos autores por meio eletrônico. No entanto, o programa adquirido foi editado para inclusão do método de deflação, a fim de calcular um número de componentes principais maior que 1. Por fim, as técnicas de redução de dimensionalidade $\mathrm{GP}^{3}$, SPCA-ZOU ${ }^{4}$ e escore de Fisher ${ }^{5}$

\footnotetext{
${ }^{1}$ Funções denominadas por: princomp, kmeans e $f c m$, respectivamente.

${ }^{2}$ Disponível em: http://www.ml.uni-saarland.de/code/IPM/IPM.html

${ }^{3}$ Disponível em: http://www.montefiore.ulg.ac.be/ journee/

${ }^{4}$ Disponível em: http://www.imm.dtu.dk/projects/spasm/

${ }^{5}$ Disponível em: http://featureselection.asu.edu/
} 
também foram obtidas por meio eletrônico, sem necessidade de nenhuma alteração na implementação desses métodos.

Os valores dos parâmetros utilizados na execução dos métodos de redução de dimensionalidade e de agrupamento de dados para cada experimento serão apresentados na próxima seção, uma vez que estes podem diferir de acordo com o conjunto de dados em questão. Na próxima seção, serão apresentados os experimentos conduzidos sobre o conjunto de dados $\operatorname{PPAR} \delta-1$.

\subsection{Experimentos com o conjunto de dados PPAR $\delta$-1}

Nesta seção, são apresentados e discutidos os experimentos realizados sobre o conjunto de dados PPAR $\delta$-1, contento 70 observações e 653 atributos, descrito em maiores detalhes no Capítulo 2.

\subsubsection{Primeiro esquema de análise exploratória: aplicação das técnicas de escore de Fisher e PCA e do conhecimento de especialista no domínio}

Em uma etapa preliminar, foram aplicadas as técnicas de redução de dimensionalidade escore de Fisher e PCA, gerando três versões reduzidas do conjunto original. Além disso, uma seleção de variáveis realizada por especialistas do domínio resultou na geração de mais um conjunto, que também foi combinado com a técnica PCA. A Figura 4 resume o esquema geral para a derivação desses cinco conjuntos reduzidos.

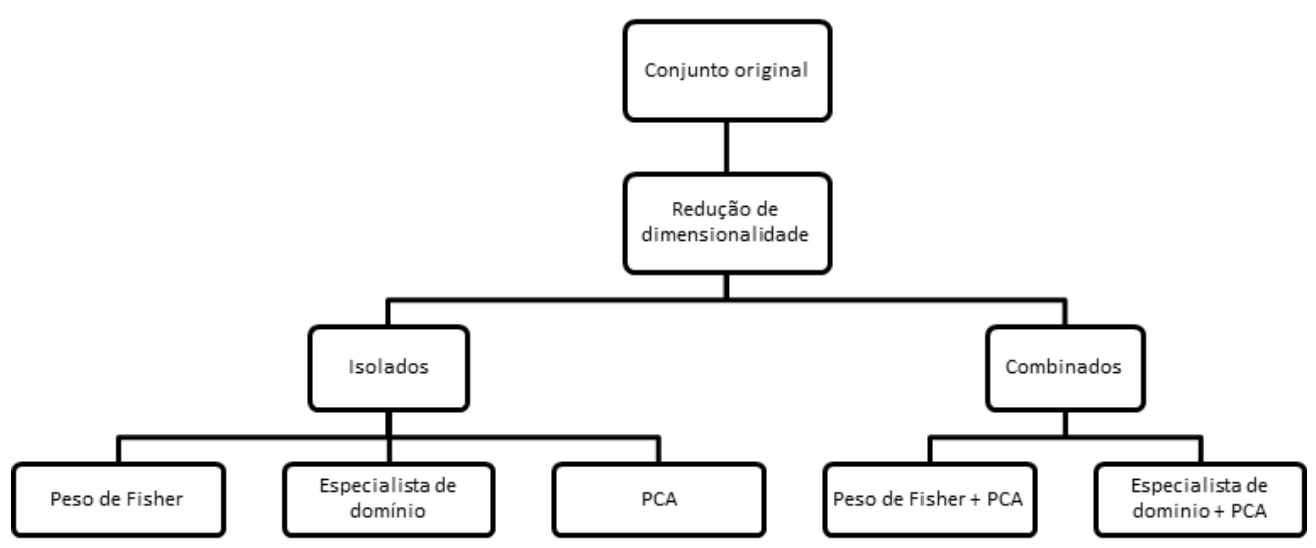

Figura 4 - Primeiro esquema proposto para redução de dimensionalidade, derivando cinco conjuntos de dimensão reduzida. 
Maiores detalhes dessa etapa são descritos como segue:

- O primeiro conjunto gerado provém das variáveis selecionadas a partir da técnica de escore de Fisher, em que as variáveis com peso maior que 0,25 foram escolhidas. Como resultado final, foram obtidas 108 variáveis;

- O segundo conjunto foi determinado pelo especialista de domínio. Do conjunto original (653 variáveis), foram escolhidas 9 variáveis que, segundo o especialista, seriam suficientes para representar o conjunto de dados nos processos de agrupamento;

- A terceira derivação foi obtida após aplicação da técnica PCA sobre o conjunto de dados original. Um total de 11 PCs foram selecionadas, resultando em $99 \%$ de retenção da variabilidade do conjunto original;

- A partir da combinação das técnicas de escore de Fisher e PCA foi obtido o quarto conjunto reduzido. Em primeiro lugar, foram selecionadas as variáveis com valor de escore de Fisher maior que 0,25 (108 variáveis). Após a seleção dessas variáveis, o conjunto de dados foi transformado empregando a técnica PCA e foram selecionadas 65 PCs, com retenção de $99 \%$ da variabilidade do conjunto gerado com a seleção de Fisher;

- A quinta derivação foi obtida a partir da aplicação da técnica PCA sobre o terceiro conjunto (com variáveis selecionadas por especialista de domínio), resultando em 9 PC's, com retenção de $99 \%$ da variabilidade do conjunto com a seleção pelo especialista.

Após a derivação dos cinco conjuntos descritos, foram aplicadas as técnicas de agrupamento de dados. Na especificação de parâmetros, para o método $k$-médias, foi utilizado o número de $k$ grupos igual a 2. No algoritmo FCM, foram informados, além do número de grupos, o índice de fuzzyficação igual a 2 e o número máximo de iterações igual a 100. Para o algoritmo EICAMM foi informado, além do número de grupos, a taxa de aprendizado $(\mu=0,1)$, o número máximo de iterações (400) e o valor de convergência para a função de log-verossimilhança ${ }^{6}(0,0001)$.

Com as partições definidas pelos algoritmos de agrupamento, seguiu-se para a etapa de validação dos resultados sendo que, antes da utilização do índice de Rand, o especialista de domínio definiu previamente classes para os compostos conforme os seguintes valores de atividade biológica (Tabela 1, ver Capítulo 2): (i) classe de compostos menos

\footnotetext{
${ }^{6}$ Diferença dos valores da função entre duas iterações consecutivas.
} 
potentes, com valores de atividade biológica entre 5,65 e 8,34, resultando em 34 compostos pertencentes a essa classe; (ii) grupo de compostos mais potentes, com atividade biológica entre 8,35 e 9,23, resultando em 36 compostos pertencentes a essa categoria. Tais classes também foram utilizadas na seleção de variáveis empregando a técnica de escore de Fisher.

Uma observação importante deve ser feita também em relação ao algoritmo FCM: para validação de todos os resultados obtidos por meio dessa técnica, empregando o índice de Rand, a matriz de pertinência gerada foi transformada em uma partição nítida (ou partição crisp), indicando somente o grupo em que a observação possuía o maior índice de pertinência. Como descrito no Capítulo 4, uma partição fuzzy contém a pertinência de uma observação aos diversos grupos pré determinados.

Os resultados obtidos com a validação dos agrupamentos são apresentados na Figura 5. O melhor índice de Rand obtido foi de 0,79 , com o agrupamento realizado pelo método EICAMM. A derivação do conjunto em que tal resultado foi obtido, combinou as seguintes técnicas de redução de dimensionalidade: escore de Fisher e PCA (quarta derivação). É observado, ainda na Figura 5, que os conjuntos de dados derivados da seleção de variáveis realizada pelo especialista de domínio e pela redução empregando a técnica PCA não forneceram informações suficientes para a tarefa de agrupamento dos dados.

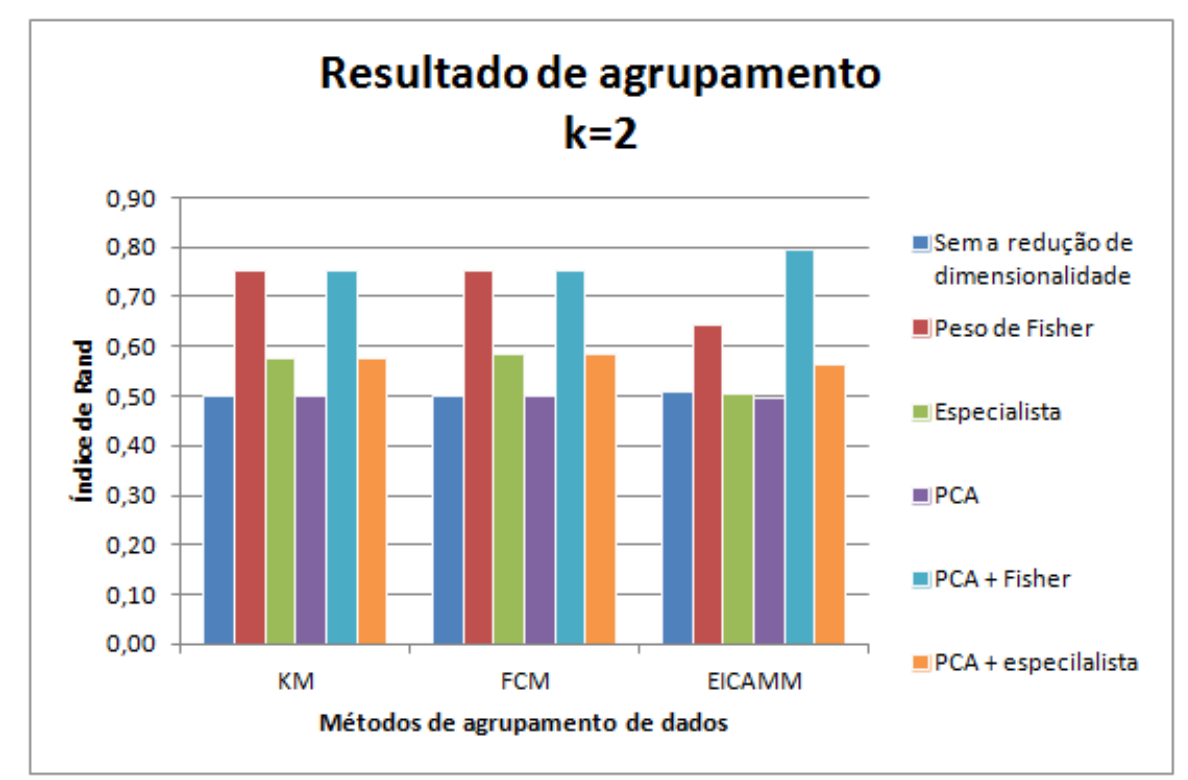

Figura 5 -Resultados de validação de agrupamentos obtidos pelas técnicas k-médias, $F C M$ e EICAMM, para o conjunto PPAR $\delta$-1 no primeiro esquema de análise exploratória.

A partir dos resultados obtidos, é perceptível que as técnicas escore de Fisher, PCA e 
EICAMM foram empregadas com sucesso no esquema de redução de dimensionalidade e de agrupamento do conjunto de dados $\operatorname{PPAR} \delta$-1. Porém, é possível observar que há, nesse primeiro esquema proposto, informações incorporadas de maneira supervisionada, como é o caso da técnica de escore de Fisher e do conhecimento do especialista. Tais informações de rótulo podem ter influenciado os resultados de agrupamento aqui discutidos. Para superar essa limitação e investigar a capacidade de extrair informações de forma totalmente auto-organizável, foi proposto um outro esquema de análise exploratória, no qual foram empregadas técnicas de redução de dimensionalidade não supervisionadas, como pode ser visto na próxima seção.

\subsubsection{Segundo esquema de análise exploratória: aplicação das técnicas PCA e SPCA}

No segundo esquema de análise exploratória proposto neste trabalho, foram aplicadas no conjunto de dados $\operatorname{PPAR} \delta-1$ as técnicas de redução de dimensionalidade não supervisionadas PCA e SPCA (GP, IPM, SPCA-ZOU), o que gerou quatro versões reduzidas do conjunto original. A Figura 6 resume o esquema geral utilizado para a derivação dos quatro conjuntos reduzidos considerados nesses experimentos.

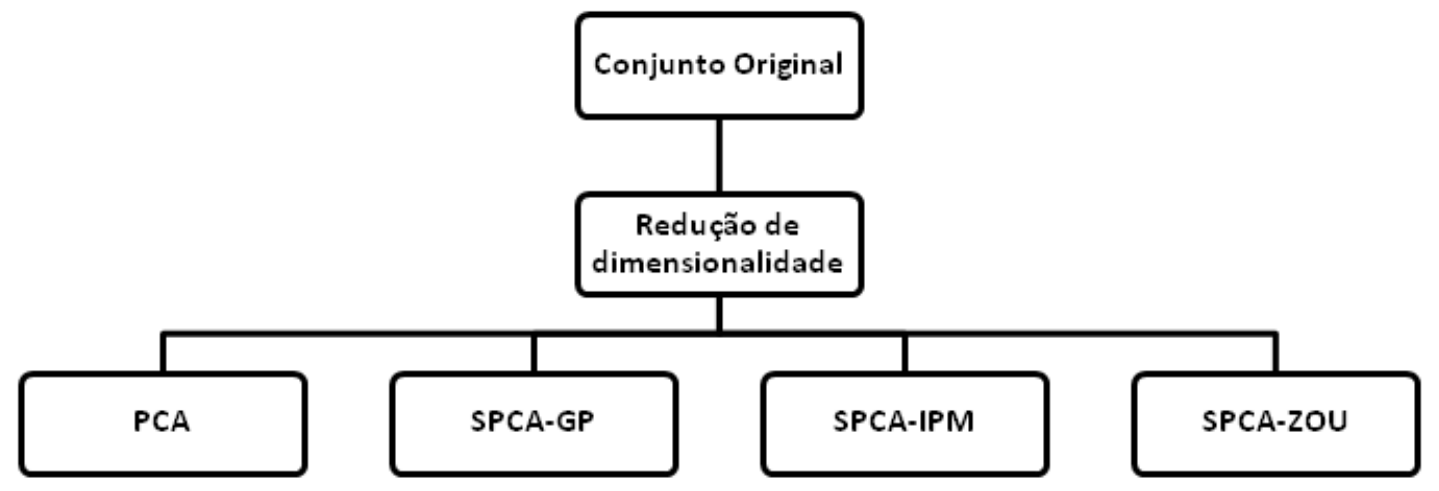

Figura 6 - Segundo esquema proposto para redução de dimensionalidade, derivando quatro conjuntos de dimensão reduzida.

Em relação às técnicas de análise SPCA, vale ressaltar que o nível de esparsidade $(\gamma)$ influencia o número de coeficientes não nulos da matriz de autovetores, utilizada na transformação linear. Por isso, para cada técnica SPCA, foi realizada a transformação do conjunto de dados, variando o nível de esparsidade no intervalo entre 0 e 1 . Além disso, para as técnicas PCA e SPCA, também foram realizadas variações no número de componentes principais (PC's) no intervalo entre 2 e 30.

Os conjuntos de dados transformados com as técnicas SPCA e PCA foram apresen- 
tados aos algoritmos de agrupamento $k$-médias, FCM e EICAMM. Para execução desses algoritmos, o número de grupos foi inicialmente fixado em $2(k=2)$. No caso do algoritmo FCM, além do número de grupos, foi determinado o índice de fuzzyficação igual a $2(m=2)$ e número máximo de iterações igual a 100. Para o algoritmo EICAMM, foram determinados a taxa de aprendizado igual a 0,1 $(\mu=0,1)$, o número máximo de iterações igual a 400 e o critério de convergência da log-verossimilhança igual a 0,0001.

O desempenho de cada um dos resultados de agrupamento foi avaliado por meio do índice de Rand. Para o cálculo desse índice, foi utilizada a partição definida pelo especialista de domínio, conforme Tabela 1 apresentada no Capítulo 2, ou seja, a primeira classe refere-se aos compostos menos potentes, os quais apresentam valores de atividade biológica entre 5,65 e 8,34 e a segunda classe refere-se aos compostos mais potentes, os quais possuem valores de atividade biológica entre 8,35 e 9,23.

A Figura 7 apresenta os valores do índice de Rand obtidos pelos algoritmos de agrupamento. O maior índice de Rand foi obtido empregando o método EICAMM e apresentou valor igual a 0,64. Nesse caso, a técnica de redução de dimensionalidade utilizada foi a técnica de análise esparsa IPM, o que gerou 24 componentes principais para um valor de parâmetro de esparsidade igual a 0,31 .

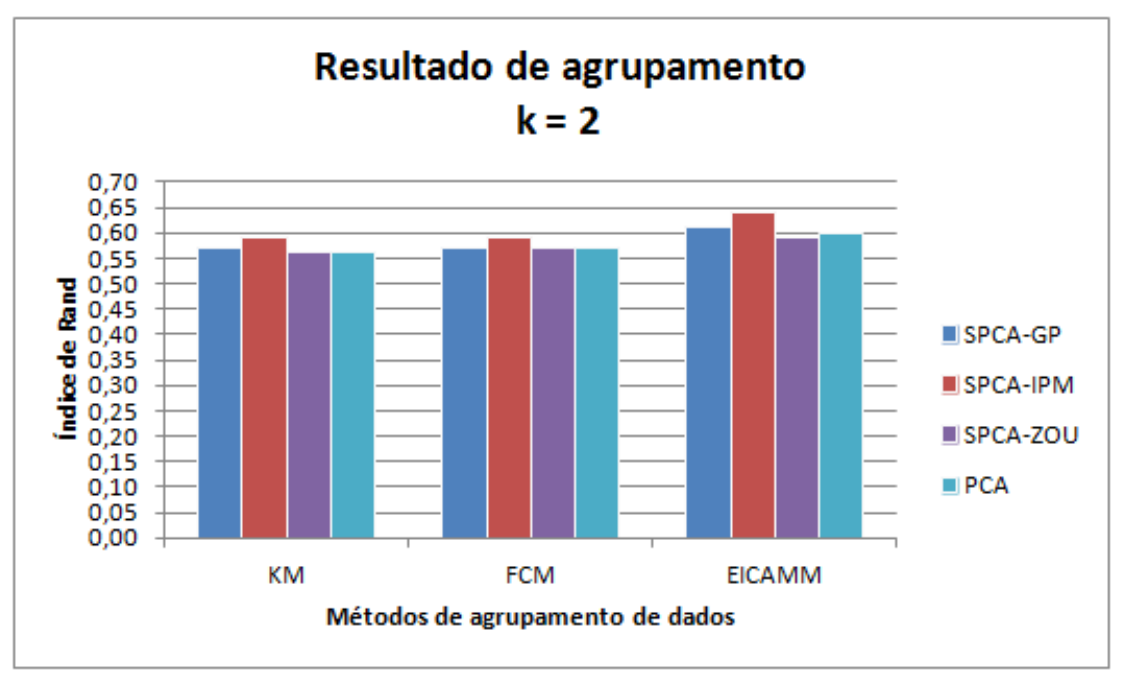

Figura 7 -Resultados de validação de agrupamentos obtidos pelas técnicas k-médias, FCM e EICAMM, para o conjunto PPAR $\delta$-1, no segundo esquema de análise exploratória.

No entanto, pode-se observar que o melhor resultado do índice de Rand, nestes experimentos, é inferior ao resultado obtido para o esquema discutido na Seção 5.2.1, que foi igual a 0,79. Entretanto, esse fato já era esperado, uma vez que aqui não há incorporação de informações externas (rótulos fornecidos pelo especialista). Com o intuito de continuar 
explorando características intrísecas dos conjuntos de dados, procedeu-se com a condução de novos experimentos nos quais números maiores de grupos $(k>2)$ foram considerados. Tais resultados serão apresentados na próxima seção.

\subsubsection{Terceiro esquema de análise exploratória: aplicação de to- das as técnicas de redução de dimensionalidade}

No terceiro experimento, conduzido sobre o conjunto de dados PPAR $\delta$-1, foram aplicadas todas as técnicas de redução de dimensionalidade discutidas no Capítulo 3, gerando nove versões reduzidas do conjunto original. O esquema de redução de dimensionalidade é apresentado na Figura 8. Nessa figura, as técnicas de redução de dimensionalidade utilizadas ficaram dispostas da seguinte forma: (i) GP; (ii) IPM; (iii) PCA; (iv) SPCA-ZOU; (v) escore de Fisher; (vi) escore de Fisher e PCA; (vii) escore de Fisher e GP; (viii) escore de Fisher e IPM; (ix) escore de Fisher e SPCA-ZOU.

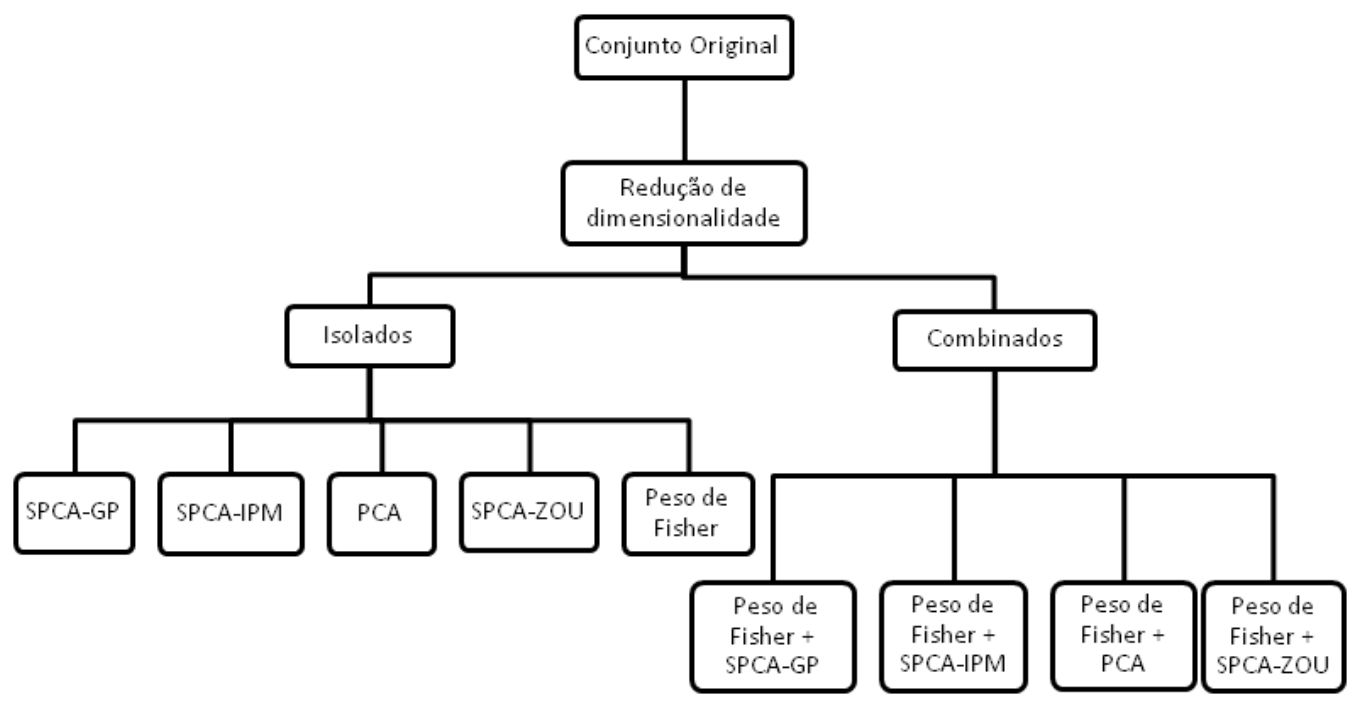

Figura 8 - Terceiro esquema proposto para redução de dimensionalidade, derivando diversos conjuntos de dimensão reduzida

Para execução desses experimentos, foram realizadas variações nos parâmetros das técnicas de redução de dimensionalidade. No caso da técnica de escore de Fisher, foram selecionadas variáveis com valor de peso maior do que o critério de peso determinado pelos especialistas de domínio. Tal critério variou no intervalo entre 0,2 e 2. Em relação às técnicas de análise SPCA, foi realizada a transformação do conjunto de dados variando o nível de esparsidade $(\gamma)$ no intervalo entre 0 e 1 . Além disso, para as técnicas PCA e SPCA, foram realizadas também variações no número de componentes principais (PC's) no intervalo entre 2 e 30 . 
Os conjuntos de dados obtidos com todas as variações de parâmetros das técnicas SPCA e PCA foram apresentados aos algoritmos de agrupamento $k$-médias, FCM e EICAMM. Para execução desses algoritmos, foram realizadas alterações no número de grupos, sendo que os melhores resultados foram obtidos com o número de grupos igual a 5 $(k=5)$. No caso do algoritmo FCM, além do número de grupos, foi determinado o índice de fuzzyficação igual a $2(m=2)$ e número de iterações igual a 100. Para o algoritmo EICAMM, foram realizadas variações na taxa de aprendizado no intervalo entre 0 e 1 , o número de iterações igual a 400 e o critério de convergência da log verossimilhança igual a 0,0001 .

Com as partições definidas pelos algoritmos de agrupamento, seguiu-se para a etapa de validação dos resultados por meio do índice de Rand. Para o cálculo desse índice, foi utilizada a partição definida pelo especialista de domínio com base no potencial biológico, conforme Tabela 1 apresentada no Capítulo 2. Os melhores índices de Rand obtidos pelas técnicas de agrupamento em combinação com os métodos de redução de dimensionalidade, considerando-se aqui todas as variações de parâmetros testados, são apresentados na Figura 9.

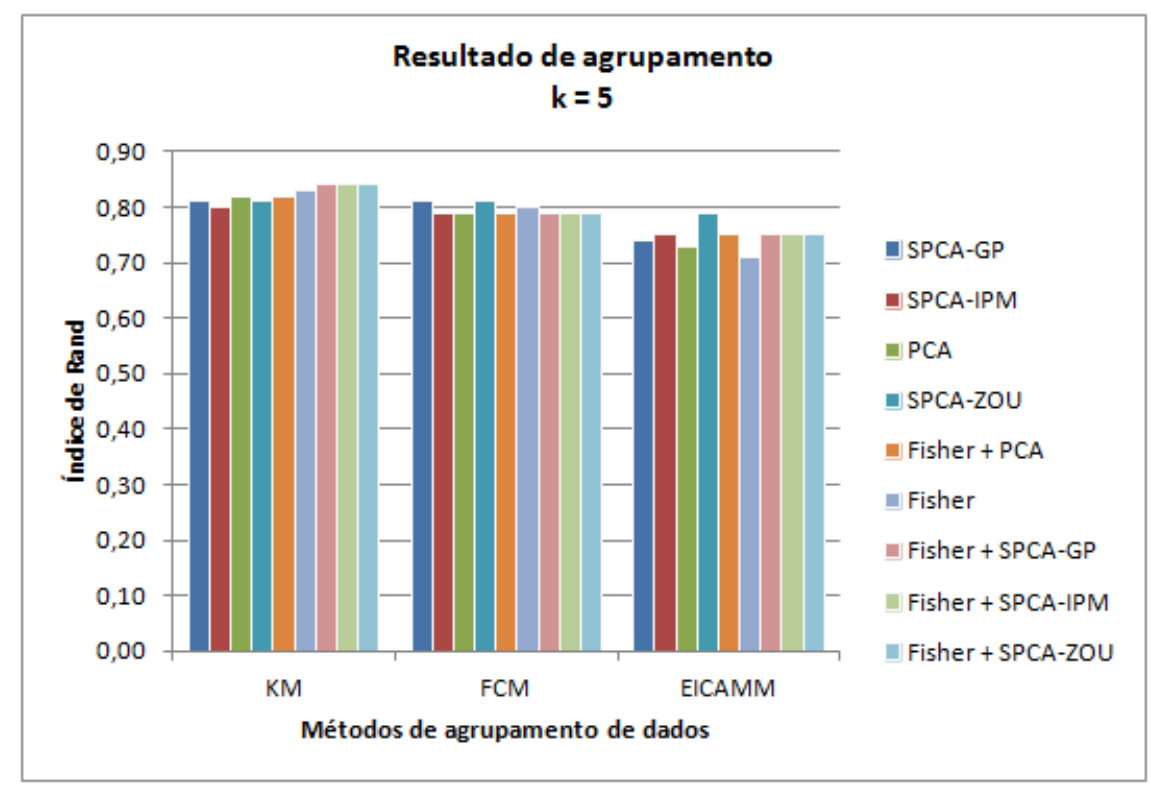

Figura 9 - Resultados de validação de agrupamentos obtidos pelas técnicas $k$-médias, FCM e EICAMM, para o conjunto PPAR $\delta$-1, no terceiro esquema de análise exploratória.

No terceiro experimento realizado sobre o conjunto de dados $\operatorname{PPAR} \delta$-1, o método $k$-médias apresentou o melhor índice de Rand com valor igual a 0,84 quando aplicadas, de forma combinada, três técnicas de redução de dimensionalidade: escore de Fisher e GP; escore de Fisher e IPM e escore de Fisher e SPCA-ZOU. Para essas combinações de 
técnicas, também foram analisados o número de variáveis selecionadas com a técnica de escore de Fisher e o número de coeficientes não nulos encontrados pela técnica SPCA, conforme apresentado a seguir:

- Escore de Fisher e GP: Em primeiro lugar, foram selecionadas 522 variáveis pelo escore de Fisher. Após a seleção dessas variáveis, o conjunto de dados foi transformado empregando a técnica GP e foram selecionadas 2 PC's, com retenção de $67,8 \%$ da variabilidade do conjunto gerado com a seleção de Fisher. Além disso, na primeira componente principal esparsa foram computados 494 coeficientes não nulos, sendo que o parâmetro de esparsidade utilizado na transformação pela técnica GP foi igual a 0,11 ;

- Escore de Fisher e IPM: Em primeiro lugar, foram selecionadas 401 variáveis pelo escore de Fisher. Após a seleção dessas variáveis, o conjunto de dados foi transformado empregando a técnica IPM e foram selecionadas 30 PC's, com retenção de $100 \%$ da variabilidade do conjunto gerado com a seleção de Fisher. Além disso, na primeira componente principal esparsa foram computados 259 coeficientes não nulos, sendo que o parâmetro de esparsidade utilizado na transformação pela técnica GP foi igual a 0,21 ;

- Escore de Fisher e SPCA-ZOU: Em primeiro lugar, foram selecionadas 455 variá-veis pelo escore de Fisher. Após a seleção dessas variáveis, o conjunto de dados foi transformado empregando a técnica SPCA-ZOU e foram selecionadas 2 PC's, com retenção de $74 \%$ da variabilidade do conjunto gerado com a seleção de Fisher. Além disso, na primeira componente principal esparsa foram computados 452 coeficientes não nulos, sendo que o parâmetro de esparsidade utilizado na transformação pela técnica GP foi igual a 0,06;

A partir do melhor resultado de agrupamento obtido, foi realizada uma análise gráfica, conforme apresentado e discutido na próxima seção.

\subsubsection{Análise gráfica dos resultados}

A fim de interpretar graficamente os resultados de agrupamento do conjunto de dados $\operatorname{PPAR} \delta$-1, foi realizada a projeção destes no espaço bidimensional sendo estes rotulados com cores diferentes para cada grupo encontrado. Para isso, foram utilizadas as duas componentes principais obtidas por meio da técnica PCA na projeção dos dados, conforme ilustra a Figura 10(a). 


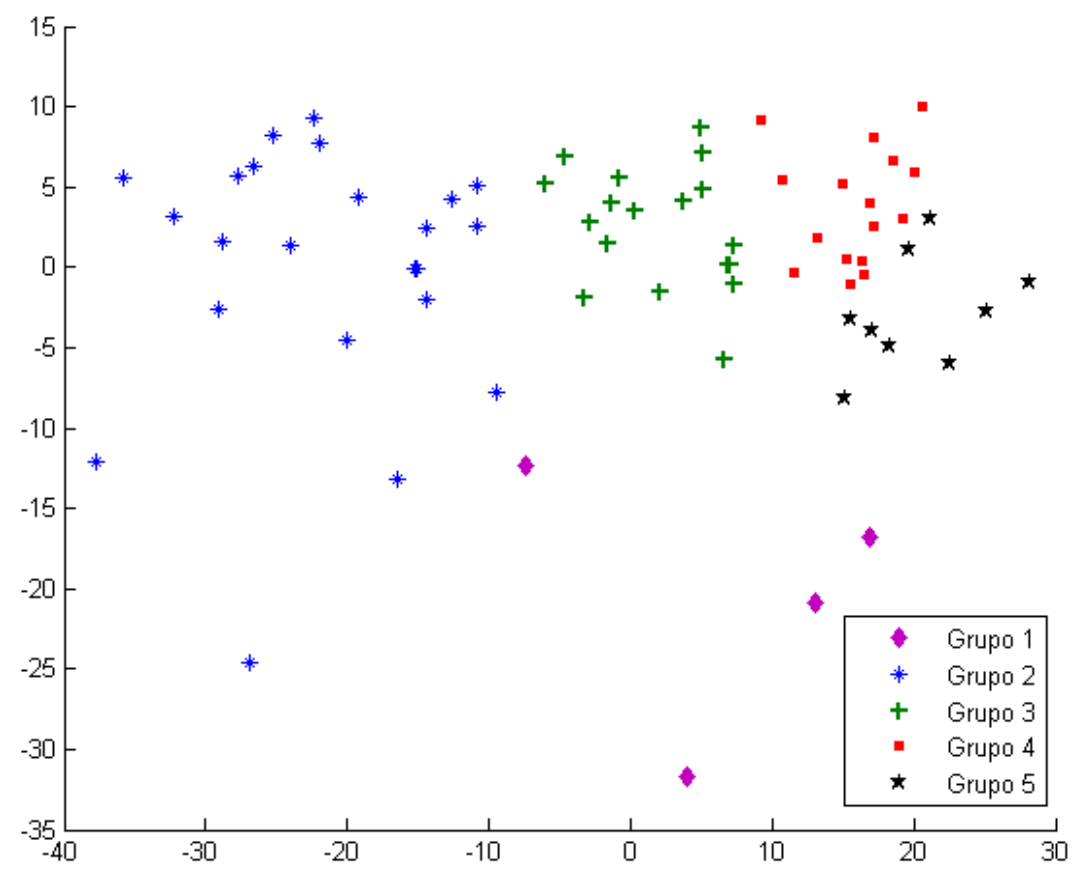

(a)

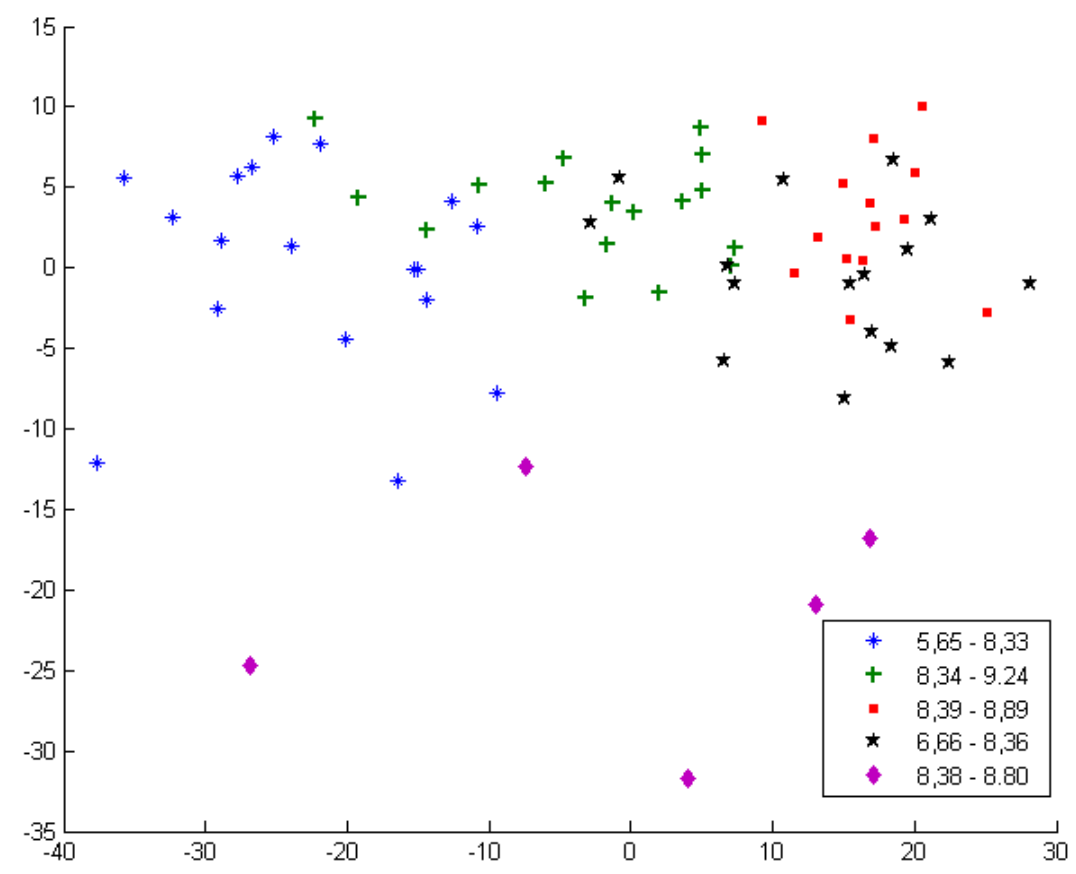

(b)

Figura 10 - Resultados de agrupamento obtidos pelo método k-médias em combinação com as técnicas escore de Fisher e GP, escore de Fisher e IPM e escore de Fisher e SPCA-ZOU: (a) Visualização dos resultados de agrupamento obtidos com o algoritmo k-médias; (b) Visualização dos dados de acordo com o nível de atividade biológica definido pelo especialista no domínio. 
Com o objetivo de validar visualmente os grupos encontrados, foram também projetados os dados tendo como rótulo cores que variam de acordo com o nível de atividade biológica previamente observada, conforme é apresentado na Figura 10(b). Parâmetros estatísticos sobre os grupos projetados nas Figuras 10(a) e 10(b) são apresentados na Tabela 5. Nota-se que as estimativas obtidas para o método de agrupamento aproximam-se daquelas observadas previamente pelos diferentes níveis de atividade biológica no conjunto de dados definidos pelo especialista de domínio.

Tabela 5 - Parâmetros estatísticos de atividade biológica dos grupos rotulados pelo algoritmo k-médias, para o conjunto de dados PPAR $\delta-1$.

\begin{tabular}{|c|c|c|c|c|}
\hline \multirow[t]{2}{*}{ Grupo } & \multicolumn{2}{|c|}{$\begin{array}{l}\text { Grupos obtidos pelo algo- } \\
\text { ritmo } k \text {-médias }\end{array}$} & \multicolumn{2}{|c|}{$\begin{array}{l}\text { Grupos selecionados por } \\
\text { níveis de atividade biológica }\end{array}$} \\
\hline & Média & Desvio padrão & Média & Desvio padrão \\
\hline Grupo $1 \diamond$ & 8,57 & 0,15 & 8,53 & 0,16 \\
\hline Grupo $2 *$ & 7,85 & 0,68 & 7,68 & 0,66 \\
\hline Grupo $3+$ & 8,49 & 0,61 & 8,72 & 0,22 \\
\hline Grupo $4 \square$ & 8,45 & 0,25 & 8,57 & 0,15 \\
\hline Grupo $5 \star$ & 8,07 & 0,45 & 7,92 & 0,48 \\
\hline
\end{tabular}

Pode-se observar que no terceiro experimento realizado, foi possível obter bons resultados na análise do conjunto de dados $\operatorname{PPAR} \delta$-1. Foi verificado que o aumento no número de grupos e as novas combinações das técnicas de redução de dimensionalidade influenciaram positivamente o processo de agrupamento, em especial o desempenho do algoritmo $k$-médias. Foi perceptível também que a aplicação das técnicas SPCA na transformação dos dados químicos resultou em um desempenho melhor do que o obtido empregando a técnica PCA, justificando o uso das mesmas no esquema de análise exploratória.

Por fim, o modelo obtido na terceira avaliação pode ser empregado para predizer a classe de novos compostos com atividade desconhecida, além de ser empregado como filtro na triagem de novas substâncias com atividade biológica relacionada às doenças DM e SM. Devido aos bons resultados obtidos sobre o conjunto de dados PPAR $\delta$ - 1 , foram realizados experimentos utilizando outros conjuntos de compostos com as mesmas características desse conjunto. A seguir, serão apresentados os experimentos conduzidos sobre o conjunto de dados $\operatorname{PPAR} \delta-2$. 


\subsection{Experimentos com o conjunto de dados PPAR $\delta$-2}

Nos experimentos realizados sobre o conjunto de dados PPAR $\delta$-2 (121 observações e 653 atributos), foram aplicadas todas as técnicas de redução de dimensionalidade discutidas no Capítulo 3. O esquema de análise exploratória utilizado foi o mesmo descrito no terceiro experimento realizado sobre o conjunto de dados PPAR $\delta$-1 (ver Figura 8, Seção $5.2 .3)$.

Para execução desses experimentos, foram realizadas variações nos parâmetros das técnicas de redução de dimensionalidade. No caso da técnica de escore de Fisher, foram selecionadas variáveis com valor de peso maior do que o critério de peso determinado pelos especialistas de domínio. Tal critério variou entre 0,2 e 2. Em relação às técnicas de análise SPCA, foi realizada a transformação do conjunto de dados variando o nível de esparsidade $(\gamma)$ no intervalo entre 0 e 0,5. Além disso, para as técnicas PCA e SPCA, foram realizadas também variações no número de componentes principais (PC's) no intervalo entre 2 e 30 .

Os conjuntos de dados obtidos com todas as variações de parâmetros das técnicas SPCA e PCA foram apresentados aos algoritmos de agrupamento $k$-médias, FCM e EICAMM. Para execução desses algoritmos, foram realizadas alterações no número de grupos, sendo que os melhores resultados foram obtidos com o número de grupos igual a 4 $(k=4)$. No caso do algoritmo FCM, além do número de grupos, foi determinado o índice de fuzzyficação igual a $2(m=2)$ e número de iterações igual a 100. Para o algoritmo EICAMM, foram realizadas variações na taxa de aprendizado no intervalo entre 0 e 0,8 , número de iterações igual a 400 e critério de convergência da log verossimilhança igual a 0,0001 .

Com as partições definidas pelos algoritmos de agrupamento, seguiu-se para a etapa de validação dos resultados a partir do cálculo do índice de Rand. Para o cálculo desse índice, foi utilizada a partição definida pelo especialista de domínio, com base nos valores de atividade biológica apresentados na Tabela 2 (ver Capítulo 2). Os melhores índices de Rand obtidos pelas técnicas de agrupamento em combinação com os métodos de redução de dimensionalidade, considerando-se aqui todas as variações de parâmetros testados, são apresentados na Figura 11. 


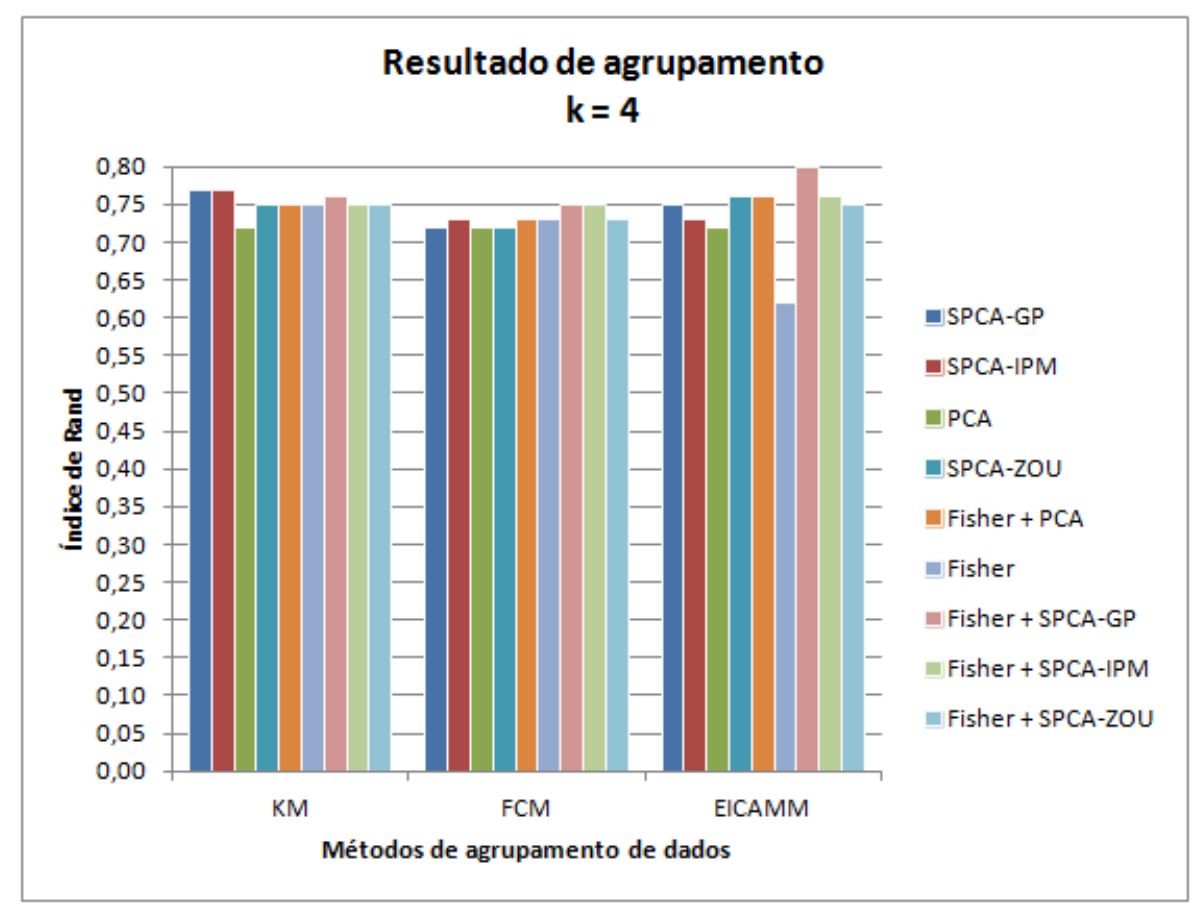

Figura 11 - Resultados de validação de agrupamentos obtidos pelas técnicas $k$-médias, FCM e EICAMM, para o conjunto PPAR $\delta$-2, após aplicação do terceiro esquema de análise exploratória (descrito na Seção 5.2.3).

No conjunto de dados PPAR $\delta$-2, o método EICAMM apresentou o melhor índice de Rand, com valor igual a 0,80. Nesse caso, a técnica de redução de dimensionalidade utilizada combinou o escore de Fisher e a análise esparsa GP. Inicialmente, foram selecionadas 239 variáveis a partir de valores de escore de Fisher e, com a transformação realizada pela técnica GP, foram geradas 2 componentes principais (para um valor de parâmetro de esparsidade igual a 0,36 ) e que reteve $84 \%$ da variabilidade do conjunto reduzido com a técnica de escore de Fisher. O número de coeficientes não nulos na primeira componente principal esparsa foi igual a 239.

A partir do melhor resultado obtido, foi realizada uma análise gráfica, conforme apresentado e discutido na próxima seção.

\subsubsection{Análise gráfica dos resultados}

A fim de interpretar graficamente os resultados de agrupamento do conjunto de dados $\operatorname{PPAR} \delta$-2, foi realizada a projeção destes no espaço bidimensional sendo estes rotulados com cores diferentes para cada grupo encontrado. Para isso, foram utilizadas as duas componentes principais obtidas por meio da técnica PCA na projeção dos dados, conforme ilustra a Figura 12(a). 


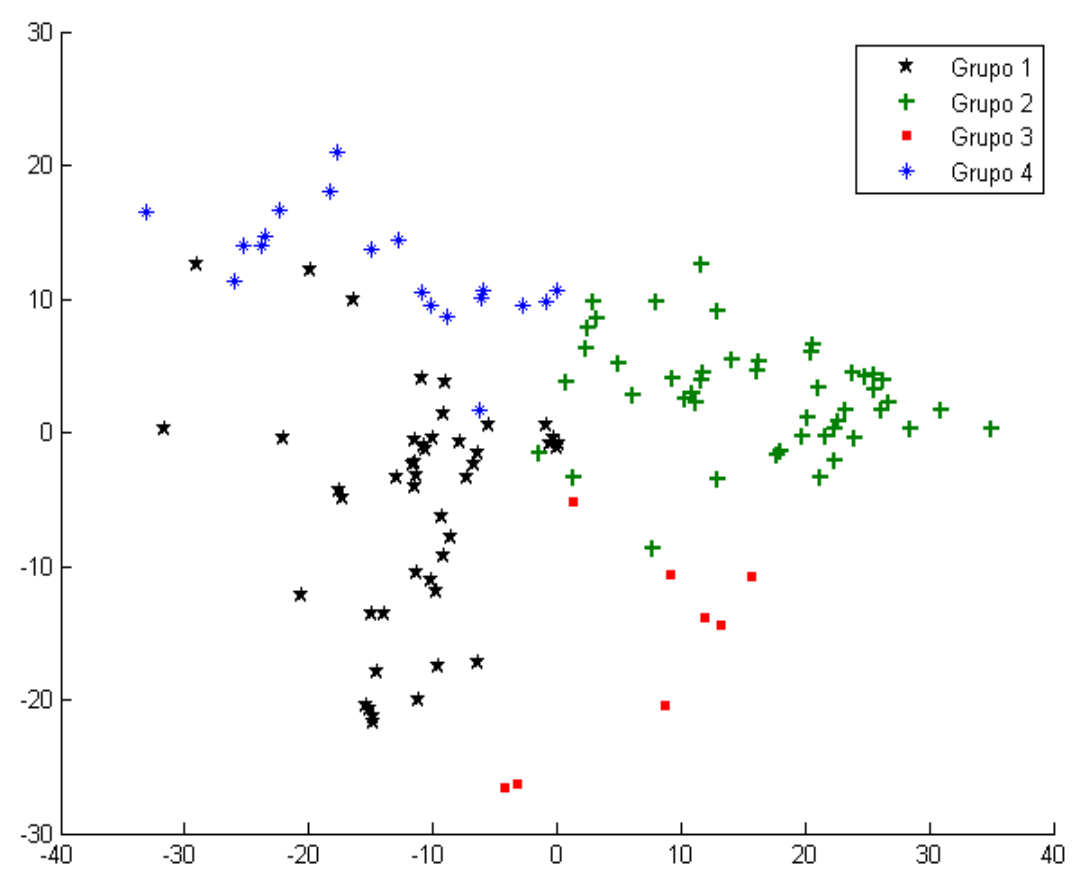

(a)

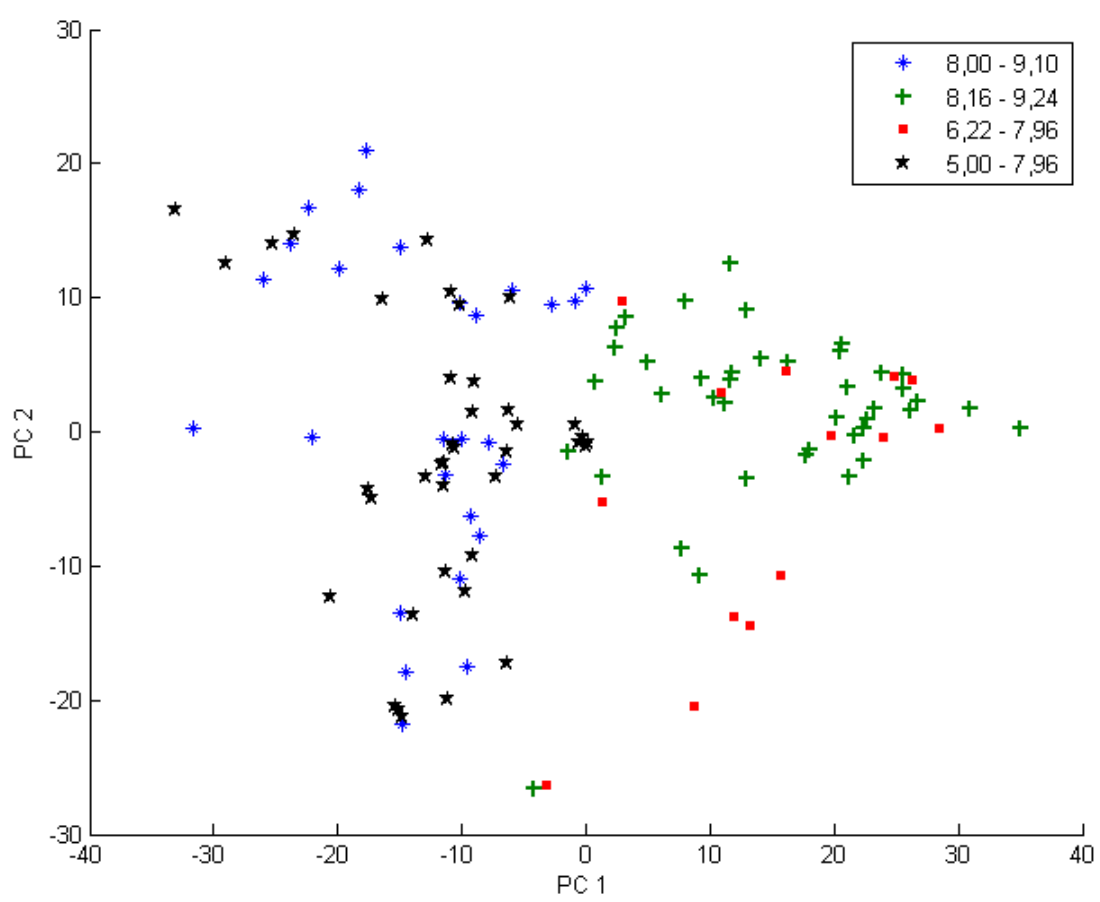

(b)

Figura 12 - Resultados de agrupamento obtidos pelo método EICAMM em combinação com as técnicas de escore de Fisher e GP, para o conjunto PPARס-2: (a) Visualização dos resultados de agrupamento; (b) Visualização dos dados de acordo com o nível de atividade biológica definido pelo especialista no dominio. 
Com o objetivo de validar os grupos encontrados, foram também projetados os dados tendo como rótulo cores que variam de acordo com o nível de atividade biológica previamente observada, conforme é apresentado na Figura 12(b). Parâmetros estatísticos sobre os grupos projetados nas Figuras 12(a) e 12(b) são apresentados na Tabela 6. É possível verificar que as estimativas obtidas para o método de agrupamento aproximam-se dos resultados previamente observados pelo especialista de domínio, conforme apresentado na Figura 12(b).

Tabela 6 - Parâmetros estatísticos de atividade biológica dos grupos rotulados pelo algoritmo EICAMM e observados pelo especialista de domínio, para o conjunto de dados PPAR $\delta$-2.

\begin{tabular}{|c|c|c|c|c|}
\hline \multirow[t]{2}{*}{ Grupo } & \multicolumn{2}{|c|}{$\begin{array}{l}\text { Grupos obtidos pelo algo- } \\
\text { ritmo EICAMM }\end{array}$} & \multicolumn{2}{|c|}{$\begin{array}{l}\text { Grupos selecionados por } \\
\text { níveis de atividade biológica }\end{array}$} \\
\hline & Média & Desvio padrão & Média & Desvio padrão \\
\hline Grupo $1 \star$ & 7,35 & 1,00 & 6,95 & 0,95 \\
\hline Grupo $2+$ & 8,39 & 0,47 & 8,55 & 0,24 \\
\hline Grupo $3 \mathbf{\square}$ & 7,51 & 0,59 & 7,42 & 0,56 \\
\hline Grupo $4 *$ & 7,85 & 0,68 & 8,42 & 0,29 \\
\hline
\end{tabular}

Pode-se observar que no experimento realizado, foi possível obter bons resultados na análise do conjunto de dados $\operatorname{PPAR} \delta$-2. O número de grupos e as combinações das técnicas de redução de dimensionalidade influenciaram positivamente o processo de agrupamento, em especial o desempenho do algoritmo EICAMM. Foi perceptível também que a aplicação das técnicas SPCA para transformação dos dados químicos resultou em um desempenho melhor do que o obtido empregando a técnica PCA, justificando o uso das mesmas no esquema de análise exploratória.

Por fim, o modelo obtido pode ser, possivelmente, empregado para predizer a classe de novos compostos com atividade desconhecida, além de ser empregado como filtro na triagem de novas substâncias com atividade biológica relacionada às doenças DM e SM. Devido aos bons resultados obtidos sobre o conjunto de dados PPAR $\delta$-2, foram conduzidos os experimentos sobre o conjunto de dados AT1, conforme descrito na próxima seção. 


\subsection{Experimentos com o conjunto de dados AT1}

Assim como nos experimentos descritos anteriormente, foram aplicadas todas as técnicas de redução de dimensionalidade discutidas no Capítulo 3 para a análise exploratória do conjunto de dados AT1 (59 observações e 1721 atributos). O esquema utilizado foi o mesmo descrito no terceiro experimento realizado sobre o conjunto de dados $\operatorname{PAAR} \delta-1$ (ver Figura 8, Seção 5.2.3).

Para execução desses experimentos, foram realizadas variações nos parâmetros das técnicas de redução de dimensionalidade. No caso da técnica de escore de Fisher, foram selecionadas variáveis com valor de peso maior do que o critério de peso determinado pelos especialistas de domínio. Tal critério variou entre 0,2 e 2. Em relação às técnicas de análise SPCA, foi realizada a transformação do conjunto de dados variando o nível de esparsidade $(\gamma)$ no intervalo entre 0 e 0,8. Além disso, para as técnicas PCA e SPCA, foram realizadas também variações no número de componentes principais (PC's) no intervalo entre 2 e 20 .

Os conjuntos de dados obtidos com todas as variações de parâmetros das técnicas SPCA e PCA foram apresentados aos algoritmos de agrupamento $k$-médias, FCM e EICAMM. Para execução desses algoritmos, foram realizadas alterações no número de grupos, sendo que os melhores resultados foram obtidos com o número de grupos igual a 4 $(k=4)$. No caso do algoritmo FCM, além do número de grupos, foi determinado o índice de fuzzyficação igual a $2(m=2)$ e número de iterações igual a 100. Para o algoritmo EICAMM, foram realizadas variações na taxa de aprendizado no intervalo entre 0 e 0,8 , número de iterações igual a 400 e critério de convergência da log verossimilhança igual a 0,0001 .

Com as partições definidas pelos algoritmos de agrupamento, seguiu-se para a etapa de validação dos resultados por meio do índice de Rand. Para o cálculo desse índice, foi utilizada a partição definida pelo especialista de domínio, com base nos valores de atividade biológica apresentados na Tabela 3 (ver Capítulo 2). Os melhores índices de Rand obtidos pelas técnicas de agrupamento em combinação com os métodos de redução de dimensionalidade, considerando todas as variações de parâmetros testadas, são apresentados na Figura 13. 


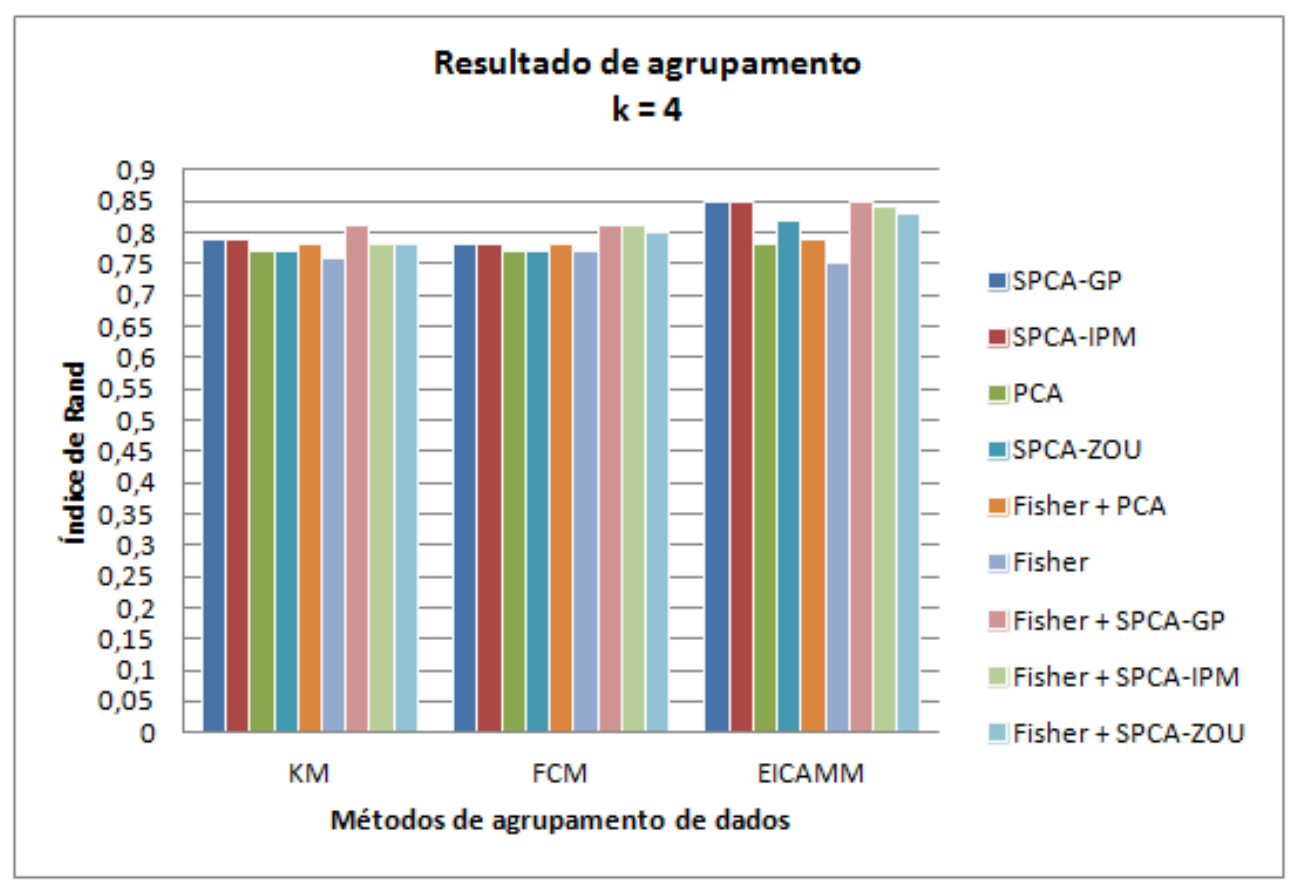

Figura 13 - Resultados de validação de agrupamentos obtidos pelas técnicas k-médias, FCM e EICAMM, para o conjunto AT1, após aplicação do terceiro esquema de análise exploratória (descrito na Seção 5.2.3).

No experimento realizado sobre o conjunto de dados AT1, o método EICAMM apresentou o melhor índice de Rand com valor igual a 0,84, quando aplicadas três técnicas de redução de dimensionalidade: GP, IPM e escore de Fisher combinado com GP. Para essas técnicas, foi analisado o número de variáveis utilizadas, conforme apresentado a seguir:

- Técnica de análise esparsa GP: Para o conjunto de dados quando empregando a técnica GP, foram selecionadas 2 PC's, com retenção de 55,83\% da variabilidade do conjunto de dados original. Além disso, na primeira componente principal esparsa foram computados 1228 coeficientes não nulos, sendo que o parâmetro de esparsidade utilizado na transformação pela técnica GP foi igual a 0,2 ;

- Técnica de análise esparsa IPM: Para o conjunto de dados transformado empregando a técnica IPM, foram selecionadas 2 PC's, com retenção de 46,36\% da variabilidade do conjunto de dados original. Além disso, na primeira componente principal esparsa foram computados 759 coeficientes não nulos, sendo que o parâmetro de esparsidade utilizado na transformação pela técnica GP foi igual a 0,1;

- Escore de Fisher e GP: Em primeiro lugar, foram selecionadas 998 variáveis pelo escore de Fisher. Após a seleção dessas variáveis, o conjunto de dados foi transformado empregando a técnica GP e foram selecionadas 14 PC's, com retenção de 
$62 \%$ da variabilidade do conjunto gerado com a seleção a partir do escore de Fisher. Além disso, na primeira componente principal esparsa foram computados 828 coeficientes não nulos, sendo que o parâmetro de esparsidade utilizado na transformação pela técnica GP foi igual a 0,56.

A partir do melhor resultado de agrupamento obtido, foi realizada uma análise gráfica dos resultados, conforme apresentado e discutido na próxima seção.

\subsubsection{Análise gráfica dos resultados}

Com o intuito de interpretar graficamente os resultados de agrupamento do conjunto de dados AT1, foi realizada a projeção destes no espaço bidimensional sendo estes rotulados com cores diferentes para cada grupo encontrado. Para isso, foram utilizadas as duas componentes principais obtidas por meio da técnica PCA na projeção dos dados, conforme ilustra a Figura 14(a). 


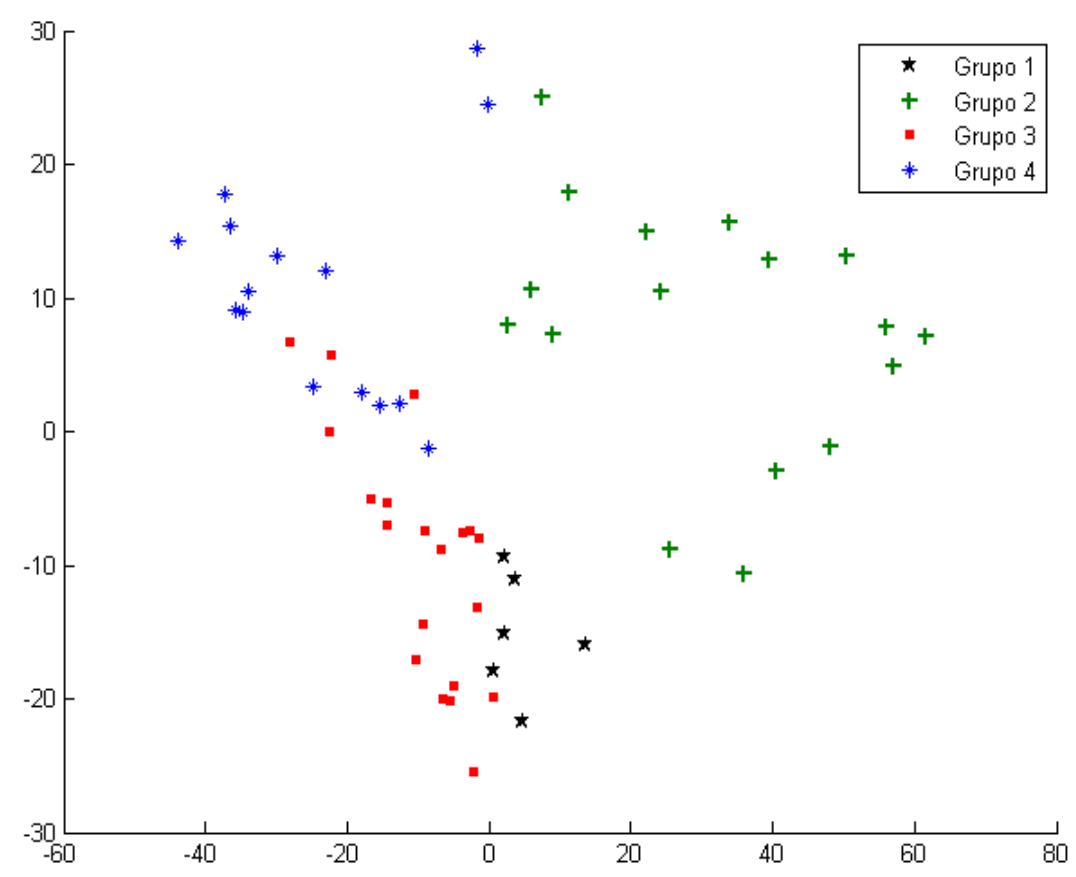

(a)

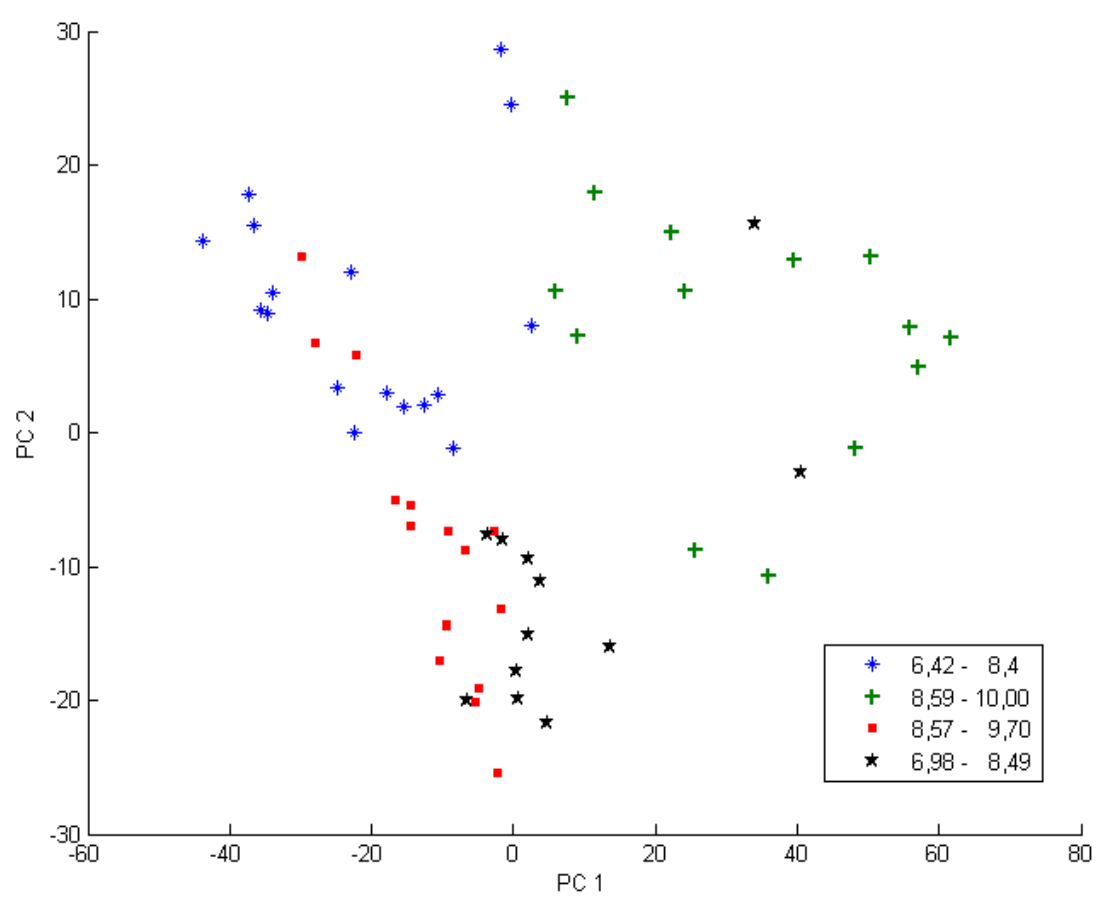

(b)

Figura 14 - Resultados de agrupamento obtidos pelo método EICAMM, para o conjunto AT1, em combinação com as técnicas GP, IPM e escore de Fisher e GP: (a) Visualização dos resultados de agrupamento; (b) Visualização dos dados de acordo com o nível de atividade biológica definido pelo especialista no dominio. 
Com o objetivo de validar os grupos encontrados, foram também projetados os dados tendo como rótulo cores que variam de acordo com o nível de atividade biológica previamente observada, conforme é apresentado na Figura 14(b). Parâmetros estatísticos sobre os grupos projetados nas Figuras 14(a) e 14(b) são apresentados na Tabela 7. As estimativas obtidas para o método de agrupamento aproximaram-se dos resultados previamente observados pelo especialista de domínio, conforme apresentado na Figura 14(b).

Tabela 7 - Parâmetros estatísticos de atividade biológica dos grupos rotulados pelo algoritmo EICAMM e observados pelo especialista de domínio, para o conjunto de dados AT1.

\begin{tabular}{|c|c|c|c|c|}
\hline \multirow[t]{2}{*}{ Grupo } & \multicolumn{2}{|c|}{$\begin{array}{l}\text { Grupos obtidos pelo algo- } \\
\text { ritmo EICAMM }\end{array}$} & \multicolumn{2}{|c|}{$\begin{array}{l}\text { Grupos selecionados por } \\
\text { níveis de atividade biológica }\end{array}$} \\
\hline & Média & Desvio padrão & Média & Desvio padrão \\
\hline Grupo $1 \star$ & 7,45 & 0,42 & 7,69 & 0,47 \\
\hline Grupo $2+$ & 9,14 & 0,67 & 9.36 & 0,53 \\
\hline Grupo $3 \mathbf{\square}$ & 8,73 & 0,67 & 9,07 & 0,32 \\
\hline Grupo $4 *$ & 7,64 & 0,65 & 7,63 & 0,59 \\
\hline
\end{tabular}

Pode-se observar que no experimento realizado, foi possível obter bons resultados na análise do conjunto de dados AT1. O número de grupos e as combinações das técnicas de redução de dimensionalidade influenciaram positivamente o processo de agrupamento, em especial o desempenho do algoritmo EICAMM. Foi perceptível também que a aplicação das técnicas SPCA para a transformação dos dados químicos resultou em um desempenho melhor do que o obtido empregando a técnica PCA, justificando o uso das mesmas no esquema de análise exploratória.

Um caso especial é observado nos resultados obtidos sobre o conjunto AT1 (Figura 13). A transformação empregando somente as técnicas SPCA (GP e IPM) produziu resultados semelhantes à combinação dos métodos do escore de Fisher e GP. Esse resultado sugere que, mesmo sem a rotulação prévia dos dados para seleção de variáveis, a redução realizada por meio das técnicas SPCA resultou no bom desempenho do algoritmo de agrupamento EICAMM.

Por fim, o modelo obtido pode ser empregado para predizer a classe de novos compostos com atividade desconhecida, além de ser empregado como filtro na triagem de novas substâncias com atividade biológica relacionada às doenças cardiovasculares. Devido aos bons resultados obtidos sobre o conjunto de dados AT1, também foram conduzidos expe- 
rimentos sobre o conjunto de dados TGF, conforme discutido na próxima seção.

\subsection{Experimentos com o conjunto de dados TGF $\beta$}

Assim como nos experimentos descritos anteriormente, foram aplicadas todas as técnicas de redução de dimensionalidade discutidas no Capítulo 3 para a análise exploratória do conjunto de dados TGF $\beta$ (contendo 59 observações e 1719 atributos). O esquema utilizado foi o mesmo descrito no terceiro experimento realizado sobre o conjunto de dados $\operatorname{PPAR} \delta$-1 (ver Figura 8, Seção 5.2.3).

Para execução desses experimentos, foram realizadas variações nos parâmetros das técnicas de redução de dimensionalidade. No caso da técnica de escore de Fisher, foram selecionadas variáveis com valor de peso maior do que o critério de peso determinado pelos especialistas de domínio. Tal critério variou entre 0,2 e 2. Em relação às técnicas de análise SPCA, foi realizada a transformação do conjunto de dados variando o nível de esparsidade $(\gamma)$ no intervalo entre 0 e 0,8. Além disso, para as técnicas PCA e SPCA, foram realizadas também variações no número de componentes principais (PC's) no intervalo entre 2 e 30 .

Os conjuntos de dados obtidos com todas as variações de parâmetros das técnicas SPCA e PCA foram apresentados aos algoritmos de agrupamento $k$-médias, FCM e EICAMM. Para execução desses algoritmos, foram realizadas alterações no número de grupos, sendo que os melhores resultados foram obtidos com o número de grupos igual a 5 $(k=5)$. No caso do algoritmo FCM, além do número de grupos, foi determinado o índice de fuzzyficação igual a $2(m=2)$ e número de iterações igual a 100. Para o algoritmo EICAMM, foram realizadas variações na taxa de aprendizado no intervalo entre 0 e 0,9 , número de iterações igual a 400 e critério de convergência da log verossimilhança igual a 0,0001 .

Com as partições definidas pelos algoritmos de agrupamento, seguiu-se para a etapa de validação dos resultados a partir do cálculo do índice de Rand. Para o cálculo desse índice, foi utilizada a partição definida pelo especialista de domínio, com base nos valores de atividade biológica apresentados na Tabela 4 (ver Capítulo 2). Os melhores índices de Rand obtidos pelas técnicas de agrupamento em combinação com os métodos de redução de dimensionalidade, considerando-se aqui todas as variações de parâmetros testados, são apresentados na Figura 15. 


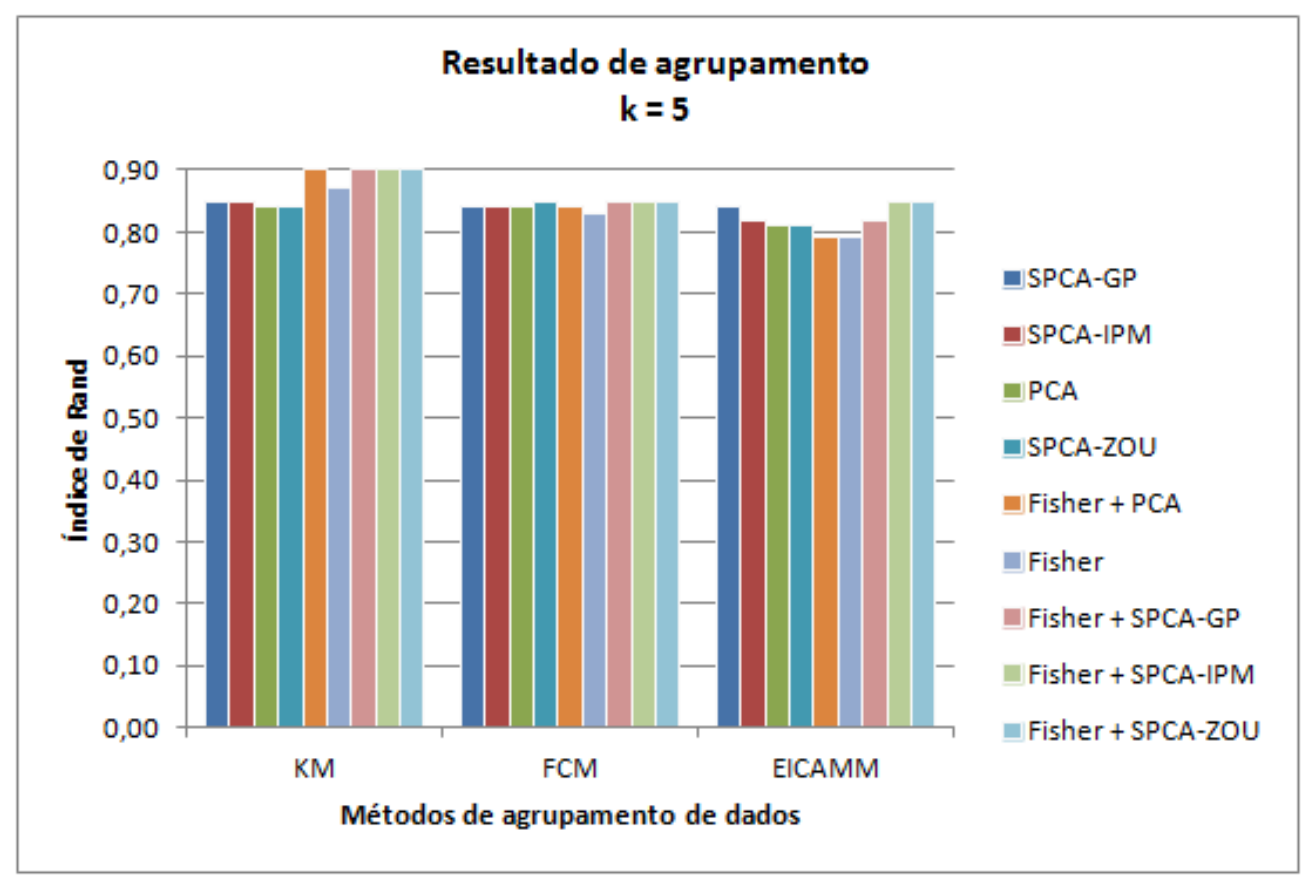

Figura 15 - Resultados de validação de agrupamentos obtidos pelas técnicas $k$-médias, FCM e EICAMM, para o conjunto TGFß, após aplicação do esquema de análise exploratória (descrito na Seção 5.2.3).

No experimento realizado sobre o conjunto de dados TGF $\beta$, o método $k$-médias apresentou o melhor índice de Rand com valor igual a 0,90, quando aplicadas, de forma combinada, quatro técnicas de redução de dimensionalidade: escore de Fisher e PCA; escore de Fisher e GP; escore de Fisher e IPM e escore de Fisher e SPCA-ZOU. Para essas combinações de técnicas, também foram analisados o número de variáveis selecionadas com a técnica de escore de Fisher e o número de coeficientes não nulos encontrados pela técnica SPCA, conforme apresentado a seguir:

- Escore de Fisher e PCA: Em primeiro lugar, foram selecionadas 626 variáveis pelo escore de Fisher. Após a seleção dessas variáveis, o conjunto de dados foi transformado empregando a técnica PCA e foram selecionadas 28 PC's, com retenção de 99\% da variabilidade do conjunto gerado com a seleção por meio do escore de Fisher;

- Escore de Fisher e GP: Para essa combinação de técnicas, foram selecionadas, inicialmente, 626 variáveis a partir do valor do escore de Fisher. Após a seleção dessas variáveis, o conjunto de dados foi transformado empregando a técnica GP e foram selecionadas 26 PC's, com retenção de $96 \%$ da variabilidade do conjunto gerado com a seleção do escore de Fisher. Além disso, na primeira componente principal esparsa foram computados 619 coeficientes não nulos, sendo que o parâmetro de esparsidade utilizado na transformação pela técnica GP foi igual a 0,11; 
- Escore de Fisher e IPM: Inicialmente, foram selecionadas 626 variáveis a partir do escore de Fisher. Após a seleção dessas variáveis, o conjunto de dados foi transformado empregando a técnica IPM e foram selecionadas 18 PC's, com retenção de 99\% da variabilidade do conjunto gerado com a seleção a partir do escore de Fisher. Além disso, na primeira componente principal esparsa foram computados 616 coeficientes não nulos, sendo que o parâmetro de esparsidade utilizado na transformação pela técnica IPM foi igual a 0,06 ;

- Escore de Fisher e SPCA-ZOU: No caso dessa técnica, foram previamente selecionadas 626 variáveis pelo escore de Fisher. Após a seleção dessas variáveis, o conjunto de dados foi transformado empregando a técnica SPCA-ZOU e foram selecionadas 16 PC's, com retenção de $97 \%$ da variabilidade do conjunto gerado com a seleção a partir do escore de Fisher. Além disso, na primeira componente principal esparsa foram computados 619 coeficientes não nulos, sendo que o parâmetro de esparsidade utilizado na transformação pela técnica GP foi igual a 0,36;

A partir dos melhores resultados de agrupamento obtidos, foi realizada uma análise gráfica, conforme apresentado e discutido na próxima seção.

\subsubsection{Análise gráfica dos resultados}

A fim de interpretar graficamente os resultados de agrupamento do conjunto de dados $\operatorname{TGF} \beta$, foi realizada a projeção destes no espaço bidimensional sendo estes rotulados com cores diferentes para cada grupo encontrado. Para isso, foram utilizadas as duas componentes principais obtidas por meio da técnica PCA na projeção dos dados, conforme ilustra a Figura 16(a). 


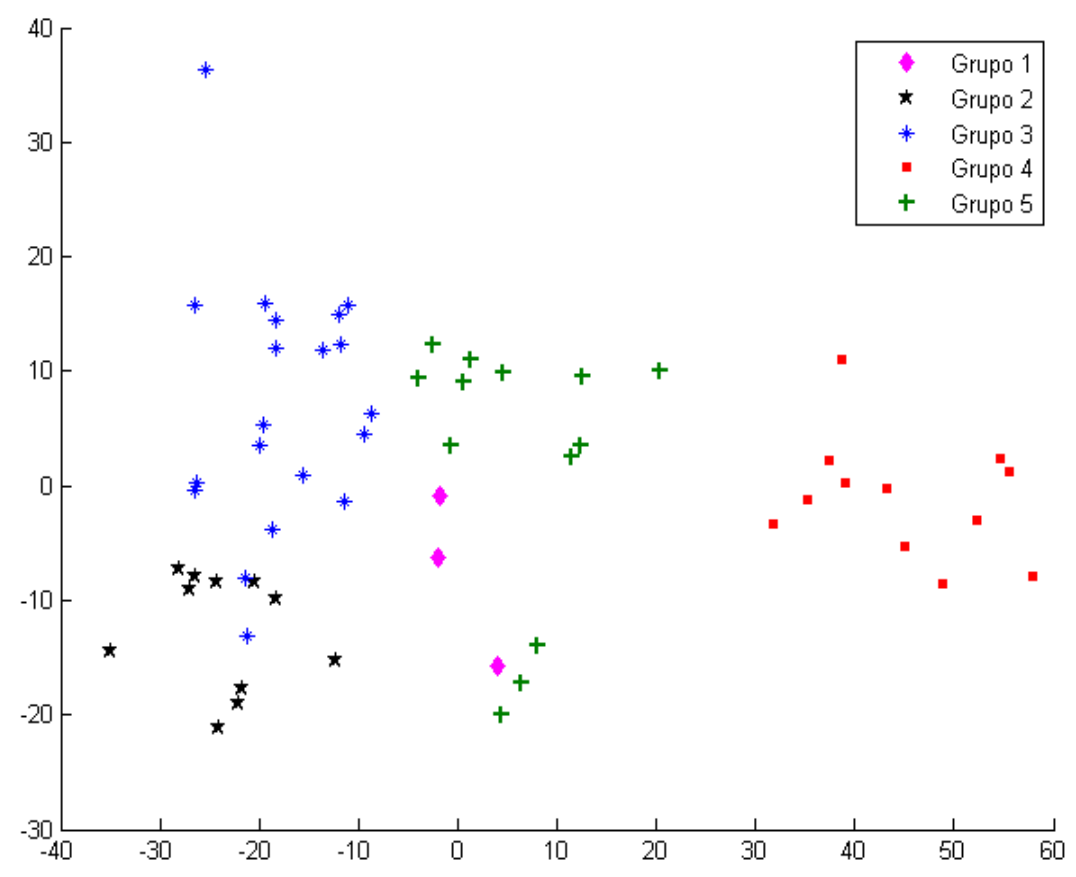

(a)

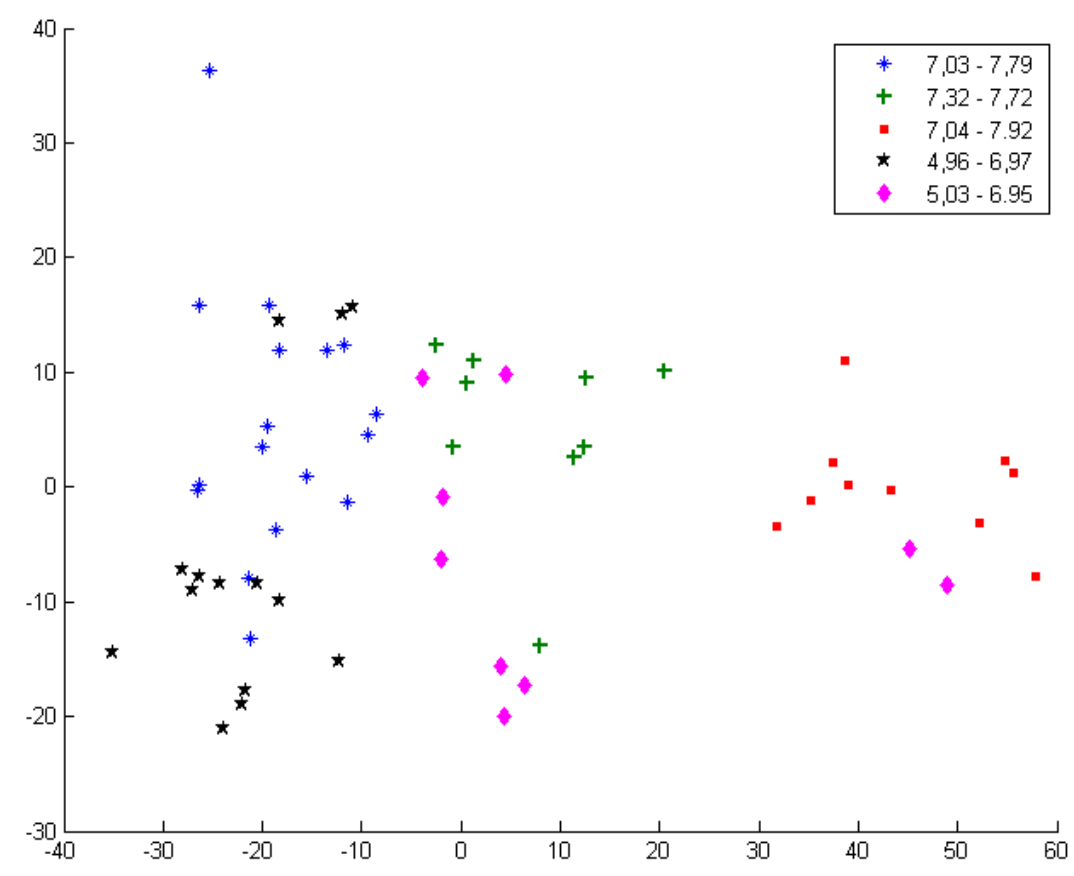

(b)

Figura 16 - Resultados de agrupamento obtidos pelo método k-médias em combinação com as técnicas escore de Fisher e PCA, escore de Fisher e GP, escore de Fisher e IPM e escore de Fisher e SPCA-ZOU, para o conjunto TGF : (a) Visualização dos resultados de agrupamento; (b) Visualização dos dados de acordo com o nível de atividadde biológica definido pelo especialista no dominio. 
Com o objetivo de validar os grupos encontrados, foram também projetados os dados tendo como rótulo cores que variam de acordo com o nível de atividade biológica previamente observada, conforme é apresentado na Figura 16(b). Parâmetros estatísticos sobre os grupos projetados nas Figuras 16(a) e 16(b) são apresentados na Tabela 8. É perceptível que as estimativas obtidas para o método de agrupamento aproximam-se daquelas observadas pelo especialista de domínio.

Tabela 8 - Parâmetros estatísticos de atividade biológica dos grupos rotulados pelo algoritmo k-médias e observados pelo especialista de dominio, para o conjunto de dados TGF $\beta$

\begin{tabular}{c|cc|lc}
\hline \multirow{2}{*}{ Grupo } & \multicolumn{2}{|l|}{$\begin{array}{l}\text { Grupos obtidos pelo algo- } \\
\text { ritmo } \boldsymbol{k} \text {-médias }\end{array}$} & $\begin{array}{l}\text { Grupos } \\
\text { níveis de atividade biológica }\end{array}$ \\
\cline { 2 - 5 } & Média & Desvio padrão & Média & Desvio padrão \\
\hline Grupo $1 \bullet$ & 5,96 & 0,46 & 6,35 & 0,69 \\
Grupo $2 \star$ & 5,60 & 0,52 & 5,87 & 0,72 \\
Grupo $3 *$ & 7,40 & 0,29 & 7,50 & 0,20 \\
Grupo 4 & 7,40 & 0,30 & 7,50 & 0,30 \\
Grupo $5+$ & 7,17 & 0,73 & 7,55 & 0,12 \\
\hline
\end{tabular}

Pode-se observar que no experimento realizado, foi possível obter bons resultados na análise do conjunto de dados TGF $\beta$. O número de grupos e as combinações das técnicas de redução de dimensionalidade influenciaram positivamente o processo de agrupamento, em especial o desempenho do algoritmo $k$-médias. É possível também que a aplicação das técnicas SPCA para transformação dos dados químicos resultou em um desempenho semelhante ao obtido empregando a técnica PCA, justificando o uso das mesmas no esquema de análise exploratória. Por fim, o modelo obtido pode ser empregado para predizer a classe de novos compostos com atividade desconhecida, além de ser empregado como filtro na triagem de novas substâncias com atividade biológica relacionadas ao tratamento do câncer.

\subsection{Considerações finais}

Neste capítulo, foram discutidos os experimentos realizados empregando os métodos de redução de dimensionalidade e de agrupamento na análise de dados de QM. Em primeira instância, foram realizados três experimentos sobre o conjunto de dados PPAR $\delta-1$. 
O primeiro experimento apresentou o desempenho dos algoritmos de agrupamento para separação desse conjunto em duas classes, após obtenção de cinco derivações de dimensão reduzida. A combinação das técnicas de escore de Fisher e PCA resultou no melhor agrupamento de dados alcançado com o método EICAMM.

Logo após, na segunda análise do conjunto $\operatorname{PPAR} \delta$-1, foram empregadas as técnicas PCA e SPCA na etapa de redução de dimensionalidade, gerando resultados menos significativos em comparação ao primeiro experimento. Tal resultado já era esperado por conta da ausência de informação externa no processo de redução de dimensão dos dados. No terceiro experimento, foi realizada a comparação de desempenho dos algoritmos de agrupamento após a redução de dimensionalidade empregando todas as técnicas de redução de dimensionalidade descritas no Capítulo 3 (escore de Fisher, PCA e SPCA). Além disso, foi realizada uma variação no número de grupos contendo as observações do conjunto em estudo. Os resultados alcançados no terceiro experimento foram superiores aos obtidos anteriormente, sugerindo que além da redução de dimensionalidade, deve-se atentar para o número de grupos presentes no conjunto de dados.

A partir dos resultados obtidos no terceiro experimento realizado sobre o conjunto $\operatorname{PPAR} \delta$-1, procedeu-se com o estudo dos conjuntos $\operatorname{PPAR} \delta-2$, AT1 e TGF $\beta$, os quais possuem características semelhantes ao conjunto $\operatorname{PPAR} \delta-1$. Nesses dados foi possível verificar o bom desempenho dos algoritmos de redução de dimensionalidade e de agrupamento na análise dos mesmos.

Durante a realização dos experimentos, duas técnicas apresentaram os melhores resultados para o agrupamento dos dados: $k$-médias e EICAMM. Uma observação importante sobre o método $k$-médias é que a concepção desse algoritmo é mais simples quando comparado ao método EICAMM. Mesmo assim, na análise dos conjuntos PPAR $\delta$ - 1 e TGF $\beta$, os resultados obtidos pelo método $k$-médias foram relativamente melhores que o método EICAMM.

Quanto aos métodos de redução de dimensionalidade, as técnicas GP, IPM e escore de Fisher apresentaram bom desempenho na redução dos conjuntos de dados. Um caso que merece destaque foi a avaliação do conjunto AT1 em que os métodos de redução GP e IPM geraram resultados semelhantes ao método de redução combinando as técnicas escore de Fisher e GP. Por fim, os resultados obtidos após as análises desses conjuntos mostram a potencialidade de utilização dos métodos de redução de dimensionalidade e de agrupamento de dados para redução e definição de classe dos compostos. 


\section{Conclusões, Contribuições e Trabalhos Futuros}

Pesquisas realizadas na área de QM têm por objetivo compreender mecanismos de interação entre uma molécula e seu alvo biológico, a fim de propor novas substâncias químicas candidatas a medicamentos. Para isso, os pesquisadores são responsáveis por validar os alvos biológicos, descobrir e desenvolver um candidato a fármaco com melhor atividade biológica, assim como realizar testes biológicos em laboratório, entre outras atividades.

Dentre as diversas etapas existentes no processo de descoberta de novos medicamentos é discutida a análise SAR, apresentada no Capítulo 2. Nessa etapa, são aplicados diversos métodos computacionais para o estabelecimento das relações entre a estrutura química e a atividade biológica de uma série de moléculas.

Os conjuntos de dados analisados nas análises SAR são caracterizados por sua alta dimensionalidade, o que torna complexa a modelagem de fenômenos moleculares que constituem os processos bioquímicos. Por conta disso, faz-se necessária a aplicação de métodos para reduzir a dimensão dos conjuntos de dados e auxiliar o processo de análise. No Capítulo 3, foram apresentadas diversas abordagens para redução de dimensionalidade tais como as técnicas de escore de Fisher, PCA e variações da SPCA.

Além da redução de dimensionalidade, ainda há a necessidade de encontrar grupos de moléculas com atividade biológica distinta dentro dos conjuntos de dados em estudo. Por isso, no Capítulo 4, foram descritos os algoritmos de agrupamento de dados utilizados neste trabalho: $k$-médias, FCM e EICAMM.

As técnicas de redução de dimensionalidade e de agrupamento de dados foram combinadas gerando diversos esquemas de análise exploratória de dados, com o intuito de realizar a análise dos dados químicos de forma efetiva. O conjunto $\operatorname{PPAR} \delta-1$ foi o primeiro conjunto de dados em que tais esquemas de análise foram aplicados, conforme descrito na Seção 5.2. O melhor resultado foi alcançado pelo algoritmo $k$-médias após alteração no número de grupos, além da combinação dos métodos de redução de dimensionalidade GP 
e escore de Fisher, conforme descrito na Seção 5.2.3. A partir dos resultados obtidos nesse experimento, foram realizadas análises dos conjuntos PPAR $\delta-2$, AT1 e TGF $\beta$ aplicando o mesmo esquema de análise exploratória, conforme descrito nas Seções 5.3, 5.4 e 5.5, respectivamente. $\mathrm{Na}$ análise do conjunto $\operatorname{PPAR} \delta$-2, as técnicas combinadas de escore de Fisher, GP e EICAMM alcançaram o melhor resultado. No caso do conjunto AT1, as técnicas GP, IPM e escore de Fisher combinado com GP, além do algoritmo EICAMM apresentaram o melhor desempenho. Por fim, para o conjunto TGF $\beta$ as técnicas de escore de Fisher, IPM e $k$-médias apresentaram o melhor resultado de análise exploratória.

Os experimentos realizados neste trabalho e os resultados obtidos sugerem a utilização dos algoritmos de agrupamento para a tarefa de classificação dos dados químicos de forma a descrever níveis de atividade biológica dos compostos estudados, podendo ser utilizados como guias no processo de descoberta e desenvolvimento de novos compostos em QM.

\subsection{Contribuições}

As principais contribuições do presente trabalho são:

- Utilização das técnicas SPCA no processo de avaliação dos dados químicos. Essa abordagem de redução de dimensionalidade ainda é pouco utilizada na análise dos dados químicos. Por isso, este trabalho serve como guia para pesquisadores em QM na condução de novos experimentos em que seja necessária a aplicação dessas técnicas;

- Apresentação de novas formas de análise exploratória de dados que visam contribuir para a descoberta de novos medicamentos. O emprego dos métodos de redução de dimensionalidade e de agrupamento de dados apresentaram bons resultados no processo de análise dos dados químicos. Com isso, tais métodos podem ser aplicados para descoberta de padrões em dados relacionados a outras doenças crônicas.

\subsection{Trabalhos futuros}

Em trabalhos futuros, pretende-se investigar novos métodos para redução de dimensionalidade dos conjuntos de dados químicos. Uma abordagem a ser verificada é a de analisar, com maiores detalhes, os coeficientes dos autovetores obtidos por meio das técnicas SPCA, a fim de determinar as variáveis com maior importância no processo de transformação dos 
dados. Outra abordagem a ser verificada é a de desenvolver uma técnica SPCA baseada em redes neurais artificiais, de forma a apresentar uma base de transformação esparsa e que no processo de transformação seja possível garantir a propriedade de não correlação da técnica PCA.

Outra pretensão de trabalho futuro tem relação com os algoritmos de agrupamento. Durante a revisão bibliográfica sobre as técnicas SPCA, foram encontrados algoritmos que utilizam as normas de regularização (por exemplo $\ell_{1}$ e $\ell_{2}$ ) no processo de aprendizado, permitindo simultaneamente a realização da seleção de variáveis e o aprendizado do algoritmo. Pretende-se realizar uma revisão aprofundada sobre esses métodos de aprendizado e, se possível, propor incorporação dessas técnicas de regularização ao método EICAMM.

Os trabalhos futuros citados anteriormente (SPCA e agrupamento de dados) tem por objetivo contribuir para resolução de desafios existentes na área da ciência da computação. De acordo com os autores Hopcroft, Soundarajan e Wang (2011), os próximos desafios dessa área consistem na aplicação de métodos computacionais em grandes bases de dados, além do desenvolvimento de métodos que incorporem características esparsas ao seu processo de aprendizado.

Por fim, pretende-se analisar também métodos para aumentar o número de observações em um conjunto de dados. É sabido que, quanto maior o número de observações para treinamento, melhor o resultado de um algoritmo de aprendizado. Tal expansão no número de observações deverá ser realizada por meio de busca de novos compostos na literatura ou a partir da expansão artificial do conjunto de dados. 


\section{Referências}

ABDI, H.; WILLIAMS, L. J. Principal component analysis. Wiley Interdisciplinary Reviews: Computational Statistics, v. 2, p. 433-459, 2010.

ANDONIE, R. Extreme data mining: Inference from small datasets. International Journal of Computers, Communications and Control, v. 5, p. 280-291, 2010.

ARAUJO, S. C. Propriedades Químicas de Substâncias Inibidoras do Receptor do TGFß Tipo I (ALK-5), Alvo Biológico Envolvido com o Câncer. São Paulo - SP, 2013. (Monografia).

BEZDEK, J. C. Pattern Recognition with Fuzzy Objective Function Algorithms. Norwell, MA, USA: Kluwer Academic Publishers, 1981.

BISHOP, C. M. Neural Networks for Pattern Recognition. Oxford, uk: Oxford University Press, 2005.

BROWN, N. Chemoinformatics-an introduction for computer scientists. ACM Comput. Surv., ACM, New York, NY, USA, v. 41, n. 2, p. 1-38, 2009. ISSN 0360-0300.

BURDEN, R.; FAIRES, J. Numerical Analysis. Boston, MA: Thomson Brooks/Cole, 2005 .

CORMANICH, R. A.; GOODARZI, M.; FREITAS, M. P. Improvement of multivariate image analysis applied to quantitative structure-activity relationship (qsar) analysis by using wavelet-principal component analysis ranking variable selection and least-squares support vector machine regression: Qsar study of checkpoint kinase wee1 inhibitors. Chemical Biology 85 Drug Design, Blackwell Publishing Ltd, v. 73, p. 244-252, 2009.

D'ASPREMONT, A.; GHAOUI, L. E.; JORDAN, M.; LANCKRIET, G. A direct formulation for sparse pca using semidefinite programming. SIAM Review, v. 49, n. 3, p. 434-448, 2007.

DEMMEL, J. Applied Numerical Linear Algebra. Society for Industrial and Applied Mathematics, 1997. (Miscellaneous Bks). Disponível em: $<$ http://books.google.com.br/books?id=fjC2d0odoi8C $>$.

DOWNS, G. M.; BARNARD, J. M. Clustering methods and their uses in computational chemistry. In: Reviews in Computational Chemistry. : John Wiley \& Sons, Inc., 2003. p. 1-40.

DRAGON 2.1. 2002. Chemometrics, Milano.

DUDA, R.; HART, P.; STORK, D. Pattern classification (2nd Edition). : WileyInterscience, 2001. (Pattern Classification and Scene Analysis: Pattern Classification). 
DUNN, J. C. A fuzzy relative of the isodata process and its use in detecting compact well-separated clusters. Journal of Cybernetics, v. 3, p. 32-57, 1973.

FISCHER, E. Einfluss der configuration auf die wirkung der enzyme. Berichte der deutschen chemischen Gesellschaft, WILEY-VCH Verlag, v. 27, n. 3, p. 2985-2993, 1894. ISSN 1099-0682.

FRISCH, M. J.; TRUCKS, G. W.; SCHLEGEL, H. B.; SCUSERIA, G. E.; ROBB, M. A.; CHEESEMAN, J. R.; MONTGOMERY JR., J. A.; VREVEN, T.; KUDIN, K. N.; BURANT, J. C.; MILLAM, J. M.; IYENGAR, S. S.; TOMASI, J.; BARONE, V.; MENNUCCI, B.; COSSI, M.; SCALMANI, G.; REGA, N.; PETERSSON, G. A.; NAKATSUJI, H.; HADA, M.; EHARA, M.; TOYOTA, K.; FUKUDA, R.; HASEGAWA, J.; ISHIDA, M.; NAKAJIMA, T.; HONDA, Y.; KITAO, O.; NAKAI, H.; KLENE, M.; LI, X.; KNOX, J. E.; HRATCHIAN, H. P.; CROSS, J. B.; BAKKEN, V.; ADAMO, C.; JARAMILLO, J.; GOMPERTS, R.; STRATMANN, R. E.; YAZYEV, O.; AUSTIN, A. J.; CAMMI, R.; POMELlI, C.; OCHTERSKI, J. W.; AYALA, P. Y.; MOROKUMA, K.; VOTH, G. A.; SALVADOR, P.; DANNENBERG, J. J.; ZAKRZEWSKI, V. G.; DAPPRICH, S.; DANIELS, A. D.; STRAIN, M. C.; FARKAS, O.; MALICK, D. K.; RABUCK, A. D.; RAGHAVACHARI, K.; FORESMAN, J. B.; ORTIZ, J. V.; CUI, Q.; BABOUL, A. G.; CLIFFORD, S.; CIOSLOWSKI, J.; STEFANOV, B. B.; LIU, G.; LIASHENKO, A.; PISKORZ, P.; KOMAROMI, I.; MARTIN, R. L.; FOX, D. J.; KEITH, T.; AL-LAHAM, M. A.; PENG, C. Y.; NANAYAKKARA, A.; CHALLACOMBE, M.; GILL, P. M. W.; JOHNSON, B.; CHEN, W.; WONG, M. W.; GONZALEZ, C.; POPLE, J. A. Gaussian 03, Revision C.02. Gaussian, Inc., Wallingford, CT, 2004.

Gertrudes, J. C.; Maltarollo, V. G.; Silva, R. A. A.; OliveirA, P. R.; HONóRIO, K. M.; SILVA, A. B. F. D. Machine learning techniques and drug design. Current Medicinal Chemistry, v. 19, p. 4289-4297, 2012.

GOODARZI, M.; FREITAS, M. P.; JENSEN, R. Feature selection and linear/nonlinear regression methods for the accurate prediction of glycogen synthase kinase- 3 beta inhibitory activities. Journal of chemical information and modeling, v. 49, p. 824-32, 2009. ISSN 1549-9596.

GU, Q.; LI, Z.; HAN, J. Generalized fisher score for feature selection. Proceedings of the 27th Conference on Uncertainty in Artificial Intelligence, UAI 2011, p. 266-273, 2011.

HASTIE, T.; TIBSHIRANI, R.; FRIEDMAN, J. The Elements of Statistical Learning. : Springer, 2009.

HEIN, M.; BUHLER, T. An inverse power method for nonlinear eigen problems with applications in 1-spectral clustering and sparse pca. Advances in Neural Information Processing Systems (NIPS 2010), p. 1-10, 2010.

HOPCROFT, J. E.; SOUNDARAJAN, S.; WANG, L. The future of computer science. Int J Software Informatics, v. 5, p. 549-565, 2011.

HYVARINEN, A.; KARHUNEN, J.; OJA, E. Independent Component Analysis. : John Wiley \& Sons, 2001.

JAIN, A. K. Data clustering: 50 years beyond k-means. Pattern Recognition Letters, v. 31, p. $651-666,2010$. 
JOLLIFFE, I. T. Principal Component Analysis. : Springer, 2002. 487 p.

JOURNEE, M.; NESTEROV, Y.; RICHTáRIK, P.; SEPULCHRE, R. Generalized power method for sparse principal component analysis. Journal of Machine Learning Research, v. 11, p. 517-553, 2010.

KING, H.; AUBERT, R. E.; HERMAN, W. H. Global burden of diabetes, 1995-2025: Prevalence, numerical estimates, and projections. Diabetes Care, v. 21, p. 1414-1431, 1998.

KOUL, A.; ARNOULT, E.; LOUNIS, N.; GUILLEMONT, J.; ANDRIES, K. The challenge of new drug discovery for tuberculosis. Nature, v. 469, n. 7331, p. 483-490, 2011.

LEE, T.-W.; LEWICKI, M.; SEJNOWSKI, T. Ica mixture models for unsupervised classification of non-gaussian classes and automatic context switching in blind signal separation. Pattern Analysis and Machine Intelligence, IEEE Transactions on, v. 22, n. 10, p. 1078-1089, 2000.

LOUNKINE, E.; NIGSCH, F.; JENKINS, J.; GLICK, M. Activity-aware clustering of high throughput screening data and elucidation of orthogonal structure-activity relationships. Journal of Chemical Information and Modeling, v. 51, p. 3158-3168, 2011.

LU, Z.; ZHANG, Y. An augmented lagrangian approach for sparse principal component analysis. Mathematical Programming, v. 135, p. 149-193, 2012.

LUSS, R.; D'ASPREMONT, A. Clustering and feature selection using sparse principal component analysis. Optimization and Engineering, v. 11, n. 1, p. 145-157, 2010.

MALTAROLlO, V. G. Relação Quantitativa entre Estrutura Química e Atividade Biológica de Substâncias com Afinidade pelo Receptor PPAR $\delta$. Dissertação (Mestrado) - Universidade Federal do ABC, 2009.

MALTAROLLO, V. G.; HONóRIO, K. M. Ligand-and structure-based drug design strategies and ppar $\delta / \alpha$ selectivity. Chemical Biology \& Drug Design, Blackwell Publishing Ltd, v. 80, n. 4, p. 533-544, 2012.

MALTAROLLO, V. G.; MELlO, P. Homem-de; HONORIO, K. M. Role of physicochemical properties in the activation of peroxisome proliferator-activated receptor $\delta$. Journal of Molecular Modeling, v. 17, n. 10, p. 2549-2558, 2011.

MALTAROLlO, V. G.; SILVA, D. C.; HONóRIO, K. M. Advanced qsar studies on ppar $\delta$ ligands related to metabolic diseases. Journal of the Brazilian Chemical Society, scielo, v. 23 , p. $78-84,2012$. ISSN 0103-5053.

MOGHADDAM, B.; WEISS, Y.; AVIDAN, S. Spectral bounds for sparse pca: Exact and greedy algorithms. In: . 2005. p. 915-922.

NIE, F.; XIANG, S.; JIA, Y.; ZHANG, C.; YAN, S. Trace ratio criterion for feature selection. In: Proceedings of the 23rd national conference on Artificial intelligence - Volume 2. : AAAI Press, 2008. (AAAI'08), p. 671-676. 
NING, X.; KARYPIS, G. In silico structure-activity-relationship (sar) models from machine learning: a review. Drug Development Research, Wiley Subscription Services, Inc., A Wiley Company, v. 72, n. 2, p. 138-146, 2011.

OLIVEIRA, P. R.; ROMERO, R. A. Improvements on ica mixture models for image pre-processing and segmentation. Neurocomputing, v. 71, n. 10-12, p. 2180-2193, 2008.

PERES, S. M.; BíSCARO, H. H.; MADEO, R. C. B.; BOSCARIOLI, C. Tutorial sobre fuzzy-c-means e fuzzy learning vector quantization abordagens híbridas para tarefas de agrupamento e classificação. Revista de Informática Teórica e Aplicada, v. 19, p. 120 $163,2012$.

PROKHOROV, E.; PONOMAREVA, L.; PERMYAKOV, E.; KUMSKOV, M. Fuzzy classification and fast rules for refusal in the qsar problem. Pattern Recognition and Image Analysis, v. 21, n. 3, p. 542-544, 2011.

QI, X.; LUO, R.; ZHAO, H. Sparse principal component analysis by choice of norm. Journal of Multivariate Analysis, v. 114, p. 127-160, 2013.

RIBEIRO, P. B.; ROMERO, R. A.; OLIVEIRA, P. R.; SCHIABEL, H.; VERCOSA, L. B. Automatic segmentation of breast masses using enhanced ica mixture model. Neurocomputing, 2013. ISSN 0925-2312.

RIVERA-BORROTO, O. M.; PONCE, Y. M.; VEGA, J. M. Garcia-de-la; GRAUÁLBALO, R. d. C. Comparison of combinatorial clustering methods on pharmacological data sets represented by machine learning-selected real molecular descriptors. Journal of Chemical Information and Modeling, v. 51, p. 3036-3049, 2011.

RODRIGUES, C. F. ANÁLISE COMPARATIVA ENTRE OS MÉTODOS DE DECOMPOSIÇÃO EM VALORES SINGULARES E ANÁLISE DE COMPONENTES PRINCIPAIS ENVOLVENDO MATRIZES ESPARSAS DE GRANDE PORTE. Dissertação (Mestrado) — UNIVERSIDADE FEDERAL DE MINAS GERAIS, 2011.

ROY, K.; GHOSH, G. Qstr with extended topochemical atom (eta) indices. 12. qsar for the toxicity of diverse aromatic compounds to tetrahymena pyriformis using chemometric tools. Chemosphere, v. 77, n. 7, p. 999-1009, 2009.

SCIOR, T.; MEDINA-FRANCO, J. L.; DO, Q.-T.; MARTINEZ-MAYORGA, K.; ROJAS, J. A. Y.; BERNARD, P. How to recognize and workaround pitfalls in qsar studies: A critical review. Current Medicinal Chemistry, v. 16, n. 32, p. 4297-4313, 2009.

SHEN, H.; HUANG, J. Sparse principal component analysis via regularized low rank matrix approximation. Journal of Multivariate Analysis, v. 99, n. 6, p. 1015-1034, 2008.

SILVA, D. C. Estudos de modelagem molecular para uma série de ligantes do receptor tipo 1 da antiotensina II com atividade anti-hipertensiva. Tese (Doutorado) - Universidade Federal do ABC, 2013.

SILVA, T. B.; PEREIRA, M. A.; MALTA, V. S.; BENTO, E. S.; SAN-MIGUEL, M. A.; ZIOLLI, R. L.; MARTINS, J. B. L.; SIH, A.; TAFT, C. A. Study of the structureactivity relationship for theoretical molecular descriptors using density functional theory and chemometric methods in cannabinoid metabolites. International Journal of Quantum 
Chemistry, Wiley Subscription Services, Inc., A Wiley Company, v. 108, n. 13, p. 25302539, 2008. ISSN 1097-461X.

SOUTO, M. C. P. de; COSTA, I. G.; ARAUJO, D. S. a. de; LUDERMIR, T. B.; SCHLIEP, A. Clustering cancer gene expression data: a comparative study. BMC bioinformatics, v. 9, p. 497, 2008.

SPARTAN'08. 2008. Wavefunction, Inc. Irvine, CA.

STEINHAUS, H. Sur la division des corp materiels en parties. Bull. Acad. Polon. Sci, v. 1, p. 801-804, 1956.

THEODORIDIS, S.; KOUTROUMBAS, K. Pattern Recognition. 2003.1 - 689 p.

VARIN, T.; SAETTEL, N.; VILLAIN, J.; LESNARD, A.; DAUPHIN, F.; BUREAU, R.; RAULT, S. 3d pharmacophore, hierarchical methods, and 5-ht4 receptor binding data. Journal of Enzyme Inhibition and Medicinal Chemistry, v. 23, n. 5, p. 593-603, 2008.

VERLI, H.; BARREIRO, E. J. Um paradigma da quÃmica medicinal: a flexibilidade dos ligantes e receptores. QuÃmica Nova, v. 28, p. 95 - 102, 022005.

WEBER, K. C.; SILVA, A. B. da. A chemometric study of the 5-ht1a receptor affinities presented by arylpiperazine compounds. European Journal of Medicinal Chemistry, v. 43, n. 2 , p. $364-372,2008$.

WILSON, H.; BOOTS, B.; MILLWARD, A. A comparison of hierarchical and partitional clustering techniques for multispectral image classification. In: . 2002. v. 3, p. 1624-1626.

XU, R.; WUNSCH-II, D. C. Clustering. New Jersey: , 2009. 358 p.

YAN, L.; SHEIHK-BAHAEI, S.; PARK, S.; ROPELLA, G.; HUNT, C. Predictions of hepatic disposition properties using a mechanistically realistic, physiologically based model. Drug Metabolism and Disposition, v. 36, n. 4, p. 759-768, 2008.

YANG, L.; SONG, G.; CARRIQUIRY, A.; JERNIGAN, R. L. Close correspondence between the motions from principal component analysis of multiple hiv-1 protease structures and elastic network modes. Structure, v. 16, n. 2, p. 321 - 330, 2008.

YANYUN, C.; JIANLIN, Q.; XIANG, G.; JIANPING, C.; DAN, J.; LI, C. Advances in research of fuzzy c-means clustering algorithm. In: Network Computing and Information Security (NCIS), 2011 International Conference on. 2011. v. 2, p. 28 -31.

YOUNG, D. C. Computational drug design - A Guide for Computational and Medicinal Chemists. : Wiley, 2009.

ZOLADEK, A.; JOHAL, R.; GARCIA-NIETO, S.; PASCUT, F.; SHAKESHEFF, K.; GHAEMMAGHAMI, A.; NOTINGHER, I. Label-free molecular imaging of immunological synapses between dendritic and t cells by raman micro-spectroscopy. Analyst, v. 135, n. 12, p. 3205-3212, 2010.

ZOU, H.; HASTIE, T.; TIBSHIRANI, R. Sparse principal component analysis. Journal of Computational and Graphical Statistcs, v. 15, p. 265-286, 2006. 